\title{
PERSPECTIVES ON THE PROVISION OF COUNSELLING FOR WOMEN IN IRELAND
}


2 


\section{Table of Contents}

Glossary

Acronyms 6

Chapter 1: Introduction $\quad 8$

\begin{tabular}{ll} 
The Project & 8 \\
\hline
\end{tabular}

Layout of the Report $\quad 9$

Chapter 2: The Context of Counselling 12

Women's Mental Health $\quad 12$

$\begin{array}{ll}\text { Overview of Counselling } & 14\end{array}$

Efficacy and Effectiveness of Counselling/Therapy 19

Counselling Within Ireland $\quad 22$

Chapter 3: Women's Views of Counselling $\quad 30$

Questionnaire Survey of Women 30

Interviews with Women $\quad 45$

Chapter 4: Health Professionals $\quad 54$

Health Board Personnel $\quad 54$

Community/Voluntary Sector Personnel $\quad 63$

$\begin{array}{lr}\text { Professional Organisations } & 64\end{array}$

$\begin{array}{lc}\text { Chapter 5: Service Providers } & 68\end{array}$

$\begin{array}{lc}\text { Health Board Managers } & 68\end{array}$

$\begin{array}{ll}\text { Community/Voluntary Service Providers } & 73\end{array}$

$\begin{array}{ll}\text { Chapter 6: Discussion } & 78\end{array}$

$\begin{array}{ll}\text { Overview of the Study } & 78\end{array}$

$\begin{array}{ll}\text { Context } & 79\end{array}$

$\begin{array}{lr}\text { Information and Help Seeking } & 79\end{array}$

$\begin{array}{lr}\text { Knowledge and Experience of Counselling } & 80\end{array}$

Counselling Service Provision $\quad 82$

$\begin{array}{lr}\text { Suggestions for Future Provision } & 85\end{array}$

$\begin{array}{ll}\text { Conclusion } & 89\end{array}$

Chapter 7: Recommendations $\quad 92$

$\begin{array}{lr}\text { Bibliography } & 96\end{array}$

$\begin{array}{ll}\text { Appendices } & 106\end{array}$ 


\section{Glossary of Terms}

Accreditation

Allied professional

Analytic therapies

Behavioural therapy

Bibliotherapy

Cognitive therapy

Counselling

Counsellor

Effectiveness

Efficacy

Feminism

Human potential therapy

Implicit belief
The act of receiving credit for ones achievements, experience or qualifications. In this case, being allowed or entitled to use a specific title (e.g. counsellor).

A person with a professional qualification (other than medicine or nursing) that works in the health service. Their work activities are described as allied to medicine, e.g. psychologists, social workers, occupational or speech therapists, radiographers.

Psychoanalytic psychotherapists work with their clients by helping them enter into their unconscious world to look at their present problems in relation to their family and childhood experiences. There are many schools of psychoanalysis (e.g., Freudian and J ungian therapies). With these methods, not only are the present behaviours and emotions addressed, but also emotional difficulties that remain from childhood can be resolved.

Behavioural therapies are based on the premise that the clients' problems are rooted in maladaptive behaviour. Therapists will often combine behavioural and cognitive therapies (see below) as they can complement each other.

Self-improvement based on written material

Cognitive therapists postulate that clients' difficulties are often due to maladaptive thought processes or pre-suppositions. Therapists will often combine behavioural (see above) and cognitive therapies as they can complement each other.

A generic term that is used to cover the several processes of interviewing, testing, guiding, etc. designed to help an individual solve problems and plan for the future. At its core, counselling is a searching human relationship where the client and the counsellor work towards to finding responses to the client's present difficulties and needs. Counselling incorporates the giving of time, attention and respect in a confidential relationship. It provides an opportunity to explore, to discover and to clarify ways of living more resourcefully towards greater well-being.

A professional who is trained to listen in an accepting and non-judgmental way. The counsellor encourages the client to express feelings openly and will not become burdened by them. Within Ireland the term 'counsellor' should only be applied to persons registered with the Irish Council for Psychotherapy, the Irish Association for Counselling and Therapy, or the Psychological Society of Ireland.

Effectiveness studies ask whether an intervention can produce an effect in the real world, i.e. does the intervention work in the real world?

Efficacy asks under controlled circumstances, does this particular procedure produce any particular effect above and beyond a comparison procedure, i.e. can the intervention work? The favoured procedure for establishing efficacy is the randomised control trial (RCT).

Any theory or theorist that sees the relationship between the sexes as one of inequality, subordination or oppression, that sees this as a problem of political power rather than a fact of nature, and that sees this problem as important for political theory and practice.

The objective of human potential therapy is not to diagnose but to enable the client to develop his/her own potential. This self- development could be either in reaction to a personal crisis or as a desirable experience in itself. Therapies within this school of thought include person-centred therapy, gestalt therapy, family therapy, transactional analysis, primal integration and primal theory, psychodrama and art therapy. The principle aim of human potential therapies is to achieve personal growth and fulfilment.

A belief that is covert or not directly observable. 
Medical

Meta-analysis

Nursing

Paramedical

Person-centred

Placebo

Primary care

Psychoanalyst

Psychoanalysis
Peer counselling

In this context, referring to all staff with medical qualifications, for example physicians, surgeons or anaesthetists.

A popular and methodologically sophisticated technique for quantitatively summarising findings from a large body of empirical research. Numerous individual studies are quantified and coded so that they can be compared with one another. Typically an effect size (ES) is calculated for each study, indicating the size of the difference between the treated and untreated group.

In this context, referring to all staff with nursing qualifications and primarily employing these skills, including student and staff nurses, nurse managers and nurse tutors.

Professionals who operate as support staff to the medical profession within the health services (excluding nurses).

Peer counselling programmes build on spontaneous naturalistic peer support and seek to equalise access opportunities, develop the organisation and deepen and widen the impact (Topping, 1996).

Counselling that takes as its central focus, the presenting client, Counselling rather than relying on theories or practice imposed by the therapist.

An inactive substance disguised as an active one, e.g., a sugar pill, given to a control group in a drug experiment, or to a patient in hospital who would not benefit from an active drug but needs to feel that he is receiving treatment.

The first setting in which a patient or client would encounter a health professional, such as a GP surgery or a Public Health Nurse clinic.

A professional who has completed specialist postgraduate training in psychoanalytic approaches to the understanding and treatment of psychological disorder.

A form of psychotherapy associated with Sigmund Freud. Places a great emphasis on the uncovering and understanding of unconscious motivation (see analytic therapies above).

Psychological distress A negative psychological state, commonly referring to depressive or anxious symptoms

Psychologist

A person involved in the study of mind and behaviour.

Psychotherapist

A professional who practices psychotherapy.

Psychotherapy

The diagnosis, comprehensive knowledge and planned treatment of psychosocial and/or psychosomatically derived behavioural disturbances or states of suffering by means of scientific and psychotherapeutic methods.

\section{Randomised}

controlled trials

In a randomised controlle trial consenting patients are randomly allocated to either one or more 'active' intervention groups (e.g. counselling or the prescription of antidepressants) or to a control group (placebo or 'do nothing' option). The outcomes of interest from each option are measured over the trial period and the differences are tested for statistical significance.

Stigma

Greek for mark or brand. Refers to person, object or entity that is perceived as being different or marked in some way.

Support worker

A trained "listener" who is available to women who want to talk. The listener provides a safe, confidential and understanding "ear" and is available to women who seek information and who are inquiring about rights and services

Validity

The confidence that we have that a test, measurement or experimental manipulation is actually doing the job it has been designed to do. 


\section{Acronyms}

\begin{tabular}{|c|c|}
\hline BAC & British Association of Counselling \\
\hline BUPA & British United Provident Association \\
\hline CDoP & Counselling Division of Psychology \\
\hline CES-D & Centre for Epidemiologic Studies - Depression Scale \\
\hline CSA & Child Sexual Abuse \\
\hline DED & District Electoral Division \\
\hline EAC & European Association of Counselling \\
\hline EAP & European Association of Psychiatry \\
\hline EEC & European Economic Community \\
\hline ERHA & Eastern Regional Health Authority \\
\hline ES & Effect Size \\
\hline EU & European Union \\
\hline GHQ-12 & General Health Questionnaire - with 12 questions \\
\hline GMS & General Medical Services \\
\hline GP & General Practitioner \\
\hline IACT & Irish Association of Counselling \& Therapy \\
\hline IAAAC & Irish Association of Alcohol and Addiction Counsellors \\
\hline ICGP & Irish College of General Practitioners \\
\hline ICP & Irish Council of Psychotherapy \\
\hline IHC & In-House Counselled \\
\hline MDD & Major Depressive Disorder \\
\hline NWHB & North Western Health Board \\
\hline PSI & Psychological Society of Ireland \\
\hline PTSD & Post Traumatic Stress Disorder \\
\hline RT & Routine Treatment \\
\hline SHB & Southern Health Board \\
\hline SLÁN & Survey of Lifestyle, Attitudes and Nutrition \\
\hline TCD & Trinity College Dublin \\
\hline UCC & University College Cork \\
\hline UCD & University College Dublin \\
\hline UK & United Kingdom \\
\hline VHI & Voluntary Health Insurance \\
\hline WHAC & Women's Health Advisory Committee \\
\hline WHO & World Health Organisation \\
\hline
\end{tabular}


Chapter One: Introduction 


\section{Introduction}

The last decade has seen a growing interest in attention to women's health, including women's mental health. Women are the most frequent users of the health services and are more likely to present with mental health issues, most notably depression and anxiety (Breslau et al., 1995). During the consultative process for the Plan for Women's Health (1997-1999) the health services were criticised for not responding appropriately to women's mental health needs. Women perceived the services as being primarily concerned with treating mental illness, rather than protecting and promoting mental health. Women specifically requested greater access to counselling ${ }^{1}$ services, located in appropriate physical environments that were not medically orientated. Such counselling should be proactive, attracting clients for whom mental health issues had not developed into more serious problems. These services would help them to develop coping skills and assertiveness.

There is no copyright or patent on the use of the term 'counselling' and amongst the general public and the caring professions, there is a view of counselling as the current popular term for giving advice to people. The broader aim of counselling is improved human effectiveness, this is often expressed as "becoming a happier and more productive member of society" and "to live more fully and satisfyingly" (Bayne and Nicolson, 1993).

As the demand for counselling services has grown, so has the number of different perspectives on counselling. These range from the more traditional methods of behaviour, cognitive and psychotherapies to the less common psychodrama and art therapies. Not all approaches are accepted within the professional domain and within Ireland many professionals who use counselling in their everyday practice are attempting to regulate its usage by becoming members of professionally recognised counselling organisations. However, this is not always the case and many counsellors in the community and private practice do not warrant professional recognition. More recently the use of the term counselling has become more specific and a need has arisen to find a way of labelling the roles many professionals and volunteers take on when they are applying the methods of counselling within their daily work, e.g., nurse-patient, psychologist-client, etc. An increasingly accepted term for this role is 'using counselling skills'. A variety of health service staff that employ counselling skills as part of their jobs would not be eligible for membership of professional organisations and would not necessarily perceive themselves as counsellors.

\section{The Project}

In response to the request by women made during the consultative process for the Plan for Women's Health in relation to the development of counselling services, the Women's Health Council in collaboration with the regional Women's Health Advisory Committees of the Eastern Regional Health Authority (the Northern Area Health Board, the East Coast Area Health Board and the South Western Area Health Board), the North Western Health Board and the Southern Health Board developed a proposal for joint research on counselling provision. Following a process of application and negotiation, the tender was awarded to Dr. Vivienne Batt of the Women's Studies Centre, NUI Galway and Dr. Saoirse Nic Gabhainn of the Centre for Health Promotion Studies, NUI Galway.

The aim of this research was to explore with women, health professionals and service providers their concepts and experiences of counselling, how accessible they perceive it to be and how a more effective counselling service could be provided in the future.

\section{METHODOLOGY}

Four distinct methods of data collection were employed.

1. Research literature regarding counselling and psychotherapy were collected and reviewed. This focussed on developments in therapy, evaluation issues and the situation in Ireland.

2. Study specific self-completion questionnaires were designed to collect data from women in the community and from health and voluntary service staff.

3. Interviews, some in-depth, all semi-structured, were held with women in the community, health board staff, and health service managers.

4. Documentation was requested for the purposes of secondary data analyses from health boards, health and voluntary service managers and professional organisations. 
This combination of methods was employed in order to maximise the quality of the data collected and to enable a more holistic picture of the current situation to be described and interpreted.

Thus, empirical data were collected from:

- Women in the general public and those who had received some form of counselling

- Staff who work with women in the provision of counselling and psychotherapy and those who employ counselling skills in their work as well as the professional representative organisations that these staff are affiliated to.

- The representatives of management in both the statutory and the voluntary / community sector.

\section{Layout of the Report}

Chapter 2 reviews relevant literature, providing an overview of women's mental health, examining the history and types of counselling and therapy; recent developments in counselling provision; the efficacy and effectiveness of counselling and therapy; and counselling within Ireland. Chapter 3 reports on women's views of counselling, current and future provision; elicited through a selfadministered questionnaire and face-to-face interviews with women. Chapter 4 presents the views of health professionals of counselling. This includes personnel from health boards, the voluntary and community sector and professional associations; employing the techniques of self-administered questionnaires, telephone interviews and secondary data collection. Chapter 5 examines service providers, including health board and voluntary and community service manager's views of current and future counselling service provision; utilizing telephone and face-to-face interviews and written submissions. Chapter 6 discusses the implications of the research findings and Chapter 7 presents conclusions and recommendations for future provision in the areas of counselling and therapy services. 
10 
Chapter Two: The Context of Counselling 


\section{The Context of Counselling}

This chapter provides a short summary of the status of women's mental health and a brief history of the development of counselling. It reviews the wide range of models and conceptualisations of counselling and therapy. It also documents the specific nature of many of the approaches in this field.

\section{Women's Mental Health}

The last decade has seen a growing interest in attention to women's health, including women's mental health. Women are the biggest consumers of health care world wide, they make more visits than men to their doctors, fill more prescriptions and have more surgeries (Niaz, 2000). Women have unique health needs across the reproductive life cycle related to menstruation, fertility, pregnancy and the menopause that have only relatively recently received attention from mental health professionals. As well as the content of women's health, one must also be concerned with the social context in which it frequently occurs: i.e. poverty, violence, discrimination and work inequities.

\section{Mental Health Difficulties}

Gender differences in the prevalence of mental health problems have long been recognised. These occur more frequently in women than men especially the depressive and anxiety related disorders (Breslau et al., 1995). Anxiety disorders are the most common mental health problem. In the general population it occurs in one in ten individuals (Robbins et al., 1984; Bland et al., 1988). The number of women who develop anxiety disorders is far greater than men (Weissman et al., 1984; Breslau et al., 1995). The term anxiety refers to an unpleasant and overriding mental tension. However, while the term anxiety disorders refers to a range of specific mental illnesses, which include phobias, panic disorder, post-traumatic stress disorder, and obsessive-compulsive disorder.

Studies have documented high rates of co morbidity between Major Depressive Disorder (MDD) and anxiety, concurrently within episodes of illness and over the lifetime of individuals (see review in Maser \& Cloninger, 1990). Within episodes, anxiety symptoms are more likely to precede depressive symptoms than to follow them (Alloy et al., 1990) and tend to predate the onset of major depression (Angst et al., 1990).

Depression is a common mental disorder that presents with depressed mood, loss of interest or pleasure, feelings of guilt or low selfworth, disturbed sleep or appetite, low energy, and poor concentration. Today depression is a major public health problem. It is projected to be the second greatest cause of death and disability worldwide by the year 2020 (WHO, 2001). Epidemiological data worldwide clearly demonstrates that major depression is approximately twice as common in women than in men (Lawlor \& J ames, 2000; Kirby et al., 1997), as its onset peaks during the childbearing years of life (O'N eill et al., 1990; Greene et al., 1991; Cryan et al., 2001). Research studies also show that gender disparity in the rates of first onset of depression begins early, around 13 to 15 years of age (Houlihan et al., 1994) and that this disparity is maintained throughout life (Kessler et al., 1993; Nolen-Hoeksema \& Girgus, 1994).

Children of depressed parents are at high risk for developing MDD. Myrna Weissman's ten year follow-up of the offspring of depressed parents compared with the offspring of non-depressed parents clearly shows that parental depression led to a three fold increased risk of MDD in their children (Weissman et al., 1997). Children of depressed parents had more serious and recurrent depression, were more socially and vocationally impaired over the 10 years follow-up period and were less likely to seek treatment. It has therefore been argued that successful treatment of parental depression especially maternal depression may provide primary prevention by reducing the symptoms of depression, that have clearly shown to impair parenting skills.

\section{What Women Want}

Attention to women's perceptions of the quality of the health service in the past has been criticised for two main limitations. The first is a tendency to focus on reproductive health services exclusively and the second is to focus on services within the biomedical model to the exclusion of other alternative models of health care in which women in particular have been interested. As Conlon (1999) 
points out, the need for more information about women's perceptions of general health services and their demand for the incorporation of other models (i.e., non-traditional) of health care into current service provision needs to be addressed by health services planners.

During the consultative process for the Plan for Women's Health (1997-1999) there was widespread concern that the health services were not responding appropriately to women's mental health needs. Women were critical of the pre-occupation of services with treating mental illness and of the absence of services to protect and promote mental health. It was argued that women are particularly prone to depression. While some of this depression is biological much is associated with the stress women experience because of conflicting multiple roles, lack of control of their fertility, violence, low income, low status and self esteem. As presently organised, neither the mental health services nor the health services in general are in a position to offer women support to cope with the crises which arise in their lives and which threaten their mental health. Women made the point that, in the absence of an organised response to these needs, women's mental health problems are medicalised. It should be recognised that medication in such circumstances can mask the underlying problems and could lead to dependence and addiction to the prescribed drug.

During the consultative process women requested access to counselling services, preferably in a non-medical environment, which would help them develop coping skills and self-assertiveness. At present counselling services with some public funding are provided for women in special circumstances, e.g. women with crisis pregnancies, women who have suffered rape and/or sexual abuse, women who are victims of crime and women with marital problems. What women now want is a more proactive approach, with access to counselling for women at an earlier stage in the stress cycle so that more serious problems.

\section{Delivery of Services}

Although women asked for services in a non-medicalised environment this may not always be feasible for women living in rural settings in which the closest health service may be the local General Practitioner (GP). The tendency to use GP services for problems associated with depression and anxiety is most evident in rural areas where women are living at a distance from specialist services (O'Hare \& O'Connor, 1987).

Recent Irish studies have found that girls living in a rural environment experience greater psychological disturbance than girls from urban areas (Houlihan et al., 1994). Kelleher et al. (1998) examined variations in suicide in the eight Health Boards of the Republic of Ireland for the years 1976 to 1995 . They found that since the mid nineteen-eighties, female rates have been somewhat higher in the southern half of the country. They suggest that this variation may reflect a difficulty with contacting services for psychological distress in rural areas. This could be either because of stigma or simple practical problems associated with transport (Kirby et al., 1997). Recommendations included the development of appropriate services, especially in rural areas, should be at the top of the health care agenda.

Byrne et al. (1991) in their survey of a rural community in N orth-West Connemara reported that they encountered many depressed, demoralised and miserable people. Many of these symptoms can be traced to the struggle of trying to live on low incomes. Women, in particular, were tired, fatigued and stressed. Several talked about the need for Social Workers in the area to help with family problems. Many women, particularly those whose spouses were dependent on alcohol, felt the absence of counselling and family support services. Women do not know whom to turn to for help and advice. These findings are supported by a study of women's lives in a community in South West Mayo (Byrne \& Owens, 1996) which describes how service depletion in rural areas has placed a severe strain on women in particular as they have responsibility for caring for others who are young, elderly or unwell.

Gender differences in mental health problems may result from the interaction of multiple factors including psychosocial factors, i.e., social status, socialisation, coping styles, and increased vulnerability to sexual and domestic violence. Biological factors may also explain the differences in mental health between men and women or they may be more apparent because women may be likely to report symptoms, or seek help.

The importance of understanding help-seeking behaviour is increasingly recognised by service providers across various sectors. In a comprehensive study of information seeking in the United Kingdom (Marcella \& Baxter, 1999) it was reported that citizens find information provided by government departments difficult to use. The most frequently occurring difficulties in finding help arise in connection with legal issues, education, welfare benefits, health care, and employment. The relationship between help-seekers and 
help-providers is important. Helpers are judged more positively if they are readily available, knowledgeable in areas important to the help-seekers, and good listeners who are willing to spend time with the person in need of assistance.

Research conducted by Borkowski et al. (1983) on the reports of battered women who sought help from shelters or half-way homes found that if help is not found easily, the (abused) woman tends to give up the search until there is an emergency. Five of the key factors that discourage help seeking have been presented by Harris et al. (2001):

- Help seekers cannot find the service they need because it does not exist where they live

- Help-seekers do not know which agency to contact

- Help-seekers do not reach an appropriate service agency because of language difficulties or other forms of social isolation resulting from cultural differences, literacy problem and physical or developmental difficulties

- Help-seekers who succeed in reaching appropriate service agencies encounter obstacles that are deliberately or inadvertently constructed by the agencies

- Help-seekers fail to receive assistance because the services they contact are not adequately funded or staffed.

\section{Overview of Counselling}

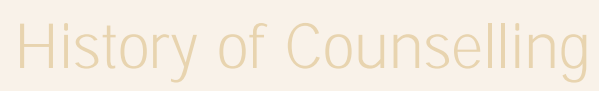

The sociological, cultural and technological changes that swept Western Europe and the United States in the late nineteenth century resulted in the breakdown of the extended family system and the sense of community. Labour mobility within and between countries led to the loss of familial and religious contact. It was at this time of the breakdown in more traditional support structures that professional family care began in the United States. Work with families was being carried out as early as 1877. Over the following years, this work became more standardised and by 1911, family social-work agencies were in place. It was in this social support setting that counselling techniques had their origin (Kennedy, 1999).

In the latter half of the nineteenth century Sigmund Freud started to develop his theory of psychoanalysis. Others soon joined him such as Carl Jung and Alfred Alder who developed their own psychoanalytic theories. While the popularity of psychology and psychoanalysis grew, the first university course in couples counselling was founded in 1937 at Duke University in the United States. The philosophy of the Marriage Bureaux soon became established and spread throughout Europe.

Throughout the latter half of the twentieth century, the concept of counselling grew and was encompassed as a topic in many applied psychology courses, it is now taught as a discipline in its own right. It has been estimated that there are over 400 different named therapies, which can be seen as variations on the basic themes within a smaller number of families of theories and techniques (Roth \& Fonagy, 1996). These therapies are used to tackle many social problems including marriage and family difficulties, anxiety, depression, addiction, sexual abuse, rape, psycho-sexual difficulties, eating disorders, bereavement, adolescent difficulties and AIDS and HIV.

\section{The Counselling and Therapy Types}

Many members of the general public have difficulty distinguishing between the terms counselling and psychotherapy. Within the literature the boundaries between the terms are very blurred, with counsellors tending to have had a shorter, broader training and working with patients with less deeply seated difficulties. Eatock (2000) notes that it is an interesting fact that counselling rather than psychotherapy has been the service that has become popular in primary care counselling. Could it simply be that there are generally more practitioners who call themselves a 'counsellor' rather than a 'psychotherapist'? This may be to do with costs. As Dryden (1996) commented; "The difference between a counsellor and a psychotherapist is about $£ 8,000$ a year". Alternatively, counselling may 
have increased in popularity because it is more acceptable to patients without the prefix of 'psycho' and this therefore helps to destigmatise the client and their 'treatment'.

The differences or lack of them, between counselling and psychotherapy form one of the most divisive issues in this whole area and the debate continues both in academic, practice and policy oriented contexts. The question of whether there even is a difference, never mind what those differences are, is not agreed. Numerous authors debate this issue (e.g. Naylor-Smith, 1994; Dryden, 1996; J acobs, 1996 1998; Feltham, 1999; Thorne, 1999). In this report we do not intend to enter a debate on the differences between the fields of counselling and psychotherapy, but we recommend anyone wishing to read more on this topic to Feltham's (1999) publication 'Controversies in Psychotherapy and Counselling'. Throughout this report we use the term 'counsellor' as a generic term to apply to any counsellor, psychotherapist or psychologist conducting a psychological therapy, and the terms 'counselling' 'psychotherapy' and 'therapy' are used interchangeably.

There are numerous psychological therapies that a counsellor can use in their work. Cooper and Lewis (1995) suggest that they can be examined under the following four groupings: counselling therapies, analytic therapies, human potential therapies, behavioural and cognitive therapies.

\section{COUNSELLIN G THERAPIES}

These are more short-term than the other therapies. They are ideal for looking at focused, identifiable problems or patterns of behaviour. There are a wide range of differing counselling sub-specialties, including crisis counselling, addiction counselling, bereavement counselling, couples counselling, counselling for gay and lesbian people, illness counselling, counselling for rape and sexual abuse, counselling for children and counselling for eating problems.

\section{ANALYTIC THERAPIES}

Psychoanalytic psychotherapists work with their clients by helping them enter into their unconscious world to look at their present problems in relation to their family and childhood experiences. There are many schools of psychoanalysis (e.g., Freudian and J ungian therapies). Child psychotherapy is a specific sub-specialty. Clients usually attend an analytical therapist for a year or more. With these methods, not only are the present behaviours and emotions addressed, but also any emotional difficulties that remain from childhood can be resolved.

\section{HUMAN POTENTIAL THERAPIES}

The objective of human potential therapy is not to diagnose but to enable the client to develop his/her own potential. This selfdevelopment could be either in reaction to a personal crisis or as a desirable experience in itself. Therapies within this school of thought include person-centred therapy, gestalt therapy, family therapy, transactional analysis, primal integration and primal theory, psychodrama and art therapy. The principle aim of human potential therapies is to achieve personal growth and fulfilment.

\section{BEHAVIOURAL AND COGNITIVE THERAPIES}

Behavioural therapies are based on the premise that the clients' problems are rooted in maladaptive behaviour. Cognitive therapists postulate that clients' difficulties are often due to maladaptive thought processes or pre-suppositions. Therapists will often combine behavioural and cognitive therapies as they can complement each other. Included in this class of therapies are behaviour therapy, reality therapy and cognitive analytical therapy. These types of therapies are commonly used to address sexual issues, post traumatic stress disorder (PTSD), depression and anxiety.

It is must be born in mind that there are a significant number of patients for whom counselling is inappropriate and possibly harmful, and who do require psychiatric assessment. Patients who have active psychosis or who are too emotionally depressed or anxious to engage actively in counselling require psychiatric intervention. In counselling terms they are 'not available for counselling'.

The therapy business has escalated to the point that some have now called it an 'industry'. Although still based predominantly in the private sector, counsellors and therapists are increasingly working in public settings such as general practice, mental health units and industry. In the United Kingdom (UK) there has been a rapid expansion of counselling provision in primary health care practice. Estimates suggest that one third of all General Practices now have some kind of practice counsellor (Hooper, 1997). 


\section{Recent Developments in Counselling Provision}

\section{COUNSELLIN G IN GENERAL PRACTICE}

There has been little research on counselling in general practice within Ireland. The research described in this section is mainly based on studies conducted in the UK. Estimates of the prevalence of psychological problems in general practice populations have varied from 13\% (The Health of the Nation White Paper, 1991) to 30\% (Gray, 1988). Of these, 95\% attend their GP at some stage during the course of their disturbance (Goldberg \& Huxley, 1980) and only 10\% are referred on to secondary care (Goldberg, 1991).

Although there is clear evidence that antidepressants are both effective and relatively safe in the treatment of major depressive disorder, public opinion is largely negative about their use. A survey of public attitudes as reported by Paykel et al. (1998) following the UK Defeat Depression Campaign (1992-1996) found that, of approx. 2,000 people interviewed, 74\% believed antidepressants to be addictive and $60 \%$ believed them to be an effective treatment for depression. Only $24 \%$ believed that people with depression should be offered antidepressant medication. By contrast, public opinion strongly favoured the use of psychological treatments for depression. The survey found that $86 \%$ of respondents believed 'counselling' to be an effective intervention for depression, and $90 \%$ agreed that people with depression should be offered it (see Churchill, et al. 1999). Thorne (1992) reported that given a choice, $84 \%$ of GP attenders consulted stated that they would prefer to be counselled in general practice for an emotional problem, rather than receive medication or a sick note.

The pivotal role of the GP was shown in a study of 281 adults of all ages who admitted to a personal or emotional problem; $43 \%$ of the women and $27 \%$ of the men had discussed their personal problems with their GP. Health visitors were also important as confidant(e)s with $10 \%$ of the women and $3 \%$ of the men indicating that they had discussed their personal problems with a health visitor (Corney, 1990). Other agencies were mentioned by smaller percentages of the sample; approx. $8 \%$ had contacted a Psychiatrist, $7 \%$ a Social Worker, $6 \%$ a Counsellor or Psychotherapist and $6 \%$ a Priest.

While most GPs would argue that they counsel in almost every consultation, few have the time or training to get involved in 'formal counselling'. An important consideration for GPs who counsel is the use of time in a busy clinical setting. On average a consultation with a GP lasts 10 minutes (Nic Gabhainn \& Kelleher, 2000), whereas a counselling session lasts between 30 and 50 minutes. Thus GPs may not be able to offer patients the same time available to counsellors when attempting to be psychotherapeutic. McLeod (1987) also points out that although many GPs may be interested in their patients' psychological problems, others may not. The majority of doctors enter general practice with little training in counselling. This lack of preparation for counselling, together with the very real constraints of time has limited the capacity of many GPs to recognise patients needs adequately and to respond effectively to these needs (McLeod, 1992).

Counselling in primary care has been regarded as a desirable development by members of primary health care teams (Monach \& Monro, 1995) and by patients themselves (Thomas, 1993). Some of the advantages that have been reported include promptness of referral, ease of access (Brook \& Temperley, 1976), and a reduction in stigma, which resulted from referral to psychiatric services (Thomas, 1993)

\section{TELEPHONE COUNSELLING AND HELP LINES}

The past decade has seen widespread use of telephone and computer technologies to provide a broad array of health behaviour interventions and health services. The proliferation of telephone delivered interventions has been driven in part by the growing emphasis on reducing the cost of health care and the consequent incentives for management of demand on services (Ormond et al., 2000). Combined with the proliferation of counselling training courses now on offer this explosion in the telecommunications industry has opened up the help-line world.

A major advantage of telephone counselling is its significant convenience for the caller. The telephone allows access to a wider section of the public who would not, for geographic or socio-economic reasons, otherwise have access to counselling services (Wheeler \& Siebelt, 1997; Bartlam \& McLeod, 2000). Telephone contact with health care professionals may also decrease the number of unnecessary clinic visits and increase the number of appropriate referrals (Lester, 1995; Williams et al., 1995). Moreover, the immediacy of the communication, whether needed or not, is usually identified by the caller as a benefit (Coleman, 1997).

Communication by telephone in a supportive capacity can be divided into two distinct areas, counselling by telephone and using counselling skills on the phone. Many counsellors have adapted their face-to-face skills and theoretical knowledge in order to work 
effectively by phone. Help-line workers must be using counselling skills to some degree in their telephone work, whether these skills are formally taught and recognised as such.

Many community agencies, hospitals, and psychological associations have offered telephone crisis intervention (Lester \& Brockopp, 1973). Often provided by trained paraprofessional volunteers, these support lines, suicide call lines, or crisis line services have offered callers a variety of non-directive counselling, referral advice, advocacy, support, information and/or befriending services.

The term 'telephone help-line' can be defined as a telephone service that has an active listening and supportive focus, which also provides factual information or is a combination of any of these (Rosenfield, 1997). Furthermore, the help-line can be a short- term service and may be available just for a few hours or a few days or a long term, permanent service, such as many help-lines operated by health-focused charities, children's charities, employee assistance programmes and welfare groups. With most help-lines, the calls are mainly 'one-off'. There may be, however, regular callers to a help-line who may call for several months and it is usual for a particular worker to always work with that caller. The process of this work could be similar to brief counselling although it should be more accurately labelled 'brief support work' since the helpline worker is not working as a trained counsellor. The Telephone Helplines Association in 1993 estimated that in the UK a call was made to a help-line every seven seconds. Whether trained counsellors or not, the Telephone Helplines Association recommends that, anyone working by telephone with vulnerable or distressed people should ensure that they provide a high quality service.

\section{NEWER FORMS OF COUNSELLING}

\section{Peer Counselling}

Peer counselling programmes build on spontaneous naturalistic peer support and seek to equalise access opportunities, develop the organisation and deepen and widen the impact (Topping, 1996). Talking your problems through with a friend is hardly a new concept, and is increasingly the preferred method of support as children proceed into and through adolescence. But it is not an option if your problem is that you don't have a friend. This technique has been widely used with children (Abu-Rasain \& Williams, 1999) and it is used increasingly with disadvantaged adults. Simonson (1987) reports on a project where Social Workers trained volunteers to operate as peer counsellors for chronically and terminally ill hospital patients. There is also significant literature on the benefits of peer counselling, with the deaf (personal communication), smokers (Barker et al., 2000), and breastfeeding mothers (McInnes et al., 2000; Morrows et al., 1999).

\section{Brief Therapy}

The exact extent of uptake of counselling and psychotherapy is unknown. However, it is known that there can be extensive waiting lists for the free or subsidised services of voluntary organisations. Brief therapeutic interventions are being explored and used as a method to overcome both funding and waiting list problems (Baron, 1997). This brings into question the efficacy of such therapy. Blakey et al. (1994) examined the effect of short-term therapy on 100 patients referred by GPs to a psychology department over one year. The results of the study showed a significantly higher number of patients reporting satisfaction with the therapy received. Both research and practice literature suggest that meaningful and enduring change can occur within the context of brief, and sometimes very brief, interventions (Steenbarger, 1993).

\section{Self-Help Groups}

Self or mutual help groups have been part of the mental health arena for many years. They have traditionally provided valuable support to people recovering from mental illness, from alcoholism and drug addiction and to those coping with the effects of illness and disability. Where community based care involves the patient living alone or with his/her family, the patient and/or the family may have difficulty coping with the illness or its consequences on their own. The potential of self-help groups in such circumstances has been noted by both policy makers and health researchers. During the consultative process for the Plan for Women's Health 19971999 the importance of self-help groups for developing women's ability to cope was emphasised by many women. However, noting the potential of self-help groups in healthcare has not led to their promotion as an integral part of the health service in Ireland, or elsewhere, to any significant extent (Borkman, 1997). Self-help groups are seen as especially useful in the treatment and management of addictive behaviours, and in particular of alcohol addiction. They are also considered a valuable resource for women with breast cancer (Kennedy et al., 2000). Self-help groups are less likely to be suggested to patients with behavioural or psychosocial problems (Dunne \& Fitzpatrick, 1999).

A recent survey on the attitudes of Irish GPs working within the GMS found that while practitioners had a generally positive attitude to the principle of self-help, they did not have a clear view on how the self-help movement in general might or should relate to mainstream medical services (Dunne \& Fitzpatrick, 1997). In general, self-help organisations are seen by health professionals as 
providing support to patients and their families; information on mental illness/health to the general public; and lobbying for services relevant to the needs of their members. It has been reported (O'Mahony, 1997) that mental health care practitioners from a psychosocial background (Psychologists, Counsellors and Social Workers), are believed by self-help group members to hold generally more positive attitudes about the group than those from a medical perspective (GPS and Psychiatrists). While some professionals see a role for self-help organisations in the mental health care system, reservations were expressed about a possible clash between self-help groups' approach and professional mental healthcare practice need to be addressed so that the potential of both positions can be realised (Nic Gabhainn, 1999).

\section{Contemporary Feminist Contributions}

Traditionally, developmental theorists have held male patterns of development to be superior to female patterns (Belenky et al., 1986; Gilligan, 1982). Before the feminist movement in psychology, the typical male patterns of development went unchallenged as the 'normal and healthy' way to think and behave, while the typical female patterns of development were generally accepted as 'immature and inferior' ways of thinking and being (Crose, 1991).

Many of the central theories that have informed counselling, have emanated from studies of male experience. In the case of Erikson, his whole theory of the stages of human development was based on research into a limited number of case studies of young men. Kohlberg, similarly, based his theory of moral development on a sample of young men. In these examples, male experience is used to represent human experience. In the majority of cases male interpretation of experiences has also informed the theories. It is well documented that Freud denied huge chunks of female experience as he developed his theoretical standpoints. What is less researched is how the gender of other theorists has influenced their interpretation of experiences.

Over the decades of the 1980s and 1990s, several innovations have been made in the therapeutic arena. Luise Eichenbaum and Susie Orbach were instrumental in developing a specific model of psychotherapy, and in introducing a new forum for working in the form of the London Women's Therapy Centre. Several such centres are now in operation, spanning perspectives from eclectic models of counselling to pure, long-term psychotherapy. Rape crisis centres were set up from the mid-1970s onwards, to deal with issues that affect women and girls from a woman's perspective and not from a gender-neutral perspective. More recently, Woman's Aid refuges, long familiar with the value and relevance of the use of counselling skills in their work, have begun to debate the inclusion of individual counselling in their practice. It has been argued that the use of individual counselling is seen as antithetical to the nature and values of Women's Aid (Perry, 1993). It is important to note that most projects specifically concerned with feminist counselling are funded from the voluntary sector, and under constant pressure to negotiate, justify and secure funding in order to survive.

Russell (1996) notes that some organisations and groups have struggled with the dilemma of whether individual counselling is useful to the aims of feminism. The point is made that counselling brings with it a whole new language, whether through concentrating on feelings to the exclusion of all else, or in the mind-game arena where one person's perception is given analytic status as a 'projection' rather than being valued for what it is. It has also been suggested that counselling might undermine the strengths of the 'collectiveness' of lesbians, and that it has a depoliticising and conditioning effect (Mercy, 1990). Russell states that on the contrary, the alleviation of distress and the replenishing of internal resources can serve to enable individuals to pursue the political. The case for and against the value of therapy for lesbians, and women in general, remains hotly debated (Perkins, 1992; B rown, 1992).

In the ideal world, as Smail (1987) has suggested, all human beings, not only specific categories, would support each other through natural and contrived life events, and counsellors would be redundant. Unfortunately, this is not currently the case. There are other issues that need to be addressed. It has long been questioned whether male counsellors can work with female clients (Chesler, 1972). There is an increasing acknowledgement that counsellors are powerful and can be exploitative of their clients through the abuse of either power in the relationship or the power of psychological theory (Russell, 1993). How do sexism and heterosexism enter this arena? There is room for much more debate.

To ensure that feminist theory is recognised within main-stream counselling, Russell (1996) recommends that counselling education could put more emphasis on its philosophical foundations and its theories of self, with due consideration of their context of development. These should be presented alongside the feminist models of theorists and critically compared with the traditional models. The dynamics of gender issues should be integral to counselling courses, rather than an optional sideline. 


\subsection{Efficacy and Effectiveness of Counselling/Therapy}

This section examines psychotherapy and counselling from efficacy, effectiveness and cost benefit perspectives. It includes reviews and meta-analyses of the international literature in this area. The literature of interest includes both traditional positivistic approaches to evaluation as well as those including more recent feminist and consultative methods.

\section{Measurements of Validity}

Psychotherapy and counselling are today subject to the same rigours, which would be expected, of any drug or technique purporting to ameliorate physical pain or unhappiness. When seeking to establish the validity of a health care procedure, both efficacy and effectiveness research is vital (Clarke, 1995).

Efficacy asks under controlled circumstances, does this particular procedure produce any particular effect above and beyond a comparison procedure? Efficacy must be translated into effectiveness within the uncontrolled, sometimes chaotic world of the practising clinician (Weisz et al., 1995). Effectiveness studies ask whether an intervention can be conducted and produce an effect in the real world? As in actual practice, effectiveness studies follow the progress of patients who choose their treatment. In the absence of controlled conditions, it may be difficult to claim that the observed effect was due to the implemented procedure, i.e. there are serious threats to internal validity. Such 'quasi-experiments' therefore need to be replicated to disqualify competing, alternate explanations of the observed results (Cook \& Campbell, 1979).

During the last 25 years, meta-analysis has become a popular and methodologically sophisticated technique for quantitatively summarising findings from a large body of empirical research. One of the best ways to summarise the plethora of efficacy research evaluating psychotherapy is through meta-analysis. Numerous individual studies are quantified and coded so that they can be compared with one another. Typically an effect size (ES) is calculated for each study, indicating the size of the difference between the treated and untreated group.

\section{Validity of Psychotherapy Research}

Smith et al. (1980) summarized 475 studies of psychotherapy and calculated an average ES of 0.85 , indicating that the average treated person would have an outcome equal or superior to $85 \%$ of the average untreated person. The Smith study is criticised for not reporting the placebo effects that accounted for more than $20 \%$ of improvement from their findings (Epstein, 1999). With this adjustment, psychotherapy patients are only about $10 \%$ better off than the controls. On the basis of reanalysis of what they described as the credible portion of the Smith studies - the 32 studies that incorporated a placebo control - Prioleau et al. (1983) concluded that psychotherapy only confers a benefit of $6 \%$.

Eysenck reviewed 24 studies of psychotherapy and concluded that there was no evidence supporting the effectiveness of psychotherapy, and that there 'appears to be an inverse correlation between recovery and psychotherapy; the more psychotherapy, the smaller the recovery rate' (1952). However, both his methods and his conclusions have been heavily criticised (e.g., Bergin, 1971). Eysenck's studies spurred a great deal of research aimed at demonstrating the positive effects of psychotherapy.

In a meta-analysis of effectiveness studies, Howard et al. (1986) compiled and reanalysed data available from studies that included over 2,400 patients reported in studies covering a 30-year period. They found a lawful linear relationship between the number of sessions and the probability of patient improvement. By about the eighth session, almost half of patients were measurably improved, and by session 26, half of the remaining patients had improved. This 'dose-effect' has been replicated and indeed researchers (Orlinsky et al., 1994) have demonstrated that different disorders respond at different rates.

An economic assessment of cost-effectiveness must always include two different types of costs 1) direct costs related to actual monetary expenditures for delivery of the treatment and 2) indirect costs associated with lost productivity related to the illness, disability and problems on the job. "Cost-effective does not necessarily mean cheap but instead means high value; quality improvement may be cost-effective even if it increases direct treatment costs" (Wells \& Sturn, 1995). In the case of depression, for 
example, one of the 'high value' aspects of good treatment is reduced absenteeism from work and higher productivity on the job. Government agencies may also benefit as a result of fewer transfers of funds into unemployment and disability payments.

Not a single meta-analysis has found psychotherapeutic interventions to be ineffective or harmful (Matt \& Navarro, 1997). Although the data is consistent it is the direction in sign (i.e., positive effects) rather than the magnitude of the effect that is supported by the research reviews. These and other studies have established that psychotherapy as conducted in the real world is effective (Saunders, 1999).

\section{Validity of Counselling Research}

In comparison to the psychotherapy literature, the studies of the efficacy and effectiveness of counselling in primary care are relatively few in number and are somewhat contradictory. Some studies have failed to show any benefit of counselling compared with 'routine care' as normally provided by the patient's GP (Friedli et al., 1997); others have shown reductions in psychotropic drug prescribing, frequency of surgery attendance and improved symptomatology (Anderson \& Hasler, 1979; Waydenfield \& Waydenfield, 1980). On the whole, patients prefer 'talking' to 'prescribing' (Friedli et al., 1997), although the evidence is that for depression the combination of drugs and therapy together is more effective than either alone (Blackburn et al., 1981). The balance of evidence suggests that focused, problem-solving approaches are more likely to produce benefit than unstructured psychological interventions (Tylee, 1997). Several of the studies that have compared counselling with routine GP care are described below.

In a randomised controlled trial of counselling (Hemmings, 1997), compared an In-House Counselled (IHC) group of patients to a group that received routine treatment (RT) which consisted of advice from GPs. Results showed that patients within both groups improved considerably, in line with similar studies. The IHC group was significantly less likely to be referred out to mental health services than the RT group. However, there was no statistical difference between the groups on any of the measures of interpersonal problems, psychological distress, self-esteem, or in changes in subsequent service use or prescribing patterns. Patients in the IHC group were overwhelmingly in favour of counselling and stated that it had helped them with a variety of problems. The study also found that women had to have a higher level of distress in order to be referred to a counsellor. All the GPs who referred followed this pattern with only one exception.

In a meta-analysis of 11 studies, Balestrieri et al. (1988) found that counselling by mental health workers attached to a general practice surgery was $10 \%$ more effective than routine GP treatment. However, Freidli \& King (1996) point out that some of the studies did not use randomised control groups, and only two studies actually explicitly compared counsellors with usual GP care.

Booth et al. (1997) note that most of the existing studies on counselling in primary care have focused primarily on outcome of psychological interventions in comparison to routine GP care and they question how useful such findings are for practice counsellors. In their evaluation they examined 19 frequently cited studies and then reduced these to 10 by only including those that had adhered to the standards of controlled trials (Table 1). They concluded that outcome studies have shown counselling and other psychological interventions in primary care to be as effective as routine GP care and in some cases more effective at post-treatment and sometimes at later follow-up. 
Table 1: Outcome studies of counselling in general practice presented by category of professional (Booth et al., 1997)

\begin{tabular}{|c|c|c|c|c|c|}
\hline $\begin{array}{l}\text { Authors/ } \\
\text { Professional }\end{array}$ & $\begin{array}{l}\text { Type of } \\
\text { Problem }\end{array}$ & N'S & $\begin{array}{l}\text { Interventions } \\
\text { compared }\end{array}$ & $\begin{array}{l}\text { Outcome } \\
\text { variables }\end{array}$ & Outcomes \\
\hline $\begin{array}{l}\text { Practice } \\
\text { Counsellors: } \\
\text { Brodaty \& } \\
\text { Andrews (1983) }\end{array}$ & $\begin{array}{l}\text { Psychological } \\
\text { problems } \\
\text { (>6 mths) }\end{array}$ & 56 & $\begin{array}{l}\text { Psychodynamic } \\
\text { counselling versus } \\
\text { counselling by GP } \\
\text { versus routine GP care. }\end{array}$ & $\begin{array}{l}\text { Symptom assessment; } \\
\text { Social Adjustments; } \\
\text { Physical disability; } \\
\text { Medication; GP visits. }\end{array}$ & $\begin{array}{l}\text { No significant } \\
\text { differences at } \\
\text { post treatment or } \\
\text { follow-up (1 year). }\end{array}$ \\
\hline Boot et al. (1994) & Mixed & 108 & $\begin{array}{l}\text { Eclectic Counselling } \\
\text { versus routine GP care. }\end{array}$ & $\begin{array}{l}\text { Symptom assessment*; } \\
\text { GP consultations, } \\
\text { Medication*. }\end{array}$ & $\begin{array}{l}\text { *Significant } \\
\text { differences post } \\
\text { treatment } 6 \text { weeks } \\
\text { later. }\end{array}$ \\
\hline $\begin{array}{l}\text { Nursing Staff: } \\
\text { Paykel et al.(1982) }\end{array}$ & 'Neurotic patients' & 72 & $\begin{array}{l}\text { Supportive home } \\
\text { visits by CPN versus } \\
\text { Psychiatric outpatient } \\
\text { clinics. }\end{array}$ & $\begin{array}{l}\text { Symptom assessment; } \\
\text { Social Adjustment; } \\
\text { Relatives assessment; } \\
\text { Contact with psychiatric } \\
\text { services*. }\end{array}$ & $\begin{array}{l}\text { No significant } \\
\text { differences except* } \\
\text { CPNs superior } \\
\text { at } 6 \text { months. }\end{array}$ \\
\hline
\end{tabular}

Marks (1985)

Phobias,

Behaviour therapy

Problem/work/leisure Experimental group

obsessive-

versus routine GP care.

compulsive disorder

Social Workers: $\quad$ 'Chronic neurotic 189

Cooper et al. (1975) illness'

Corney (1984)
Supportive social care versus routine GP care.

Social Worker intervention versus routine GP care.

\begin{tabular}{|c|c|c|c|}
\hline $\begin{array}{l}\text { Clinical } \\
\text { Psychologists: } \\
\text { Earil \& } \\
\text { Kincey (1982) }\end{array}$ & Mixed & 50 & $\begin{array}{l}\text { Behaviour therapy } \\
\text { versus routine } \\
\text { GP care. }\end{array}$ \\
\hline Robson et al. (1984) & Mixed & 429 & $\begin{array}{l}\text { Behaviour therapy } \\
\text { versus GP care. }\end{array}$ \\
\hline
\end{tabular}

Psychiatric Clinics: Depression Scott \& Freeman (1992)

$\begin{array}{ll}\text { GP as counsellor: } & \text { 'Minor } \\ \text { Catalan et al. (1984) } & \text { affective disorders' }\end{array}$
121 Cognitive-behavioural therapy versus social work counselling versus psychiatric drug versus routine GP care.

91

GP counselling

versus anxiolytic medication from GP. ratings; Fear questionnaire. significantly better at 1 year.

Psychiatric assessment;

Social Adjustment; Medication;

Experimental group significantly better at 1 year.

Extramural services

Psychiatric assessment; Overall no significant Social Adjustment; Medication; GP visits.

difference except for acute on chronic group at 6 mths.

Medication; GP visits; Use of extramural services; Psychological health; Life satisfaction.

Ratings of: problem severity/effect on Experimental group significantly better treatment but not at 7 mths follow up.

Experimental group significantly better up to 34 weeks.

sufferer/household; GP assessment of satisfactory outcome; GP visits.

Symptom assessment;

Social work Psychiatric assessment; counselling only Social Adjustment; superior to GP care at 16 weeks. treatment.

Symptom assessment;

No significant Visits to GP. differences between groups at 7 mths. 
Mellor-Clarke (2000) in contrast to the earlier reviews (Freidli \& King, 1996; Godber, 1996; Roth \& Fonagy, 1996) that found no overall supportive efficacy for (heterogeneous) 'counselling' in primary care However, the results of a systematic review of controlled trials of counselling (Rowland et al. 2000) showed that while there are no clear cost advantages associated with either counselling or usual GP care, counselled patients tend to be more satisfied and tended to show modest but statistically significant improvements in symptom levels compared to those treated by GPs. There was very tentative evidence to suggest that counselled patients are more likely to recover than usual care patients are, but this result requires further investigation.

Hemmings (2000) conducted a review of the unpublished literature (26 studies) from various UK sources; Health Authorities, NHS Trusts, etc. Just under half of these studies attempted to measure cost-effectiveness of the counselling service. The reviews of Rowland et al. and Hemmings offer a consensus of support from both efficacy and effectiveness perspectives. While both reviews are careful to point out the dangers of over-interpretation of the results because of a variety of methodological weaknesses, both acknowledge the supportive direction of their results. Additionally, both reviews found consistently high levels of patient and GP satisfaction. Furthermore, each review included some studies that had considered cost-effectiveness through either reduced onward referrals, reduced psychotropic medication prescribing, or post-counselling GP consultation rates. On balance, it would appear that the overall direction was more positive than negative.

\section{Sub-groups}

The few studies that have analysed the reaction of specific subgroups to counselling, suggest that particular groups may benefit from counselling more than others. The characteristics of people who have been found to particularly benefit include women in unhappy marriages, who lack a confiding relationship and have a diagnosis of 'acute or chronic depression' (Corney, 1984) and those with previous episodes of emotional distress (Catalanet al.,1991).

Studies in the US (e.g., Cummings et al., 1993) have focused on targeting specific groups of patients to receive counselling interventions; for example, patients suffering from heart disease, diabetes or asthma. It has been shown that the use of specific, focused counselling interventions can have a potentially major impact on improving the quality of patient care, while reducing total healthcare costs and producing a quantifiable health gain and high levels of patient satisfaction. It appears that certain subgroups of patients are likely to benefit more from counselling, but further research is required to identify which groups (Booth et al., 1997).

\section{Counselling Within Ireland}

This section documents the development of counselling within Ireland, both within and external to the statutory health services. It includes the development of training, employment, professional organisation and roles within the Irish Health Services.

Psychotherapy within Ireland tends to be used by people who have sufficient disposable income. As Boyne (1993) states "despite its importance and potential, there is no doubt that psychotherapy is among the most privatised of all the caring services in Ireland". For therapy to be made more available than it is at present to those on lower incomes, it would be necessary for the State to provide funding to set up a greater range of services. Holmes \& Lindley (1998) point out that a working class patient presenting to a doctor with emotional distress is likely to be prescribed a tranquilliser in comparison to middle class patients who are more likely to see a doctor who offers some form of therapy other than a prescription. This raises the question as to whether it is morally acceptable that distressed working class people should be medicated while their middle class counterparts are more likely to receive therapy.

Up until recently one of the problems inhibiting the expansion of therapy services has been the ambiguous position of psychotherapy and counselling as professions. Some people argue that counselling and psychotherapy should be merely an ancillary activity of certain professionals, such as medical doctors, Psychiatrists or Psychologists. Others have suggested that they should be professions in their own right, with their own standards of entry and qualification. This brings the debate on the differences between counselling and psychotherapy back into focus. Many practitioners are strongly opposed to the establishment of one professional accreditation body overseeing both counselling and psychotherapy. Consequently, three main accrediting bodies have emerged within Ireland; the Irish Council for Psychotherapy (ICP), the Irish Association for Counselling and Therapy (IACT) and the Counselling Division of Psychology of the Psychological Society of Ireland (COD, PSI). For a full description of the membership requirements for each of these organisations please see section 2.4.5. 
A number of research studies have been carried out in Ireland on public beliefs and attitudes towards mental health and mental disorder. The first systematic survey carried out on behalf of the Mental Health Association (1973) surveyed 1,578 people on their awareness of and attitudes toward mental health and illness. People regarded 'mental illness' as a serious social problem (43\% perceived mental illness as one of the country's most prevalent social problems, ranking third behind alcoholism and unemployment), they also tended to prejudice against people with mental health problems. Some $67 \%$ of respondents agreed that people are ashamed of mental illness in the family, $65 \%$ agreed that most people would not employ a person discharged from a mental hospital and $60 \%$ of respondents agreed that mental illness could be inherited.

Moran (1977) set out to determine the structure and dimension of Irish attitudes towards mental disorder and reported that the stigma attached to 'mental illness' was greater in rural respondents. A more recent national survey by McKeon and Carrick (1991), looked specifically at public attitudes to depression. A national survey of 1,403 respondents throughout Ireland revealed that the vast majority of people interviewed expressed positive attitudes, they regarded depression as being treatable (73\%) and requiring active interventions (81\%) and the authors noted that the public's concepts of causes and possible treatments generally concurred with those used in clinical practice. Stress, bereavement and hereditary factors were the most frequently cited causes of depression, and some $32 \%$ of the sample reported that they had somebody close to them who had been treated for depression. Respondents over 65 years, farmers and rural dwellers were found to be more likely to express more negative attitudes.

Barry (1994) interviewed 200 respondents to explore the perceptions and implicit beliefs surrounding mental disorder held by members of a rural community in the West of Ireland. Apart from personal life experience $(58 \%$ were characterised as having experienced high levels of psychiatric contact, i.e., frequently with a family member), the prime source of information concerning mental health matters was TV or radio with few of the respondents having read anything on the topic. Results suggested that 'mental illness' still held a certain amount of stigma for members of the sample. When asked whom would they recommend as sources of help, it was apparent that the GP was considered the first point of contact in most cases, followed by the Psychiatrist. For the most part, respondents did not consider recommending other professionals such as Psychologist, Counsellors or Social Workers. It is possible that this reluctance may have been due to a lack of information about the services that these professionals provide and of how to go about contacting them. In contrast to this was respondents' knowledge concerning the services provided by Alcoholics Anonymous and their endorsement of its success in dealing with drinking problems. Barry states that there clearly is much work to be done in promoting the range of services on offer from professionals such as Psychologists, in informing people about how to contact services and in the provision of information on the types of treatments available.

In 2000, Barry et al. reported on a study encompassing four rural communities in Ireland. A cross-sectional study of the mental health beliefs and perceptions of 1014 people was conducted. Findings show that men expressed more reluctance about consulting a GP and/or a Psychologist for depression than did women. Overall, 53\% of the sample reported that they would find it either 'difficult' or 'very difficult' to advise someone with depression and 71\% reported a perceived difficulty in advising someone who was suicidal. With regard to perceptions of the effectiveness of the services, $71 \%$ considered the Psychiatrist to be effective in treating depression and $60 \%$ the GP. In terms of advising a person with depression, 35\% recommended talking to someone close, $34 \%$ recommended contact with the GP, $12 \%$ endorsed seeing the Psychiatrist, 10\% advised 'pull yourself together', $6 \%$ recommended the Samaritans and $2 \%$ suggested asking a member of the clergy for help. Concerning barriers to seeking professional help, over half $(62 \%)$ of respondents indicated that there was nothing that would prevent them personally from seeking help. Of those who did suggest barriers, $12 \%$ made reference to the social stigma surrounding mental health services, $4 \%$ to distrust of the services and $4 \%$ to not recognizing the need for help and spontaneous remission. It would be interesting to explore these issues in more detail, particularly given the key role played by the GP as a first point of contact for most presenting clients.

\section{Statutory Provision of Counselling}

The Department of Health and Children has overall responsibility for the development of health policy and for the planning of health services. The ten health boards are the statutory bodies responsible for the provision of health and personal social services in their functional areas. They are the main providers of health care at regional level although the Department of Social, Community and Family Affairs also provide funding for marriage and child counselling services. The voluntary sector also plays a vital role in the delivery of health and personal social services. Voluntary agencies range from major hospitals and national organisations to small 
community-based support groups set up in response to local needs. In addition, a number of specialist agencies have been established to address particular needs or to provide particular services.

A review of each of the ten health boards' Annual Reports and Service Plans was conducted to establish the current and planned provision of counselling within each of the health board areas. The two main areas of service provision are for drug/alcohol addiction and adultsexual abuse. A brief summary of the services currently offered is detailed below.

\section{Addiction Services}

Addiction Counsellors employed by the Psychiatric Services provided traditionally counselling services. The majority of the health boards are in a process of expanding the services offered and recruiting additional addiction counsellors to work with drug treatment clinics, GPs and community organisations. Community counselling and outreach services are also offered in many of the health board regions. Preventative measures are also being undertaken by the Health Promotion Units in the community and schools. The need for the development of family therapy services has also been identified by several of the health boards.

\section{Adult Counselling Service}

The Department of Health and Children has established a 'National Counselling Service: For Adults who Experienced Childhood Abuse'. This is a community-based service for men and women who suffered childhood abuse in Ireland. It is a national, free and confidential service located in each health board area. The aim of this service is to provide a high quality, accessible, communitybased counselling service to adult survivors of childhood abuse. Individual clients are enabled to become aware of the residual effects of past abuse on their current lives so that they can effectively realise their potential for health and social gain. All health boards have set up this community-based counselling service and are working on its development.

\section{Family \& Childcare}

The majority of the health boards mention their Family Therapy services and the provision of counselling within this section of their reports. One of the health boards had identified the need for further investment in staff training and development in the Community Mental Health Service, particularly in the area of counselling and family therapy. The Psychology Service in each board offers bereavement counselling as part of its range of psychological treatments.

\section{Domestic Violence}

All of the boards have opted for a community-based model of service provision for women who have experienced violence. The enhancement of regional counselling services regionally is in progress in many health boards, with an emphasis on quality professional counselling and the provision of outreach services.

\section{Mental Health Services - Suicide Prevention}

The health boards offer a variety of mental health services to the general public. However, suicide is viewed by many of the health boards as a major social problem and a potentially preventable form of mortality (Report of the National Task Force, 1998). They are in agreement that preventative approaches must involve all sectors of society and in a corrective and constructive way, influence the process of problem development as well as enhancing the individual's own resources at different phases of their life cycle. Recent developments have occurred in this area largely in response to the Report of the Government's National Task Force on Suicide (1998). Several of the health boards have appointed suicide Project Officers to take forward service initiatives in conjunction with the Mental Health Service, Public Health and Health Promotion staff, as well as with voluntary/community groups. Two of the health boards have taken a holistic approach to the social context in which health concerns arise and offer professional counselling and support to the families of those who have committed suicide. Another health board has detailed the provision of staff training, media campaign, directory of services, and establishment of a Help line in partnership with the Samaritans.

\section{Persons with Disabilities}

An enormous variety of services are offered within this sector. Several health boards mentioned that counselling nurses are employed for the assessment and counselling of the intellectually disabled and recognised that this is an important facility. Only one of the health boards mentioned a counselling nurse service for Hepatitis $\mathrm{C}$ sufferers. One of the health boards noted the developments that have been made in the establishment of the peer counselling service provided in collaboration with the Irish Wheelchair Association. The appointment of a counselling/liaison nurse to provide support and information to parents and families following the birth of a disabled child was also detailed by one health board. One health board offers a specialist counselling service for people in the Special Care Unit. 


\section{Women's Health}

The Plan for Women's Health 1997-1999 recommended the establishment of Women's Health Advisory Committees (WHAC) within each of the health board areas. Each WHAC was provided with funding from the Department of Health and Children to prepare a regional plan to promote women's health. The quality and depth of these plans are quite varied in relation to the recommendations they make and their implementation strategies. This review only covers the services detailed in the Annual Report and Service Plans of each of the health boards based on the assumption that the actions detailed in the Health Plans will have been incorporated in the daily activities of the health boards (as detailed in their Annual Reports) and their future plans (Service Plans). The commitment to women's health is clearly identified within the review material by whether it had a dedicated section or not. In one health boards' Annual Report women's health was not mentioned at all. Several of the boards did refer to the appointment, or planned appointment, of a women's health coordinator/development officer to assist in the promotion of women's health services.

The majority of the health boards stated that they wish to take a holistic approach to women's health. Most focus on the provision of family planning clinics or the development of GP based women's health services. The provision of counselling services within these settings are detailed by several health boards (although it is not always clear whether this refers to generic or pregnancy counselling). The suggestion from one of the boards that the GP training scheme incorporate a module on psychosexual counselling was innovative.

\section{Health Board Staff}

Many of the health boards acknowledged that the community sector contributes to the design and delivery of their services, particularly in the areas of mental health and adult sexual abuse. The health boards appear to be concerned with the health and well-being of its employees. Leading by example as employers, several of the boards now offer a counselling service for staff. In relation to the supervision of counsellors one health boards is currently in the process of consultation with the different counselling specialists which have developed in the Mental Health Service and elsewhere over the past number of years.

This description of current and planned counselling provision within the health boards is not intended to be an exhaustive record. Instead, it highlights the current status of counselling in the Irish health care system. It also shows that the delivery of counselling can be quite ad hoc depending on the board in question. In many regions, the only access a non fee-paying patient has to counselling services is to be referred to the local psychiatric service. General psychiatric services have little to offer these patients who often feel stigmatised and regard the referral as inappropriate medicalisation of their problem (Sibbald et al., 1993). Any member of the public enquiring as to the availability of counselling from their health board may find it a confusing experience. It should also be noted that the Department of Social, Community and Family Affairs also has a separate remit in this and provides funding for certain types of counselling, e.g., marriage and child counselling.

\section{Counselling within General Practice}

The contribution that counselling can make to the work of the GP has been detailed above and documented by the Irish College of GPs in their publication 'Counselling in Practice: A Guide for GPs' (O'Carroll \& O'Riordan, 1996). It is reported (Nic Gabhainn \& Kelleher, 2000) that $8 \%$ of Irish GPs have a practice-based counsellor and it is worth noting that this is without the package of incentives offered to their UK counterparts. Aherne and Griffin (1991) carried out a survey of patients attending a Psychologist for counselling in a general practice setting in Limerick City. The patients reported that they were happy with the service they received as they found it was orientated towards them. Patients reported that they enjoyed easy referral with what they perceived as low time constraint and they reported no stigma attached to being referred to a counsellor within the practice. They felt that they had received skilled management of their problems with good GP backup. Interestingly, two thirds of patients felt that their problems could not have been adequately managed by the GP alone. Developments to be considered include the several pilot programmes on counselling provision within general practice which have recently been developed in the Southern Health Board and in the Eastern Regional Health Authority. Reviews of these pilots are not currently available, but present vital data to help inform future counselling provision within primary care. 


\section{Community/Voluntary Sector Provision}

Within Ireland the major providers of community counselling services are the counselling, alcohol, drug addiction and marriage and family therapy centres (O'Leary, 1990a). In general, they are based in two main cities, Dublin and Cork and some are attached to the health boards. Many of these voluntary agencies are grant aided by them often in association with the Department of Social, Community and Family Affairs. It is argued that public funding is vital for these agencies so that time is not taken up with considerable fund raising.

The training requirements in each of these centres are not formalised, resulting in considerable differences in qualifications, ranging from clinical psychology and counselling psychology backgrounds to diplomas or certificates in counselling. Several of these centres run their own in-house training programs, e.g. the Rape Crisis Centres run courses which are accredited by the National Network of Rape Crisis Centres and ACCORD train their own marriage guidance counsellors.

There now exists a number of voluntary counselling services, developed in response to particular needs associated with problems such as suicide (the Samaritans founded 1980), pregnancy (CURA founded 1977), sexual abuse (Rape Crisis Centre, founded 1979) and marriage difficulties (ACCORD, formerly known as the Catholic Marriage Advisory Council). The distinctive feature in these organisations has been the voluntary status of many of the persons who function as helpers. Many groups are now finding that they have to appoint paid staff, in addition to their volunteers, in order to keep up with the demand for services and to cover staff shortages as a result of the drop in volunteerism. Personnel are usually given basic instruction in listening, counselling and empathic skills, which is often provided by professional counsellors.

Closely akin to the voluntary counselling services, are the self-help organisations to be found in Ireland, such as Alcoholics Anonymous, Gamblers Anonymous, GROW, and the Bereaved Parents Association. These organisations do not offer counselling but facilitate the establishment of groups and often provide leadership training. 'Lesser' forms of counselling such as befriending, selfhelp groups, bibliotherapy and measures to reduce social stress are also likely to help people feel better and more able to tackle their problems (O'Leary, 1990a). Some proponents of these methods even claim that they are superior to formal psychotherapy in that they have a feminist philosophy of empowering people rather than fostering dependence.

\section{The Development of Training}

A number of events in Ireland led to the introduction of counselling at a professional level (O'Leary, 1990b). In the 1960s and 1970s various initiatives were created such as free postprimary education, school transportation, comprehensive education emphasising pupil orientation, regional technical colleges, grants to enable students to attend universities and colleges and the establishment of the National Rehabilitation Board.

The first formal guidance service was established in 1960 by the Vocational Education Committee of Dublin city. In 1966, the Minister for Education initiated the School's Psychological Service. This was followed by the establishment in University College Dublin (UCD) of a 1-year full-time course of study in guidance and counselling leading to a postgraduate diploma in career guidance. Other academic institutions soon followed suit. In 1973, for example, the Mater Dei Instititute of Education in Dublin set up a similar programme with government assistance. In 1981, the Applied Psychology Department of UCC increased accessibility to guidance programmes by offering their diploma in career guidance to both university and non-university graduates. Participants have included social workers, community workers, childcare workers, police junior liaison officers, nurses and home management advisors, as well as teachers.

In 1983, a governmental decision was made to reduce the ratio of counsellor-to-student in schools from 1:250 to 1:500 (O'Leary, 1990b). This decision impacted on the demand for school counsellors and counsellor education programmes consequently adapted their training programmes and began to train mental health counsellors.

The option to train mental health counsellors in Ireland was initially pursued principally by the Department of Social Studies, TCD, which first offered a diploma in Addiction Studies in 1983. This was followed in 1986 by the Department of Applied Psychology, UCC establishing the first Master's degree in counselling in the Republic. These universities now offer a variety of counselling courses including Masters and Diploma in Counselling Psychology (TCD), and Higher Diploma in Counselling (UCC), which are IACT accredited. Other universities and counselling centres have since followed suit, although they are not necessarily IACT accredited. Generally the style of training offered in Western Europe during the 1970s was that of person-centred therapy. During the 1980s training in Gestalt Therapy became popular and is now offered at several locations throughout Ireland. 
The experience of counselling is very variable within the Western countries, it is strong in the Anglo-American countries, weak to the point of non-existence in countries like Italy and the term 'counsellor' has not been widely used in Europe. The danger is that a purely Western or Anglocentric model of counselling may not be appropriate and the non-Anglo-American countries may require counselling to be in their own national image and be restricted to medically trained people - unless the countries with wider traditions of counselling can make their counter-influence felt (Lefébure, 1996).

In order to move one's qualifications freely across transparent borders it will be necessary to have these qualifications recognised in some uniform way by one's own government. There is a requirement within the recent EU directives for equivalence of forms of training, and this in turn requires the existence of a designated authority in each country. This would be more easily established if there already existed some national body or association that set standards and controlled the work in question.

The 1st Diploma Directive (89/48/EEC) is already in force and governs all professions for which at least three years' full-time education and training at university or the equivalent level are required, as is the case for most psychotherapy training courses. The directive protects the rights of a person qualified in a particular profession in one EU country to practice that profession in another EU country without having to retrain. But the monitoring of the equivalence of training requires the existence of a so-called 'designated authority' in each country, which is in turn easily, established where there is already a 'competent authority' for that profession, i.e., a national body. There is a second directive in draft, the 2nd Diploma General Directive (COM (90)389 Final). This is creating pressure within the field of counselling towards an inter-state equivalence of training and so towards a national 'competent authority' for counselling. As there are a number of counselling bodies in Ireland this could be problematic.

The European Association for Counselling (EAC) was registered in Belgium in 1993 and assists the development of counselling as a profession in Europe. It has recently launched the European Accreditation Certificate in Counselling, which is issued through the national coordinators. The Irish Association for Counselling and Therapy holds Irish national status in the EAC. The European Association of Psychotherapy (EAP), founded in 1991, has developed a European Certificate of Training in conjunction with the European Commission. This promotes the recognition of common standards of training for psychotherapists throughout Europe and will in time ensure their mobility across member states. Until this certificate is adopted by the EC member states it cannot be a legal requirement, but it is recommended to all national coordinators (of which the Irish Council for Psychotherapy is the national awarding organisation in Ireland).

Mobility between Ireland and Great Britain is further facilitated as counsellors trained in Northern Ireland can gain automatic entry to the Irish Association for Counselling and Therapy (IACT) on the condition that they are fully accredited members of the IACT'S B ritish equivalent, the British Association for Counselling (BAC). If they are not accredited to the BAC they have to show equivalence of training. Similarly, psychotherapists seeking accreditation to one of the five sections of the Irish Council for Psychotherapy (ICP) need to show equivalence of training by providing details of the training programmes attended. Membership of the Psychological Society of Ireland (PSI) requires that the applicant hold graduate membership of the B ritish Psychological Society in order to progress the application.

Since the introduction of psychotherapy and counselling programmes to Ireland the growth of this field has been remarkable. Accompanying this growth, counsellors and psychotherapists alike have been active in regulating their new profession to safeguard public interest and to promote continued self-examination and improving of standards. Within Ireland there are three main professional organisations that are widely respected in this area; the Irish Association for Counselling and Therapy (IACT), the Irish Council of Psychotherapy (ICP) and the Counselling Division of Psychology of the Psychological Society of Ireland (CDoP, PSI). However, none of these counselling/psychotherapy organisations have officially been recognised as an accrediting body by the government. However, the question of recognition has to be addressed under EU legislation (see above) and negotiations are currently in progress between these organisations and the Department of Health and Children.

\section{Irish Council for Psychotherapy}

The Irish Council for Psychotherapy (ICP) comprises five sub-sections which represent different approaches within psychotherapy, and which in turn have their own organisational structure, training standards, code of ethics and complaints procedures. They are Cognitive and Behavioural Therapy, Constructivist Psychotherapy, Couples and Family Therapy, Humanistic and Integrative Psychotherapy and Psychoanalytic Psychotherapy. Membership of the ICP is 600. There are three criteria for accreditation for membership, which includes supervision, having attended therapy yourself and recognised training (as specified by the ICP). 
Irish Association for Counselling and Therapy

The Irish Association for Counselling and Therapy (IACT) was established in response to the perceived need by practitioners to have a National Association to set, maintain, and regulate standards for the profession of counselling and therapy, and in so doing, to protect the public. The IACT is an organisation, which promotes therapeutic counselling and represents counselling interests throughout Ireland. Established over 19 years, their membership at present exceeds 2,043. To be eligible for IACT accreditation an applicant must have completed a one-year full-time or two/three year's part-time counselling course and after training must have completed individual client work and have been in ongoing supervision in Ireland, all which must meet criteria set by the IACT.

\section{Psychological Society of Ireland - Counselling Division of Psychology}

The Psychological Society of Ireland (PSI) was founded in 1970 with a view to promoting and maintaining high standards of practice in psychology. The society has over 900 members and produces a register of its members each year. In 1998, the Society revised its criteria for the accreditation of postgraduate professional training in counselling psychology facilitated by the newly formed Division of Counselling Psychology. For a person to become a Registered Psychologist of PSI the following criteria must be fulfilled: have four years full time relevant experience in work in psychology, two referees, hold an honours degree.

In addition to the three general accrediting organisations detailed above there are a number of key specialist associations that are widely recognised, for example, the Irish Association for Addiction and Alcohol Counsellors.

\section{Summary}

The last decade has seen a growing interest in attention to women's health, including women's mental health. Gender differences in the prevalence of certain psychiatric disorders have long been recognised, especially the depressive and anxiety disorders. During the consultative process for the Plan for Women's Health 1997-1999, women asked for access to counselling services, preferably in a non-medical environment. The reduction in mental health problems through early identification and treatment using proactive approaches, e.g., increased access to counselling has been demanded by women. The Department of Health and Children has overall responsibility for the development of health policy and for the planning of health services. The voluntary sector also plays a vital role in the delivery of health and personal social services. In addition, a number of specialist agencies have been established to address particular needs or to provide particular services. The training requirements within each of these sectors vary enormously and are unregulated. Within Ireland there are three main professional organisations working in the counselling / therapy arena which have been active in regulating their profession to safeguard public interest and to promote continued self-examination and improvements of standards. However, none of these organisations have been officially appointed by government under legislation to monitor and accredit counselling qualifications.

When seeking to establish the validity of a health care procedure, both efficacy and effectiveness research is vital. Psychotherapy and counselling techniques should be subject to the same rigours, which would be expected of any drug or technique purporting to ameliorate physical pain or unhappiness. Although the data for therapeutic interventions consistently demonstrate its effectiveness, it is the direction in sign (i.e., positive effects) rather than the magnitude of the effect that is supported by the research reviews. In comparison to the psychotherapy literature, the studies of the efficacy and effectiveness of counselling are relatively few in number and are somewhat contradictory. Some studies have failed to show any benefit of counselling compared with 'routine GP care'; others have shown reductions in drug prescribing, surgery attendance and improvements in symptomatology. It could be argued that it is not necessary to prove that, on average counselling is superior to routine GP care, which usually means drug treatment. Rather it has to be shown that counselling does not produce a poorer outcome and efforts need to be made to identify clients who are likely to make most gains. From a clinical and moral standpoint, it seems more appropriate to help people with life problems through counselling than by prescribing medication, which increases the risk of having to treat the person at a later date for side effects or for problems of addiction, while the original cause of distress remains unchanged.

Research findings have shown that when seeking help for mental health issues, that is most cases the general public first turn to their GP then a Psychiatrist. In research studies there are marked differences between the pattern of help-seeking behaviour for rural and urban respondents. For the most part, the public does not consider recommending other professionals such as Psychologist, counsellors or Social Workers. Research has found that barriers to seeking professional help include the social stigma surrounding mental health services, distrust of the services, an inability to recognise the need for help and spontaneous remission. 
Chapter Three: Women's Views of Counselling 


\section{Women's Views of Counselling}

This chapter describes the collection of and presents the perspectives from women in the community regarding counselling. It includes the questionnaire survey of women and the series of interviews with women.

\section{Questionnaire Survey of Women}

\section{Method}

\section{SAMPLE}

The sample for the questionnaire of women was based on a random sample of women taken from the regions represented by the commissioning bodies (the NWHB, the SHB and the ERHA). These represent the most rural areas of the country (NWHB and parts of the SHB) as well as the most concentrated urban areas (ERHA and Cork City). They were also selected to match the other samples selected for inclusion in the surveys' of health providers and health professionals, which were also taken from within these regions.

Taking the population of the three health authorities as the sampling frame, 40 rural District Electoral Divisions (DEDs) and 40 urban DEDs were randomly selected using the table of random numbers. The only prerequisite was that all DEDs selected had to have at least 50 adult inhabitants. The purpose was to include a greater proportion of rural women in the sample than would have occurred by chance. The definitions for urban and rural are taken from the 1996 census (Central Statistics Office, 1997a), which labels DEDs as urban if the town land in which they are situated has a population of equal to or greater than 1, 500 persons. It is labelled as rural the total population of the town land will be less than 1,500. A distinction is therefore made between urban and rural respondents. This was considered an important dimension to the research question because of the general lack of data on rural women in Ireland and specific concerns that emerged during the consultation phase of the plan for women's health in relation to access to services for rural women.

Following the selection of the target DEDs, the subsidiary of An Post, Precision Marketing Information, Ltd., (PMI) was commissioned to assist with the sampling procedure. Respondents were subsequently selected through simple random sampling from with these DEDs, and comprised 1,000 urban and 1,000 rural women. This procedure was carried out by PMI who employed the Irish electoral register and subsequently supplied names and addresses to the research centre.

\section{MEASUREMENT}

The questionnaire that was employed during the survey of women, as the main data collection tool, was designed to meet a number of specific and separate needs. First, it had to be laid out and employ language that would not exclude potential respondents. Second, it had to be appropriate for completion by individual research participants in their own homes. Third, it had to demonstrate usefulness from the perspective of the research hypotheses, including appropriate levels of reliability, validity and generalisabilty, where such data existed. One of the guiding principles adopted during the selection process was that, where possible, we should avoid the construction of completely new questions and instead employ instruments or individual items that had been previously shown to be appropriate and useful with Irish women in the past.

The major source of question structure was the adult questionnaire instrument from the National Health and Lifestyle Survey - SLÁN (Friel et al.,1999). It should be noted that in turn these questions stemmed from a number of other sources including a number of the most influential epidemiological and health monitoring surveys, including MONICA, EPIC, the Trent Lifestyle Questionnaire, and the US Health Monitoring Surveys (Roberts et al., 1995; WHO Monica Project, 1997; Riboli \& Kaaks, 1997; NCHS, 1979; CDC, 1993). The SLÁN survey instrument was successfully piloted in Ireland in 1997 (Harrington, 1997; Kelly, 1997) and subsequently employed during the survey itself to collect data from more than 6, 500 Irish adults within the context of study design similar the current study. The other primary source of questions for this study was the instrument employed by Byrne et al. (1991) in their study of North-West Connemara, which was the origin of the questions on transport and rural isolation. Their purpose was to help explore hypotheses regarding the access rural women reported to services and associated transport issues.

The CES-D (Radloff, 1977) and the GHQ-12 (Goldberg, 1978) were also considered appropriate for inclusion for a number of reasons. First, they were designed to tap into elements of psychological well-being that have emerged in Ireland and elsewhere as 
being the most frequent mental health problems that women present with to Health Professionals (anxiety and depression). Second, they are widely employed tools that have illustrated their usefulness in such a research setting. Specifically, they have both been demonstrated to be appropriate in self-completion, paper and pencil surveys of this type. Third, both measures had been included in the mental health module of the National Health and Lifestyle Survey (SLÁN) in 1998. This gave them two further advantages over competitors; they had been shown to be appropriately employed with Irish women in a self-completion survey, and the possibility of nationally comparative data emerged. Friel et al. (forthcoming) report on the reliability and validity of both of these instruments and provide comparative data with which women in the current study could be compared. The GHQ-12 was also employed in a survey of health (including mental health) among the Irish prison population (Hannon et al., 1999), where it illustrated the substantial gender difference in psychological distress.

There were three sections in the questionnaire (see appendix 1). The first section sought to obtain socio-demographic information. This included a section on geographical location and access to services, medical card status and household composition. The second section focused on the participants' perceptions of their own general health, quality of life, whether they have a GP and their sources of health information. The CES-D and GHQ-12 were also in this section. The final section sought to elicit participants' knowledge, attitudes and beliefs about counselling and/or psychotherapy. Participants were asked if they knew someone who had received counselling, what they think counselling is and whether it differs from psychotherapy. Also included were a series of questions related to counselling/psychotherapy, including whether they had ever sought counselling/ psychotherapy, their opinions of the help they received, and if they would suggest counselling to others. Next there were a number of questions designed to investigate perceptions of barriers and enablers to counselling/psychotherapy, preferred location and providers of services and perceptions of the availability of counselling/psychotherapy from participants' local health boards. Finally, a list of potential problems that the participant may have personally experienced was presented in tabular form, and the participant was asked to tick (out of twelve, not mutually exclusive, options) whom, if anyone she had turned to for help.

\section{PROCEDURE}

Questionnaires were sent to all 2,000 women accompanied by a cover letter outlining the background to the study and inviting the women to participate. Anonymity and confidentiality of all data volunteered was assured. A contact name and telephone number for enquiries was provided along with a FREEPOST envelope to facilitate return.

Those who returned the questionnaire and supplied their name and address were removed from the list and two weeks later, a reminder postcard (Appendix 2) was sent to the remainder of the sample, asking them to complete the questionnaire and return it, if they had not already done so. Three weeks later the same questionnaire was sent out once more to the women remaining on the list. Once again, a cover letter was included, requesting the women to participate in the study and the same assurances were offered in relation to the data. The data received were coded by hand and entered into the Statistical Package for the Social Science (SPSS) to enable further analysis.

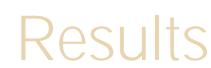

In total 1,127 questionnaires were returned, of which 255 were not completed. The non-completed questionnaires were broken down as follows:

- Marked return to sender - unknown at this address $(n=153)$

- Marked unable to fill out $(n=13)$

- Marked too old - respondent or carer thought they were too old to participate $(n=8)$

- Marked that the addressee was deceased $(n=23)$

- Blank returns - no reason given $(n=29)$

- Refusals $(n=29)$

Subtracting those who were deceased and those who were reported not to live at the given address, the valid sample size was reduced to 1818 , giving a response rate of $48 \%$. In total $443(56 \%)$ were those randomly selected from rural DEDs and 352 (44\%) from urban DEDs. In this context, it should be noted that previous attempts to collect data using the electoral register as the sampling frame have estimated that the register itself is approximately $20 \%$ incorrect (Friel et al., 1999). Thus it could be estimated that the effective response rate is closer to $68 \%$. Given that women were sampled separately from urban and rural DEDs, these two groups should not be collapsed except where there are no significant differences between them in relation to their responses to individual 
questions. Thus the sample of rural women can be considered as representative of rural women in these three board areas and the same would hold for the sample of urban women. In this context, however, it is worth considering that outside of the main metropolitan area of Dublin (or possibly Cork City), very few differences would be expected in responses based on previous health related studies (e.g. Friel et al., 1999b).

\section{A. SOCIO-DEMOGRAPHIC CHARACTERISTICS}

All responses were divided into those from urban and those from rural locations. The respondents from these two settings were compared on all the socio-demographic background variables. There were no statistically significant differences between the groups in relation to the following:

\section{Table 2: Means and standard deviations for key socio-demographic variables}

Attribute

Age (yrs)

School leaving age (yrs)

Number of children

Number of children living at home

Number of people in household

\section{Mean}

46.24

17.01

3.12

1.79

4.10

\section{Standard Deviation}

16.23

5.49

1.81

1.34

3.67

In addition there were no differences between the urban and rural respondents in relation to:

- highest level of education received (17\% primary level only, $24 \%$ finished secondary level, $24 \%$ finished third level),

- marital status (being married (67\%), co-habiting (2\%), separated (4\%), divorced (1\%) or never married (18\%) having any children (76\%),

- social class ( $39 \%$ social class I \& II, $32 \%$ social class III \& IV, $12 \%$ social class V \& VI, it was not possible to classify the remaining respondents $(17 \%)$.

- Membership of a women's community or voluntary group (29\%)

Women from urban and rural DEDs did, however, differ on type of housing $(p<0.001) 2,32 \%$ of urban dwellers lived in detached houses while $69 \%$ of those from rural areas lived in detached houses. Women from rural areas were more likely $(p<0.05)$ to report working full-time in the home $(30 \%)$ than were those from urban areas $(26 \%)$ and were also less likely $(p<0.05)$ to report having full-time jobs (25\%) when compared to women from urban areas $(31 \%)$. Women from rural DEDs were more likely $(p<0.001)$, to report having a medical card (31\%) than women fromurban DEDs (23\%).

The respondents can be compared to the adult population of women in the Irish state on a number of these variables. The last Irish census was held in 1996, during which $64.4 \%$ of women reported that they had ceased their full-time education before the age of 18 (Central Statistics Office, 1998), and the modal response for women was that they had completed upper secondary school (or leaving certificate). Among adult women who had ceased full-time education, $27.5 \%$ reported completing primary school only, while $19.9 \%$ reported completing third level education. This sample may therefore under-represent those with a primary school only education, which would not be atypical for a self-completion survey of this type.

Of the women aged 20 years and over in the 1996 census, $29.1 \%$ were single, $54.8 \%$ were married, $3.8 \%$ were separated, $0.4 \%$ were divorced (Central Statistics Office, 1997a). This compares well with the current sample, who are somewhat more likely to be married and correspondingly less likely to be single. The average household size in the country is 3.14 persons (Central Statistics

$P<0.001$ means that the likelihood of this difference being due to chance is less that one in a thousand,

$P<0.01$ means that the likelihood is less than one in a hundred and

$p<0.05$ means that the likelihood is less than 5 in a hundred. Any of these mean that differences are statistically significant. 
Office, 1997b), whereas the respondents to this survey report an average of 4.1 persons, however there is wide variation in the household size reported in this sample as evidenced by the high standard deviation. While the average respondent with children in the current sample reports 1.79 children living at home, the modal family size for a married couple in the state was 4 (two adults and two children) in 1996 (Central Statistics Office, 1997b).

The 1996 census (Central Statistics Office, 1998) classified 36\% of persons resident in the state as social class I or II (professional, managerial or technical), $35 \%$ as social class III or IV (non-manual and skilled manual) and $28 \%$ as social class V and VI (semiskilled and unskilled). The current sample has been classified into social class groups in roughly the same proportions for groups IIV. Those classifiable into groups V and VI appear to be under represented, but this sample contains a relatively high proportion of respondents who could not be classified given the information supplied $(17 \%)$, and it is unknown from which social group these stem.

\section{SUMMARY}

- The average woman in the sample is forty-six years of age and left school at 17 , she is married with 3 children, 2 of whom are still living at home. She is, or is married to, a white-collar worker.

- Women from rural areas are more likely to live in detached homes, work full-time in the home and to have a medical card.

- The current sample may be more representative for married women with at least some post-primary school education from social classes 1-IV.

\section{B. TRANSPORT AND TRAVEL}

In order to investigate hypotheses in relation to the isolation and access of rural women, the data on methods of transport and distances from services were compared across the two groups. As hypothesised, women from rural DEDs reported being significantly further away from all services and having significantly less access to all forms of transport, with the notable exception of a private car, a minibus and a lift from a neighbour. Thus fewer women $(p<0.001)$ from rural areas $(20 \%)$ reported that they used the public transport system when compared to those from urban areas $(53 \%)$ and they also reported that they were less satisfied $(p<0.05)$ with the service provided to them ( $34 \%$ satisfied) than were women from urban areas ( $49 \%$ satisfied). The percentages of women reporting using the various modes of transport and the distances to key services can be found in Appendix 3 ).

\section{SUMMARY}

- Women from rural areas live further away from all services.

- They also have less access to and are less satisfied with public transport.

There are important differences between urban and rural women that validate the decision to sample them separately. These findings confirm the specific issues that need to be addressed for service provision to rural populations, and thus the data from urban and rural respondents are presented separately below. In addition, given that a key factor in health service provision in Ireland is eligibility for GMS, all data from women have been analysed for differences between GMS and non-GMS holders. In addition, those who have experienced counselling or psychotherapy are more likely to have an informed perspective on the issues of interest and so any statistically significant differences between these groups have also been presented. Finally, those who can be classified as psychologically distressed or depressed (caseness) on the basis of GHQ-12 or CES-D scores, are probable candidates for services in this area, therefore their responses are compared to those of the respondents who did not score as highly. 


\section{SELF - REPORTED HEALTH AND WELL-BEING}

Women were asked to report on their health and well-being in a number of ways. First, they were asked how healthy they thought they were on a five point scale from excellent to poor. Twenty four per cent of urban women reported that their health was excellent while $35 \%$ reported that it was very good (sums to $59 \%$ ). This compares to $18 \%$ of rural women reporting excellent health and $35 \%$ who reported that their health was very good (sums to 53\%). These differences were statistically significant at $p<0.05$. Respondents were also asked to rate their quality of life on a five point scale, $45 \%$ of women from urban DEDs reported that their quality of life was very good and a further $44 \%$ reported that it was good (sums to $89 \%$ ) while $32 \%$ of rural women reported that their quality of life was very good and $50 \%$ that it was good (sums to $82 \%$ ). These differences were also statistically significant at $p<0.001$. Next, the women were asked to report how satisfied they were with their health, once again on a five point scale from very to not at all satisfied, in this case there were no significant differences across the two groups. Seventy nine per cent of women from urban areas reported that they were satisfied ( $29 \%$ very satisfied, $50 \%$ satisfied), while $77 \%$ of women from rural areas reported that they were satisfied ( $26 \%$ very satisfied, $51 \%$ satisfied).

In addition, respondents were asked to complete both the GHQ-12 and the CES-D. Table 3 presents the means and standard deviations for these scales in the two groups.

Table 3: Means and standard deviations on the GHQ-12 and the CES-D

$\begin{array}{ccc}\text { Scale } & \text { Urban } & \text { Rural } \\ \text { GHQ-12 } & 11.70(5.43) & 11.67(5.47) \\ \text { CES-D } & 11.67(9.66) & 11.53(8.47)\end{array}$

It is possible to re-code scores on both of these scales in order to examine those who score highly and compare them against those who do not. High scores on the CES-D reflect high levels of depression. It should be noted that $24 \%$ of the women from urban areas and $23 \%$ of rural women attained CES-D scores above the cut-off of 16 , which is an arbitrary figure recommended by (Radloff, 1977), and also employed by Friel et al., (2001), for Irish women in the national health and lifestyle survey. High scores on the GH Q12 reflect high levels of psychological distress3. The cut-off point for the GHQ-12 depends on the sample in question, and it is recommended that the range of the scores be divided at $2 / 3$ with the top third to be classified as cases, and for optimal discrimination to veer towards a split towards the middle of the range. In this case and because of the high degree of tied scores, $40 \%$ of women from urban DEDs and $39 \%$ of women from rural DEDs can be classified as GHQ cases. There were no statistically significant differences between urban and rural women on these scales. In this context, it should also be noted that virtually all women who responded ( $98 \%$ of urban women and $99 \%$ of rural women) reported that they had a family doctor.

\section{SUMMARY}

- Most women report that they were healthy, have a good quality of life and are satisfied with their health. Urban women are more likely to be positive about these factors than rural women.

- A substantial minority of women can be classified as depressed or as experiencing psychological distress.

The following parts of this results section present the collected data separately for women from urban and rural DEDs. All statistically significant differences between these groups are noted. In addition, the responses were analysed for differences between women in the total sample who had medical cards (27\%) and those who did not (73\%), those who had experienced counselling (20\%) and those who had not ( $80 \%)$, and finally, those who were depressed (based on their CES-D score) $(26 \%)$ and psychologically distressed (based on their GHQ-12 score) (39\%), and those who were not ( $74 \%$ and $61 \%$ respectively). Where significant differences emerge between these groups, they are reported below.

The GHQ-12 Manual describes high scores as indicating that the respondent is experiencing distressing symptoms similar to those reported by cases on non-psychotic disorders seen by the specialist mental health services. 


\section{SOURCES OF INFORMATION ABOUT HEALTH}

All respondents were asked where they received their information about health. Figure 1 presents the percentages reporting each source of information. Note that respondents were free to acknowledge as many sources as they wished, as the sources are not mutually exclusive.

\section{Figure 1: Percentages of women reporting their sources of health information by location}

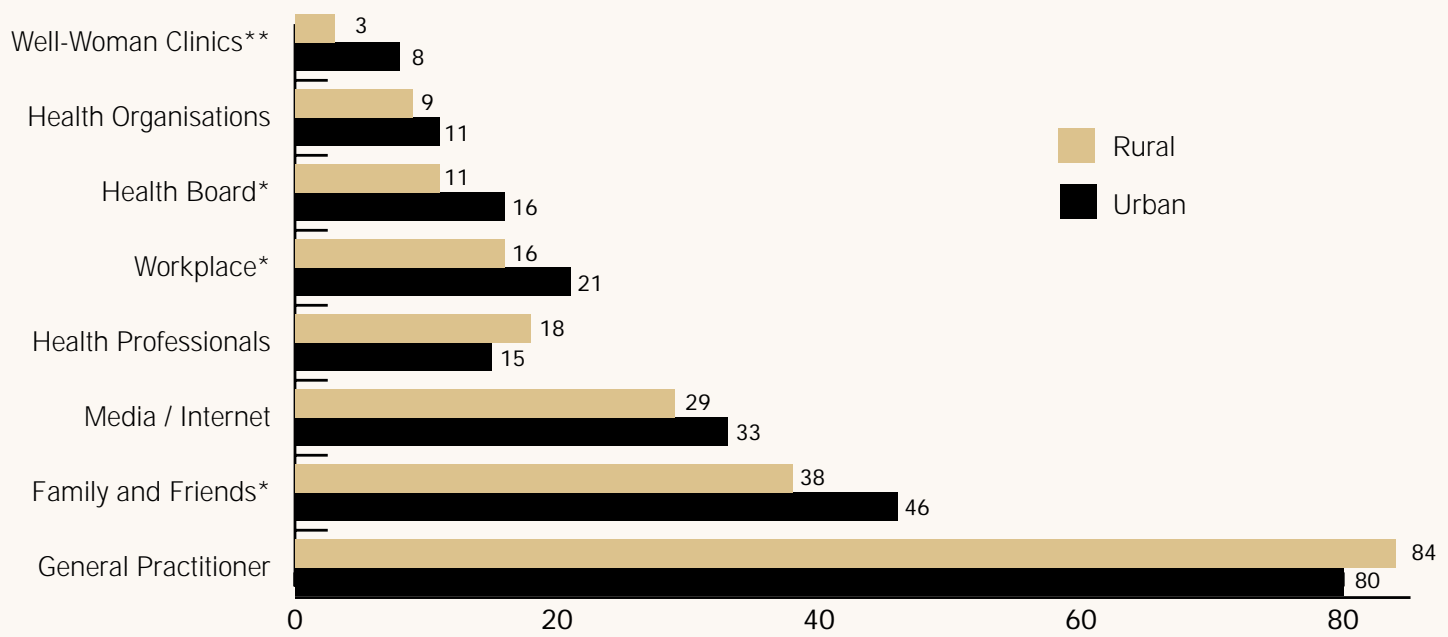

$* p<0.05 ; * * p<0.01 ; * * * p<0.001$. Note that most respondents said that they received their health related information from their GPs and a sizeable proportion cited family, friends and the media as sources. Urban women were more likely to mention Well Woman clinics, health boards, workplaces and family and friends than were rural women.

\section{Differences by medical card status}

Women with medical cards were more likely $(p<0.001)$ to report receiving information from their GPs $(91 \%)$, than those without medical cards $(80 \%)$, they were also more likely $(p<0.05)$ to report receiving health information from their health boards $(17 \%)$ than those who were without medical cards $(12 \%)$. Those without medical cards were more likely $(p<0.001)$ to report receiving health information from their workplaces (23\%) when compared to those with medical cards (4\%). In addition, those with medical cards were more likely $(p<0.001)$ to report receiving information from their family and friends $(47 \%)$ than those without medical cards $(28 \%)$ and also more likely $(p<0.001)$ to report receiving information from the media or the internet $(38 \%)$ than those without medical cards (13\%).

\section{Differences by experience of counselling}

Women who had reported receiving counselling were more likely $(p<0.01)$ to receive their health information from family and friends $(52 \%)$ than those who had never received counselling $(40 \%)$, but no other statistically significant differences were observed.

\section{Differences by caseness on the CES-D,}

Women who were depressed were less likely $(p<0.05)$ to report that they received health information from family and friends $(35 \%)$ than were those who were not $(44 \%)$. They were also less likely $(p<0.01)$ to report that they received health information from the media or the Internet (22\%) than non-depressed women (34\%).

\section{Differences by caseness on the GHQ-12}

There were no statistically significant differences on sources of health information between women who were psychologically distressed and those who were not. 


\section{SUMMARY}

- The most frequently cited sources of information regarding health are GPs, followed by family and friends and the media. Women from urban areas are more likely to cite family and friends and less likely to cite the workplace or well-woman clinics as sources of information.

- Women with medical cards are more likely to cite GPs, health boards, family and friends and the media and less likely to report sourcing health information in the workplace.

\section{E. HELP SEEKING BEHAVIOUR}

Women were asked if they had sought help for a number of problems from a variety of sources. These comprised: Family and Friends, GPs, Priest, Teacher, Social Worker, Gardaí, Solicitor, Self-Help Group, Counsellor/Psychotherapist, Psychiatrist/Psychologist, Other or No-one. All those, which were reported by more than $3 \%$ of the respondents, are included in the table below (the only exception to this are the $6 \%$ of urban and $4 \%$ of rural women who reported seeking help from a priest in relation to bereavement). Where statistically significant differences emerged between those from urban and rural DEDs, they are indicated in table 15 by percentages in bold and an associated asterisk (*).

Table 4: Percentages of women reporting having sought help for specific problems from a variety of sources by location

\begin{tabular}{|c|c|c|c|c|c|c|c|c|c|c|}
\hline \multirow{2}{*}{$\begin{array}{l}\text { Problem } \\
\text { Urban/rural }\end{array}$} & \multicolumn{2}{|c|}{ No-one (\%) } & \multicolumn{2}{|c|}{$\begin{array}{c}\text { Family / } \\
\text { Friends (\%) }\end{array}$} & \multicolumn{2}{|c|}{$\mathrm{GP}(\%)$} & \multicolumn{2}{|c|}{$\begin{array}{l}\text { Counsellor / } \\
\text { Therapist (\%) }\end{array}$} & \multicolumn{2}{|c|}{$\begin{array}{l}\text { Psychiatrist / } \\
\text { sychologist ( }\end{array}$} \\
\hline & u & r & $\mathrm{u}$ & r & u & $r$ & $\mathrm{u}$ & r & $\mathrm{u}$ & r \\
\hline Depression & 13 & 16 & 18 & 14 & 18 & 16 & 8* & 4* & 7 & 4 \\
\hline Anxiety & 13 & 17 & 18 & 17 & 13 & 12 & 4 & 4 & 3* & $1 *$ \\
\hline Relationships & $10 *$ & $14^{*}$ & $17 *$ & $12 *$ & 4 & 4 & $8^{*}$ & 4* & 1 & 1 \\
\hline Alcohol Abuse & 12 & 12 & 2 & 2 & 1 & 1 & 1 & 1 & 1 & $\varangle .5$ \\
\hline Drug Abuse & 9 & 11 & 1 & 1 & 1 & 0 & 1 & 1 & 1 & 0 \\
\hline Domestic Violence 10 & 12 & 2 & 2 & 1 & 2 & 1 & 1 & 1 & 1 & \\
\hline Sexual Abuse & 10 & 13 & 1 & 2 & $\ll 0.5$ & 2 & 1 & 1 & $\varangle 0.5$ & 1 \\
\hline Reproductive Health 8 & 10 & 5 & 4 & 15 & 16 & $\varangle .5$ & $\varangle 0.5$ & 0 & $\varangle .5$ & \\
\hline Financial Problems & 10 & 13 & 11 & 12 & 0 & 0.5 & 0 & 1 & 0 & 0 \\
\hline Physical IIIness & 8 & 10 & 5 & 6 & 20 & 18 & 1 & 1 & 1 & 0.5 \\
\hline Bereavement & 15 & 18 & 27 & 28 & 7 & 6 & 4 & 3 & 2 & 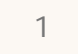 \\
\hline Abortion & 9 & 12 & 1 & 1 & 1 & 1 & $\varangle 0.5$ & $\triangleleft 0.5$ & 1 & 0 \\
\hline
\end{tabular}

$* p<0.05$. The most common problems for which women reported seeking help were depression, anxiety and relationships. The most common sources of help reported were family and friends and GPs. 
Differences based on medical card status

Table 5: Percentages of women who have sought help by medical card status

$\begin{array}{lccc}\text { Problem } & \text { Source of Help } & \text { Medical Card (\%) } & \text { No Medical Card (\%) } \\ \text { Bereavement } & \text { Family \& Friends* } & 25 & 29 \\ \text { Reproductive Health } & \text { GP* } & 12 & 17 \\ \text { Relationships } & \text { Family \& Friends* } & 10 & 16 \\ \text { Relationships } & \text { GP* } & 8 & 4 \\ \text { Anxiety } & \text { Family and Friends* } & 12 & 20\end{array}$

${ }^{*} \mathrm{p}<0.05$. Medical card holders were more likely than non-medical card holders to report that they had sought help from their GP for relationship problems. However they were less likely than non-medical card holders to report that they had sought help from family and friends for anxiety, bereavement or relationship problems or that they had sought help from their GP for problems related to reproductive health.

Differences based on having experienced counselling

The differences based on having experienced counselling were substantial. Receiving help from all sources (with the exception of no-one and family and friends), for most problems, resulted in significantly different reporting of help received. These data are presented in table 6 below.

Table 6: Percentages of women who report help-seeking for various problems from the following sources by counselling status

\begin{tabular}{|c|c|c|c|c|c|c|c|c|c|c|}
\hline Problem & No-O & e $(\%)$ & $\begin{array}{l}\text { Far } \\
\text { Frien }\end{array}$ & $\begin{array}{l}y / \\
(\%)\end{array}$ & GP & $(\%)$ & $\begin{array}{l}\text { Couns } \\
\text { Therap }\end{array}$ & $\begin{array}{l}\text { ellor / } \\
\text { st (\%) }\end{array}$ & $\begin{array}{l}\text { Psych } \\
\text { Sychol }\end{array}$ & $\begin{array}{l}\text { atrist / } \\
\text { gist (\%) }\end{array}$ \\
\hline Counselling / & $\% \mathrm{C}$ & $\% N C$ & $\% \mathrm{C}$ & $\% N C$ & $\% \mathrm{C}$ & $\% N C$ & $\% \mathrm{C}$ & $\% N C$ & $\% \mathrm{C}$ & $\% N C$ \\
\hline No Counselling & & & & & & & & & & \\
\hline Depression & $7 * * *$ & 16 & $34 * 1 * k$ & 12 & $41^{* 1 * k}$ & 11 & $25^{\text {*akk }}$ & 1 & $24 * 1 * k$ & 1 \\
\hline Anxiety & $10 * 1 *$ & 17 & $28^{* 1 * k}$ & 16 & $30 * * *$ & 8 & $20 * * *$ & $\lessdot 0.5$ & $11^{* 1 * k}$ & $\varangle .5$ \\
\hline Relationships & $7 * * *$ & 14 & $23^{* 1 * k}$ & 12 & $15^{* * *}$ & 2 & $30 * * k *$ & $\varangle 0.5$ & $4^{* *}$ & 0 \\
\hline Alcohol Abuse & $10 *$ & 13 & 1 & 2 & 2 & 1 & 3* & 1 & 1 & $\varangle 0.5$ \\
\hline Drug Abuse & $7^{* *}$ & 11 & 2 & 0.5 & 1 & 0.5 & $3^{*}$ & $\varangle 0.5$ & $1 *$ & 0 \\
\hline Domestic Violence & $8^{* * *}$ & 12 & 4 & 2 & $4^{*}$ & 1 & $6^{* * * k}$ & 0 & $3^{* *}$ & 0 \\
\hline Sexual Abuse & $8^{* * *}$ & 12 & $6^{* * * *}$ & 0.5 & $4^{* *}$ & $\varangle 0.5$ & $7^{* * * *}$ & 0 & $2^{* *}$ & 0 \\
\hline Reproductive Health & $4^{* *}$ & 11 & 6 & 4 & $20 *$ & 15 & 1 & $\lessdot 0.5$ & $1 *$ & 0 \\
\hline Financial Problems & $8^{* *}$ & 13 & $17^{* *}$ & 11 & 1 & 0 & $2 *$ & 0 & 0 & 0 \\
\hline Physical IIIness & $3^{* * *}$ & 11 & 8* & 5 & $30^{* * * *}$ & 17 & $4^{* *}$ & $\varangle 0.5$ & $2^{*}$ & 0 \\
\hline Bereavement & $8^{* * *}$ & 19 & 27 & 28 & 8 & 6 & $16^{* * *}$ & $\varangle 0.5$ & $4^{* * * *}$ & 0 \\
\hline Abortion & 8* & 12 & 2 & 1 & 1 & 1 & 1 & $\varangle .5$ & $1 *$ & 0 \\
\hline
\end{tabular}

${ }^{*} p<0.05 ; * * p<0.01 ; * * * p<0.001$. Those who had experienced counselling were more likely to have sought help from almost all sources for most problems. They were less likely to report seeking help from no-one for all problems. 


\section{Differences based on caseness on the CES-D}

Those who were depressed were more likely $(p<0.05)$ to report that they had attended a Psychiatrist or a Psychologist for anxiety $(7 \%)$, than were those who were not $(2 \%)$.

\section{Differences based on caseness on the GHQ-12}

Three differences emerged between those who were psychologically distressed and those who were not, as follows;

Table 7: Percentages of women who have sought help by GHQ Caseness

$\begin{array}{lccc}\text { Problem } & \text { Source of Help } & \text { GHQ-12 Case (\%) } & \text { GHQ Non Case (\%) } \\ \text { Anxiety } & \text { Psychiatrist / Psychologist* } & 4 & 1 \\ \text { Depression } & \text { Psychiatrist / Psychologist** } & 8 & 3 \\ \text { Depression } & \text { GP** } & 21 & 13\end{array}$

${ }^{*} p<0.05 ; * * p<0.01$. Those who were classified as psychologically distressed were more likely to report having sought help from a Psychiatrist or Psychologist for anxiety or depression and more likely to report having sought help from a GP for depression than those who were not psychologically distressed.

\section{SUMMARY}

- Very few women report seeking help from social workers, priests, teachers, Gardaí, solicitors or self-help groups.

- Women report that they are most likely not to seek-help, irrespective of the problem. However the most frequently cited sources of help for most problems are family or friends and GPs.

- Women report seeking help most frequently for depression, anxiety, relationships problems, bereavement and physical illness or disability.

- Those with medical cards are less likely to have sought help from their GPs or families and friends for various problems.

- Women with high levels of depression or psychological distress are more likely to report having attended a Psychiatrist or a Psychologist for anxiety or depression.

\section{F. KNOWIEDGE AND EXPERIENCE OF COUNSELLING}

All women were asked a series of questions about counselling. Seventy per cent of urban women and $58 \%$ of rural women reported that they knew someone who had received counselling psychotherapy $(p<0.001)$. While $49 \%$ of urban women and $42 \%$ of rural women reported that there was a difference between counselling and psychotherapy, $42 \%$ of those from urban areas and $50 \%$ of those from rural areas responded that they did not know if there was any difference ( $p=n s)$. Twenty six per cent of urban women reported that they had received some form of counselling or psychotherapy themselves, of whom $79 \%$ reported that it helped them and $2 \%$ that it hindered them in some way. Among the rural women, $16 \%$ reported that they had received some form of counselling or psychotherapy and of them $76 \%$ reported that it helped and $4 \%$ that it had hindered them. While urban women were significantly more likely to report having received counselling $(p<0.001)$, there was no difference across locations in how useful they reported the counselling had been $(p=n s)$. In addition, $28 \%$ of women from urban areas and $15 \%$ of those from rural areas $(p<0.001)$ reported that they were, or had been, members of a self-help group (including Weight Watchers).

Of those that said they had sought counselling, a number never actually accessed it $(n=5)$, while some only attended once $(n=12)$ or twice $(n=14)$ and a small minority reported that they were still attending $(n=9)$. The most common problem that they reported presenting with was marital or family difficulties $(n=49)$, followed by depression $(n=37)$, self-esteem or personal issues $(n=26)$ and anxiety/panic attacks $(n=17)$. Very few reported that they knew what kind of a counsellor or therapist they had seen. However, where this was reported, the most frequently category was marriage guidance counsellor $(n=24)$, followed by what were described as a Psychologist $(n=8)$ and a general counsellor $(n=8)$. These women were also asked how they knew where to go for counselling or psychotherapy and most frequently they said through their GP $(n=49)$ or through family or friends $(n=40)$. These were followed by reading / own knowledge $(n=11)$ and health board $(n=10)$. 
Seventy one per cent of urban women reported that they thought that counselling or psychotherapy could be helpful and $65 \%$ said that they would suggest it to a friend or family member, while $64 \%$ of those from rural areas reported that counselling could be helpful and $60 \%$ would suggest it. The difference in perceived helpfulness was statistically significant $(p<0.05)$ but the difference in reported likelihood of recommending counselling was not ( $p=n s)$. In addition, $86 \%$ of those from urban areas and $87 \%$ of those from rural areas reported that they would go to counselling or psychotherapy ( $p=n s)$.

\section{Differences by medical card status}

\section{Table 8: Percentages of women reporting their perceptions of counselling by medical card status.}

\section{Medical Card (\%) No Medical Card (\%)}

$\begin{array}{lcc}\text { Think counselling is useful** } & 59 & 70 \\ \text { Would suggest counselling* } & 56 & 64 \\ \text { Know someone who has received counselling*** } & 45 & 70 \\ \text { Would consider counselling for themselves* } & 82 & 89 \\ \text { Member of a self-help group*4 } & 8 & 18\end{array}$

$* p<0.05 ; * * p<0.01 ; * * * p<0.001$. Those with medical cards were less likely to report that they thought counselling was useful, would suggest it to others, knew someone who had received counselling or were members of a self-help group.

\section{Differences by experience of counselling}

\section{Table 9: Percentages of women reporting their perceptions of counselling by experience with counselling or psychotherapy}

\section{Have had \\ counselling (\%)}

Know someone who has had counselling*k*

Think counselling is useful***

Would suggest counselling**k

Member of a self-help group***

Counselling differs from psychotherapy*

Would go to counselling*

\section{2}

78

77

35

54

92
No counselling

experience (\%)

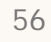

64

58

18

43

86

$* p<0.05 ; * * p<0.01 ; * * * p<0.001$. Those who reported having had counselling were more likely to report knowing someone else who has had counselling, thinking that counselling is useful and to report that counselling differs from psychotherapy as compared to those who have no personal experience of counselling. They were also more likely to say that they would attend counselling if they felt it was appropriate in the future, to suggest counselling to others and to be a member of a self-help group.

\section{Differences by caseness on the CES-D}

The only statistically significant difference $(p<0.05)$ related to depression was that those who were not depressed were less likely to report that counselling was available from their health board (17\%) when compared to those who were depressed $(23 \%)$.

\section{Differences by caseness on the GHQ-12}

Twenty two per cent of those who were psychologically distressed and 13\% of those who were not, reported that they had received counselling or psychotherapy themselves. This was the only statistically significant $(p<0.05)$ difference between the two groups. 


\section{SUMMARY}

- Most women know somebody who had received counselling or psychotherapy.

- Twenty six per cent of urban women and $16 \%$ of rural women report that they have received counselling, over three quarters of whom say that it helped them.

- Most of those who had attended counselling had gained access through their GPs or their family and friends and had attended for marriage or family problems or for depression.

- Most women reported that they think that counselling or psychotherapy could be helpful, would recommend it to a friend and would attend themselves.

- Women with medical cards are less positive about counselling, but are more likely to say that they would consider going themselves.

- Women who have experienced counselling are also more positive about counselling.

- Women who report higher levels of psychological distress are more likely to have experienced counselling.

\section{G. FACTORS WHICH INFLUENCE HELP_SEEKING}

Respondents were presented with a series of factors and asked to indicate which they thought would dissuade women from seeking counselling or psychotherapy. Once again the responses are not mutually exclusive, and thus the percentages do not sum to 100.

\section{Figure 2: $\quad$ Percentages of women indicating the following barriers to the receipt of counselling or psychotherapy by location}

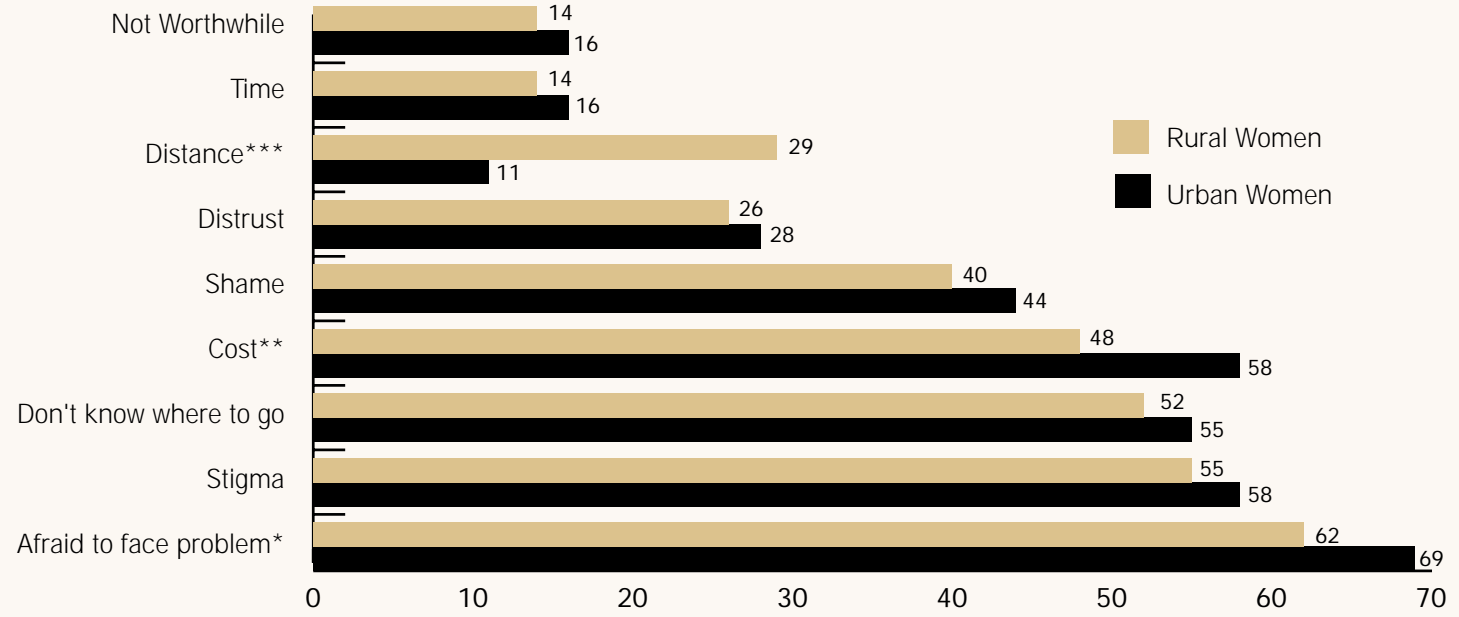

${ }^{*} p<0.05 ;{ }^{* *} p<0.01 ;{ }^{* *} p<0.001$. The most frequently cited barrier was being afraid to face up to the problem, followed by perceived stigma, not knowing where to go and cost. Urban women were more likely than rural women to cite being afraid and cost as barriers while rural women were more likely to cite distance as a barrier than urban women.

\section{Differences according to medical card status}

Only one significant difference emerged between those with and without medical cards in this section. Those with a medical card were less likely $(p<0.001)$ to report that stigma was a barrier $(46 \%)$ than those without them $(60 \%)$. 


\section{Differences according to experience of counselling}

\section{Table 10: $\quad$ Percentages of women indicating the following barriers to the receipt of counselling or psychotherapy by ever having experienced counselling}

\section{Barriers}

Cost**

Not knowing where to go*

Shame*k

Distrust***

Time**ok

Not worthwhile**

\section{Have experienced \\ Counselling (\%)}

\author{
64
}

63

52

39

25

24

\section{Have not experienced \\ Counselling (\%)}

\section{0}

52

40

24

12

13

$* p<0.05 ; * * p<0.01 ; * * * p<0.001$. Women who had experienced counselling were more likely to cite cost, not knowing where to go, shame, distrust, time and counselling not being worthwhile as barriers when compared to those how had not experienced counselling.

Differences according to caseness on the CES-D

Women who were depressed were more likely $(p<0.05)$ to report that cost was a barrier $(60 \%)$ than were those who were not $(50 \%)$.

\section{Differences according to caseness on the GHQ-12}

Those who were psychologically distressed were more likely $(p<0.05)$ to report that not knowing where to go was a barrier $(60 \%)$ than those who were not $(51 \%)$.

In addition to the barriers, respondents were asked what they thought would encourage women to go for counselling. Their responses were as follows:

Figure 3: $\quad$ Percentages of women reporting that the following would encourage women to present for counselling or psychotherapy by location

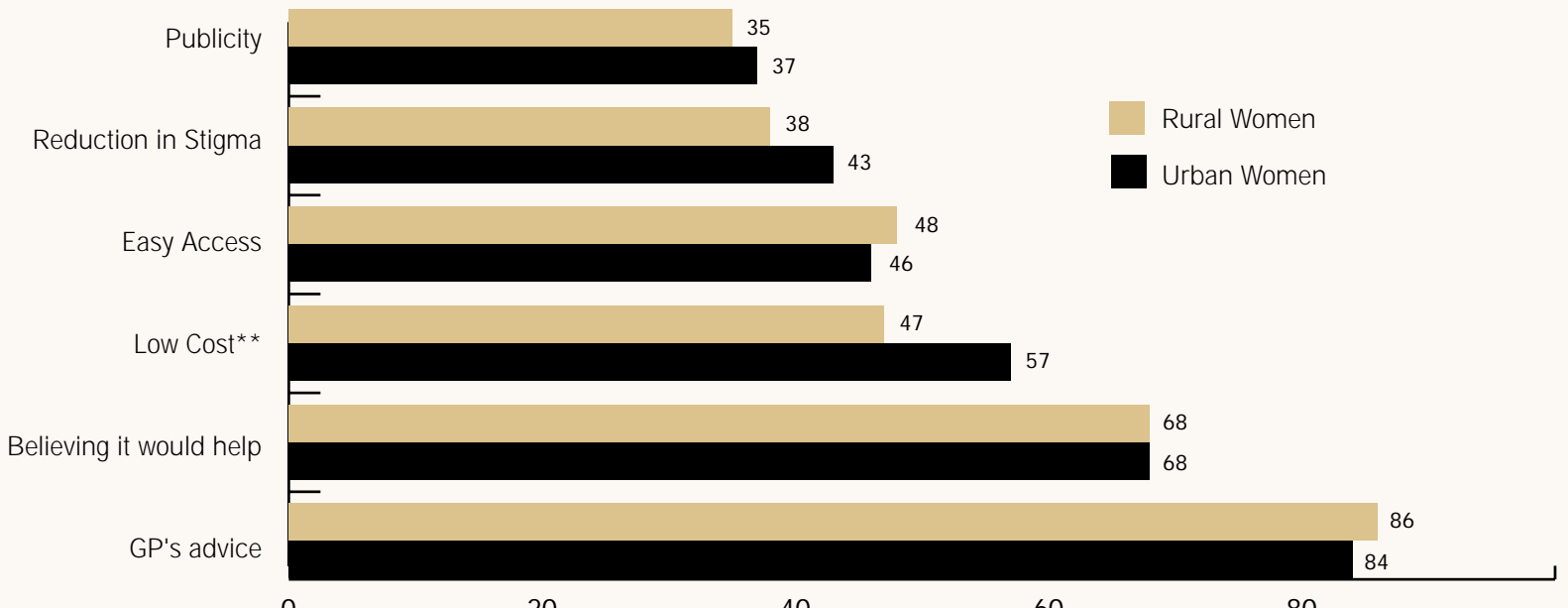

${ }^{*} \mathrm{p}<0.05 ; * * \mathrm{p}<0.01 ; * * * \mathrm{p}<0.001$. The most frequently cited encouragement was advice from a GP, followed by believing it would work and low cost. Urban women were more likely to report that low cost would be an encouragement than were rural women. 
Differences according to medical card status

Table 11: Percentages of women reporting that the following would encourage women to present for counselling or psychotherapy by medical card status

Medical Card (\%) No Medical Card (\%)

Easy access***

36

32

51

Reduction in associated stigma**

30

44

39

${ }^{*} p<0.05 ; * * p<0.01 ; * * * p<0.001$. Women with medical cards were less likely than women without medical cards to cite easy access, reduction in stigma or publicity as encouragements to present for counselling.

\section{Differences according to experience of counselling}

Table 12: Percentages of women reporting that the following would encourage women to present for counselling or psychotherapy by having experienced counselling

\section{Encouragement}

Believing it would help*

Low cost***

Reduction in associated stigma*t*

Publicity*k*

\section{Have experienced \\ counselling (\%)}

75

65

55

49

\section{Have not experienced}

counselling (\%)

66

49

37

34

${ }^{*} p<0.05 ; * * p<0.01 ; * * * p<0.001$. Those who had experienced counselling were more likely than those who had not to report that believing it would help, low cost, reduction in stigma and publicity would encourage women to present for counselling.

\section{Differences according to caseness on the CES-D}

Those who were depressed were less likely $(p<0.05)$ to report that advice from a GP would encourage people to present for counselling (80\%) as compared to those who were not (87\%).

\section{Differences according to caseness on the GHQ-12}

Those who were psychologically distressed were more likely $(p<0.05)$ to report that easy access $(58 \%)$ would encourage people to seek counselling as compared to those who were not $(46 \%)$. In addition, they were more likely $(p<0.05)$ to report that a reduction in associated stigma would encourage people (46\%) as compared to those who were not psychologically distressed (35\%).

\section{Summary}

- The most common perceived barriers to help-seeking is being afraid to face up to the problem, followed by stigma, not knowing where to go and cost. The least frequently mentioned barriers are time and counselling not being worthwhile.

- Women from urban areas are more likely to cite fear and cost as barriers. Rural women are more likely to cite distance as a barrier.

- Women with medical cards are less likely to perceive stigma as a barrier.

- Those who have had direct personal experience of counselling / psychotherapy are more likely to identify all barriers to helpseeking, most frequently cost followed by not knowing where to go and shame. 
- The most commonly perceived action to encourage help-seeking is advice from a GP, followed by believing it would work and low cost. Cost is particularly an issue for urban women.

- Women without medical cards are more likely to cite publicity, stigma reduction and ease of access as encouragements.

H. Views on the availability and location of counselling and psychotherapy services

Most women, $77 \%$ of both groups, reported that they did not know whether counselling or psychotherapy was available from their health board, while $19 \%$ of both groups reported that it was $(p=n s)$. When asked about their views on the appropriateness of various providers of such a service, their responses were as follows:

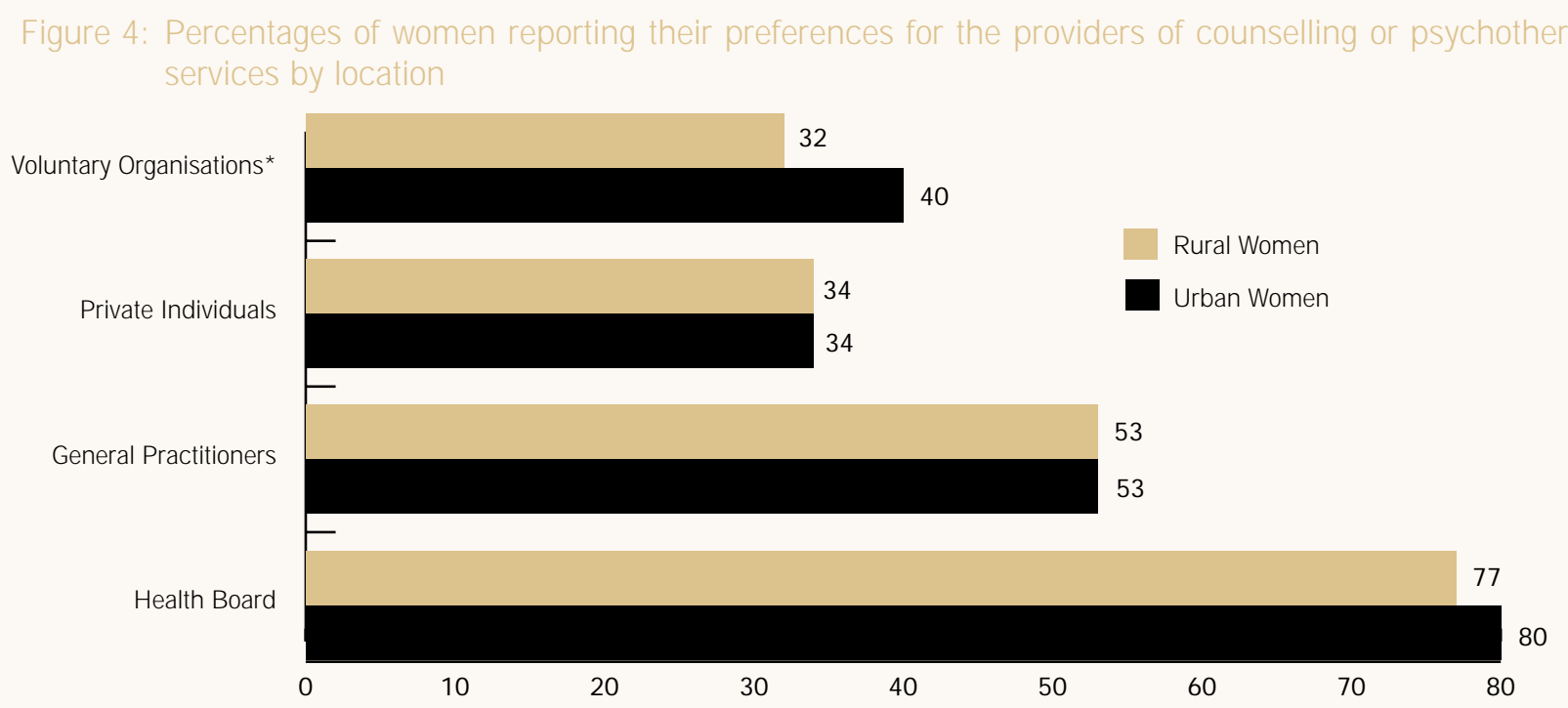

$* p<0.05 ; * * p<0.01 ; * * * p<0.001$. Health Boards were the most popular service providers, followed by GPs. Urban women were more likely to report that they would like services provided by voluntary organisations than were rural women.

Respondents were also asked their views on the most appropriate location for such services and they responded as follows:

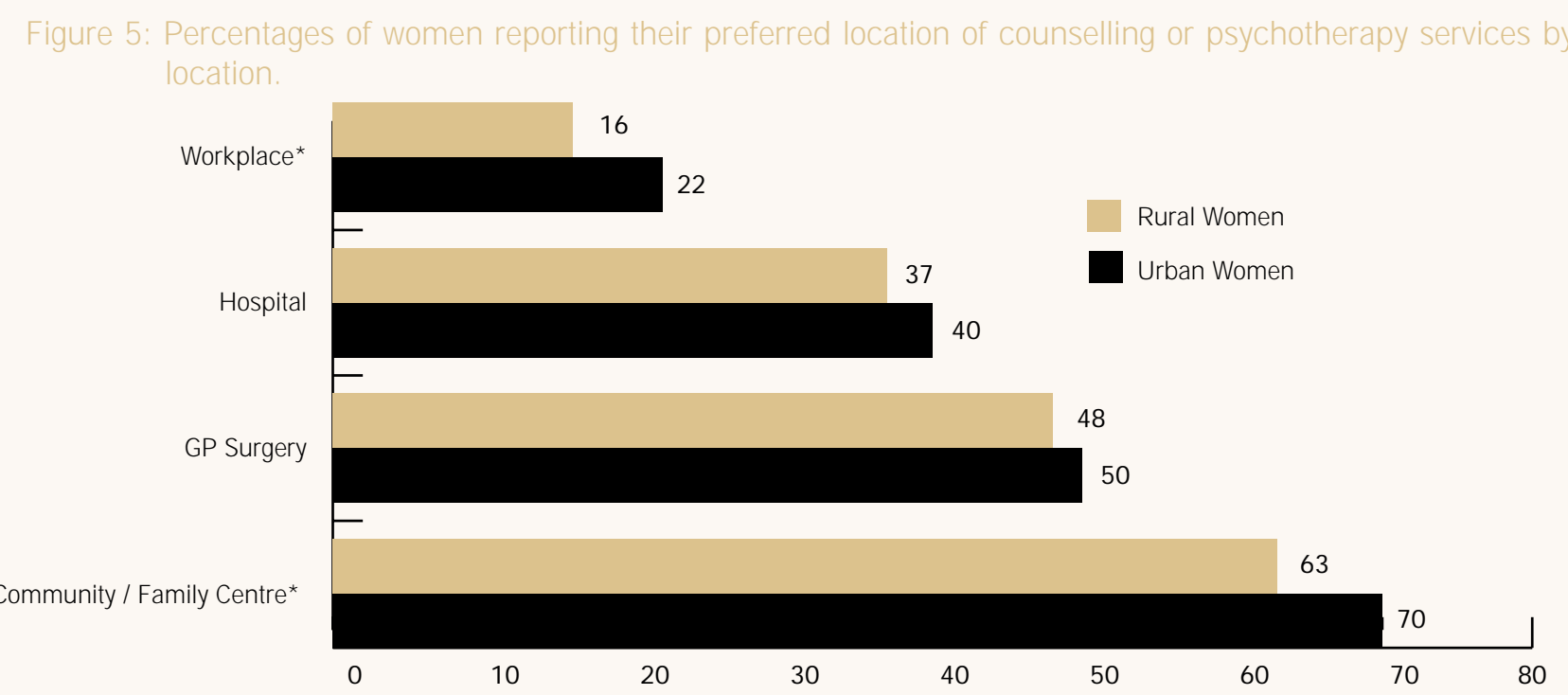

$* p<0.05$. The most popular location for the provision of services was community or family centres, followed by GP surgeries. Urban women were more likely to report that they would like services provided in community/family centres and workplaces than were rural women. 
Table 13: Percentages of women reporting their preferences for the providers of counselling or psychotherapy services by medical card status

Medical Card (\%) No Medical Card (\%)

Health Board**

72

81

Voluntary Organisations***

22

41

Private individuals*k*

40

$* p<0.05 ; * * p<0.01 ; * * * p<0.001$. Women with medical cards were less likely to report that they would like services to be provided by health boards, voluntary organisations or private individuals than were those without medical cards.

Medical cardholders reported that they would most like to see services provided by the health board (72\%) followed by GPs (57\%), and would like to see services located in family/community centres (56\%) followed by GP surgeries (54\%). Those with medical cards were less likely $(p<0.01)$ to report that they thought that counselling should be available in workplaces $(12 \%)$ as compared to those without them (22\%).

\section{Differences according to experience of counselling}

Twenty five per cent of those who had received counselling and $17 \%$ of those who had not $(p<0.05)$ reported that they knew that counselling was available from their health board. Those who had experienced counselling were more likely $(p<0.01)$ to report that they thought that counselling should be provided by voluntary organisations $(46 \%)$ than were those with no experience of counselling $(34 \%)$. In addition, they were also more likely $(p<0.01)$ to report that counselling should be provided by private individuals $(45 \%)$ as compared to those who had no experience (32\%). Amongst those who had experienced counselling, the most frequently cited preferred providers of counselling / psychotherapy services were the health board (77\%) and GPs (57\%). Those who had experienced counselling were more likely $(p<0.05)$ to report that they thought that counselling or psychotherapy should be available in a community / family centre (74\%) than those who had no experience with counselling $(65 \%)$. The most popular locations for the provision of services for those who had experienced counselling were community/family centres (74\%), followed by GP surgeries $(47 \%)$.

Differences according to caseness on the CES-D

No statistically significant differences were noted between those who were depressed and those who did not in relation to their preferred provider of counselling or psychotherapy services. Depressed women reported that their preferred service providers were health boards (81\%) followed by GPs (51\%). Neither was statistically significant differences noted between those who were depressed and those who were not in relation to their preferred location for counselling or psychotherapy services. Depressed women reported that they would most like to see services situated in family/community centres (67\%) followed by GP surgeries (54\%).

\section{Differences according to caseness on the GHQ-12}

Women who were psychologically distressed were more likely $(p<0.05)$ to report that they thought that GPs should provide counselling $(63 \%)$ as compared to those who were not distressed $(50 \%)$. They also reported that they would most like to see services provided by their health board ( $81 \%)$ followed by GPs (46\%). Their preferred location for services was in family/community centres $(70 \%)$ followed by GP surgeries $(54 \%)$. No statistically significant differences were noted between psychologically distressed and non-distressed women in relation to their preferred location for counselling or psychotherapy services.

\section{SUMMARY}

- A minority of women know that counselling or psychotherapy is available from their health board.

- The most frequently cited preference for service provision is the health board, followed by GPs, while the most frequently cited preferred location is in family/community centres followed by GP surgeries. Women from urban areas are more likely to prefer voluntary providers and both workplace and community/family centre locations than are rural women.

- Non medical card holders are more likely to prefer private individuals, voluntary organisations or health boards as well as more likely to prefer workplace provision.

- Those with experience of counselling are more positive about voluntary organisations and private individuals providing services. 


\section{Interviews with women}

\section{Method}

\section{SAMPLE}

Forty three per cent of respondents to the postal survey indicated that they would be willing to be interviewed further, and $87 \%$ of those reported that they were willing to be interviewed face to face. The priorities set for the selection of women for interview were that they should be available and willing to be interviewed within the time frame allowed. This meant that those who were interviewed were selected from those that responded early to the postal questionnaire. In addition it was decided that their home locations should be distributed throughout the three participating health board regions and the sample was to be weighted in favour of women who had received counselling themselves. The sample was thus purposively selected and is not necessarily representative of all women in the community.

\section{MEASUREMENT}

Two structured interview schedules were devised (See Appendix 3); one for women who had received counselling and one for women who had not received counselling. For the women who had received counselling, factual questions included duration of counselling, for what problem counselling was sought, cost per session, total cost, whether the counsellor was private, public or from a voluntary organisation and the distance traveled. More in-depth questioning obtained information regarding who the woman discussed the problem with, how she identified the problem, and the first steps in seeking counselling, how the counsellor was chosen, other people's attitudes, barriers to counselling, the decision to finish counselling, and whether the counselling 'worked'. Accessibility was also explored, as were perspectives on the location of services, and on whom should provide counselling.

For women who had not received counselling, similar factual questions were asked pertaining to someone they knew who had received counselling. These women were asked if that person's experience would influence them, and whether they had ever experienced problems for which counselling would have helped. They were asked how they dealt with these problems and whether they would have used counselling had it been suggested to them. Barriers and enablers to counselling were also explored. These women were asked whom they feel should provide counselling and whether the Health Board should pay. Both groups of women were asked whether they would recommend counselling to other women.

\section{PROCEDURE}

Selected women were contacted by telephone and appointments were made for interviews at their own convenience. Each woman was offered a choice of locations for their interview, almost all (90\%) preferred to be interviewed in their own home and a further $10 \%$ were interviewed either in a local hotel or community centre. A team of three interviewers were trained at the Women's' Studies Centre, NUI Galway, and they conducted all interviews over a nine day period. Each interview took between 20 and 70 minutes, the shorter interviews were with those who had no direct personal experience of counselling. These interviews were audio recorded with participants' permission and were subsequently transcribed and analysed using the qualitative data analysis computer package QSR-NUDIST. A total of 55 women were interviewed, of whom 40 reported that they had received some form of counselling.

\subsubsection{Results}

The data collection procedure for the interviews with women was not intended to select participants who were representative of all women. Instead the key feature of their selection was that they had responded early to the more quantitative survey, had indicated that they were willing to be interviewed in more depth and were distributed throughout the three health board areas. They had also reported some experience, primarily personal, of counselling or psychotherapy. Therefore this set of data was designed to provide more contextual information regarding service provision as experienced by clients. The data collected are summarised below by theme. It should be noted that, as a result of the flexible interview methods employed, every woman responded to not all questions. In addition, those who did not receive counselling answered some questions in relation to the person they knew that had received counselling (who was frequently their child or other close family member). 


\section{Deciding on counselling}

The process of obtaining counselling or therapy varied widely between interviewees. Some women reported that the need for help arose over time and gradually became apparent:

\section{Well, when you've difficulties with your husband and you know that they are not getting any better then you realise that something has to be done about it.}

for about two years before, there was a build up to it, you know

While others reported that they found themselves in a crisis situation:

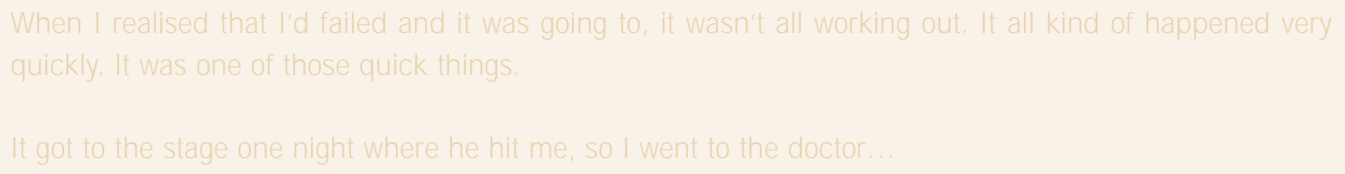

A small proportion of the interviewees had been clients of the psychiatric services in the past, but none were subject to an unsolicited intervention.

\section{I have had psychiatric problems this last 22 years, so I have to go to the Psychologist all the time. \\ So it was a problem on and off for lets say about 16 or 17 years altogether.}

Access

Many had approached their GP for assistance in the first instance and about a third reported that they had been referred on from their GP. However, others who had presented for counselling self-referred:

$$
\text { I rang them and then I had to wait.. }
$$

No, it was a self-referral.

A further group reported that other professionals or groups had referred them:

Recommended by people who were involved in the world of counselling.

The consultant gave me a choice of two.

Most frequently, women reported that they did not have any other treatment options discussed with them. While a minority were offered prescribed medication:

Once I met the Psychiatrist we immediately discussed medication.

After seeing him then I had to go and see a Psychiatrist and I was put on medication.

Or recommended to a self-help or support group:

recommended me to, to the GA (Gamblers Anonymous).

Type of problem

The greatest proportion of the women who were interviewed reported that they had attended counselling for help with their marriage:

It was generally that we weren't getting on as a couple. 
However many also reported attending for what could be described as more individual problems:

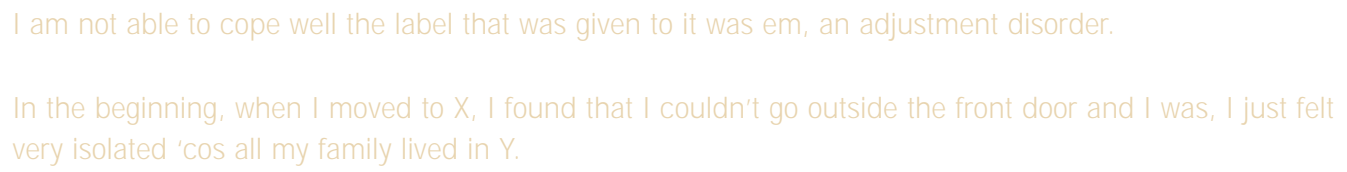

Others reported that they had attended in response to addiction issues:

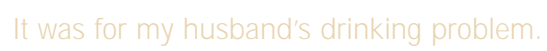

While these were the three most common types of response, other reported a range of reasons for attending counselling. These included bereavement, family problems homelessness and illness.

\section{Choice of counsellor}

Most frequently, women reported that they went to a particular counsellor on the advice of family or friends:

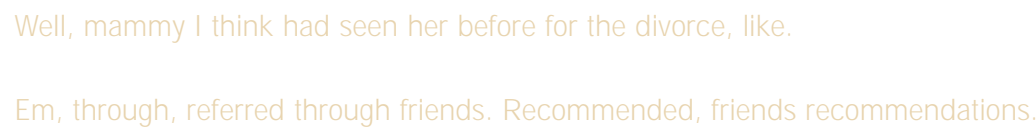

More rarely, they were recommended to a specific person by their GP:

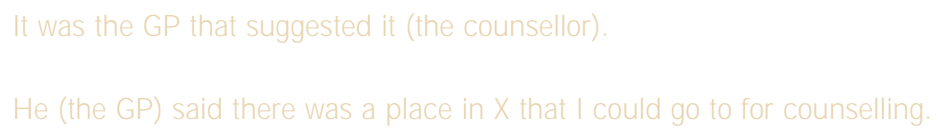

A small group reported that they had no choice of counsellor. They reported that they were allocated a duty Psychiatrist or therapist apparently based on staff availability:

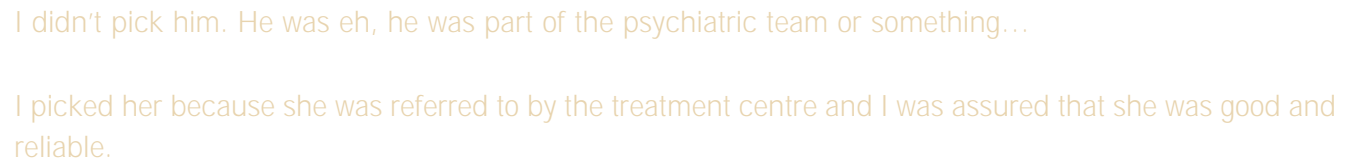

\section{Counsellors training}

Most of the women interviewed reported that they did not know or could not remember the type of training or style of therapy that their counsellor used:

\section{No. I didn't ask her either:}

However others gave specific responses:

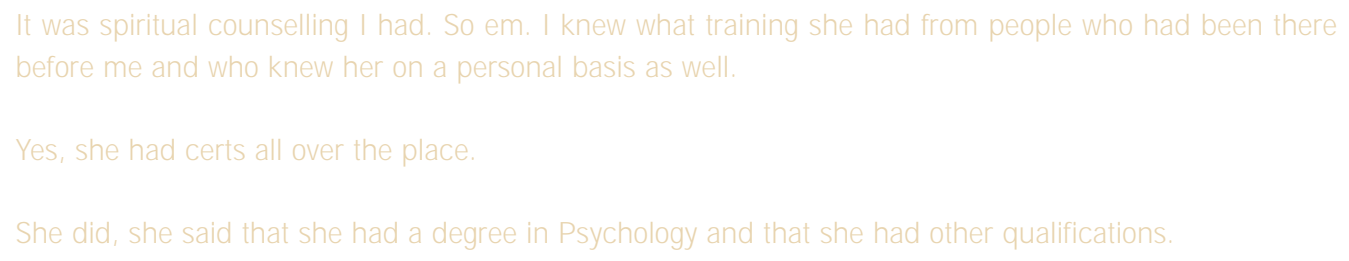




\section{The counselling experience}

The number of sessions and the time period over which women attended counselling varied depending on the problem in question. Personal problems such as depression, drug and alcohol abuse had the longest attendance rates with four women reporting that they had regularly (weekly or monthly) attended therapy for at least a year. However, women also reported attending brief therapy (8 sessions, or less than 2 months) for personal problems. Marriage guidance therapy varied in length from 1 session to up to 15 sessions. Family counselling tended to be in the form of brief therapy of less than 8 sessions (or 2 months).

The average duration of the sessions were reported to have lasted from just a few minutes to over 2.5 hours. The modal length of sessions was 1-1.5 hours (reported by 25 of the women). There was no apparent pattern between length of session and problem(s) being discussed.

The majority of women were no longer in counselling, and indicated that it had been their own choice:

\section{I felt that it was em, a certain amount I could be helped with and then the rest of it, it was up to me to get moving on. So that's what em, that's why I kind of finished on it. \\ I came to terms with what had happened and realised that there was nothing that could have been done to change it.}

Others finished by mutual agreement with the counsellor:

\section{She had brought us as far as she could and the rest was up to us. We felt we were ready and so it was kind of a joint decision thing.}

However, a minority were unhappy with the process of termination, for a variety of reasons:

\section{My husband, the other party wouldn't continue. \\ As far as the counsellor was concerned I actually had achieved what I wanted to achieve... So he decided that we were finished, he decided. \\ When I said I was going it was like she (the counsellor) had, almost a panic attack you know.... I just find that she was holding on to me. And I thought, I'm not going to do this. I've not come here just for the sake of it.}

Cost

About half of the women interviewed paid for their counselling sessions themselves:

\section{Initially it cost about $\mathrm{f15}$ an hour, and now it's up to about $\mathrm{f25}$}

While a minority received free (or made voluntary contribution towards) counselling either through the health board services or from a voluntary agency:

\section{It was through the doctor, I have a medical card}

The average reported cost per session was between $£ 25-£ 30$, although some of the women had negotiated rates with the counsellors based on their ability to pay:

\section{It went from $£ 25$ to $£ 35$, but because I couldn't afford it she only took $£ 25$}

\section{Location}

None of the respondents indicated that they had any difficulty travelling to see the counsellor. Most were located within a relatively short distance of the therapist: 
It's just, you know, fifteen minutes by car and half an hour by bus.

\section{Barriers to access}

Women were asked specifically whether the opinions of others had influenced them in relation to help-seeking. Many reported that there were few inter-personal influences on the process for them. This was either because they had told no-one or reportedly kept their counselling secret:

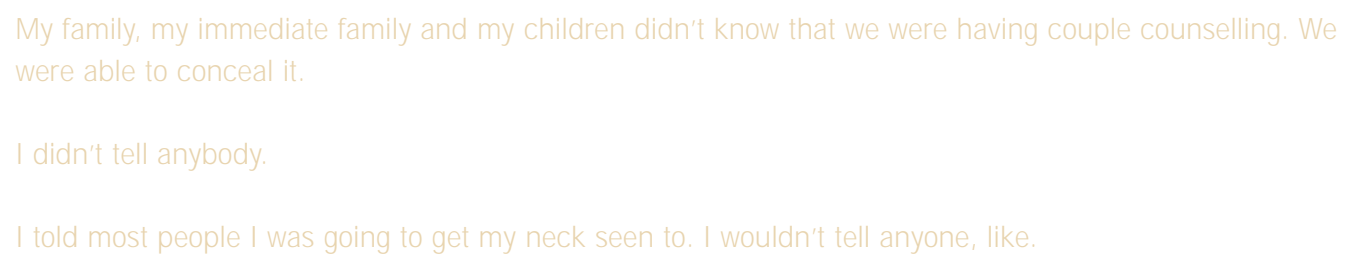

Or that they did not care what others thought:

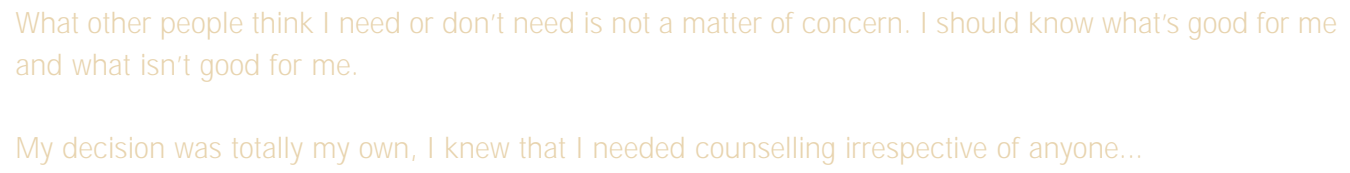

However, a few reported that others were supportive of their quest:

Only a few close friends knew and they were very supportive.

Anyone that I said it to encouraged me to go for it...

Only two women reported that the opinions of others were negative and made seeking help difficult for her.

\section{Exactly what I've said about people, like partners' opinions. And eh, you're made to feel that it's, there's something wrong with you...}

About half of the women interviewed reported that there were no barriers to their own counselling received by people they knew receiving counselling. However, the most frequently mentioned barrier was the lack of knowledge, both in relation to how to access counselling and what exactly counselling consisted of:

\section{I think general sort of knowledge of maybe where to go, who to go to or what type of counselling to get... \\ Lack of information to a degree, em there is not a great lot of information about as to what is available... \\ I suppose not knowing what it involves; not knowing that it's available for starters.}

A minority mentioned other barriers such as stigma:

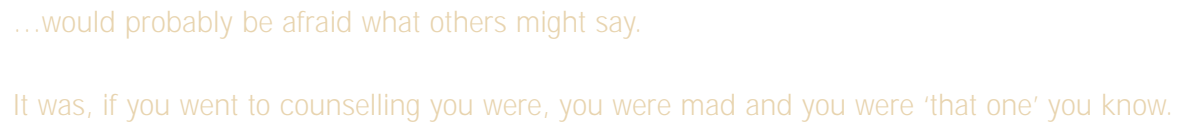

Cost and fear: 


\section{Cost is a factor, it is expensive... in a one wage family there's no way a woman would put by $£ 30$ for just that: \\ I think it is fear of counselling as something at the end of the line, almost the last thing you (would) do.}

However, those that had not received counselling were more vociferous on this issue, and raised issues such as childcare, transport, location, stigma, availability, time, and lack of self-esteem, reluctance to seek help and once again, lack of knowledge. In response to these issues, women reported that more education and publicity was required and that it was important to address the stigma associated with issues of mental health.

Future provision

All the women interviewed, when asked directly, thought that health boards should provide counselling services:

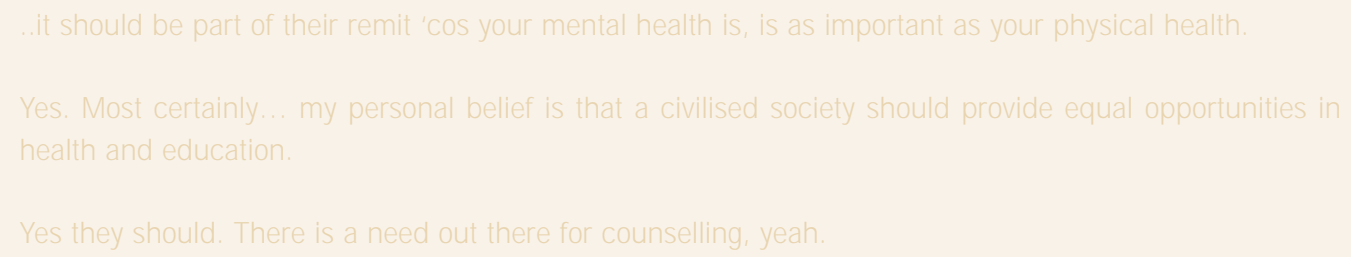

There was a relatively even split in relation to perspectives on the responsibility of health boards to fund services, twenty women reported that health boards should pay for counselling:

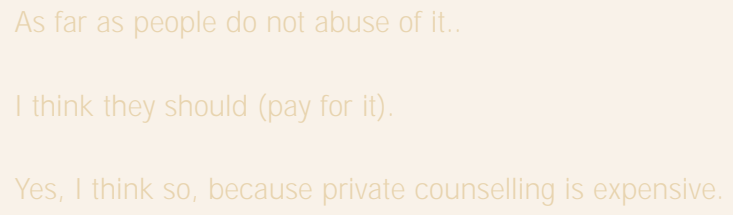

While about half suggested some partial form of payment, either on a sliding scale which would be means tested or as part of the general medical card scheme. They key issue that arose was affordability:

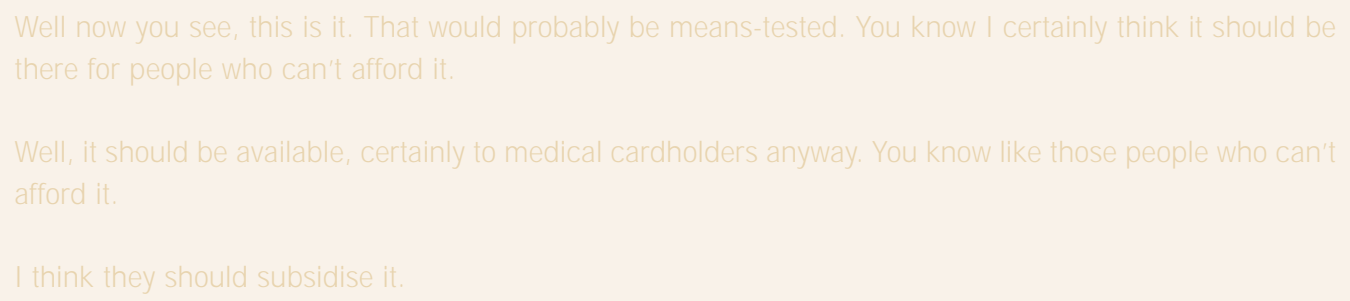

One woman thought the health board should not fund counselling and a further two were unsure.

. not always, I mean if money is going to stop you from seeking help .....

Not necessarily no.

As regards location, the most popular options were GP surgeries:

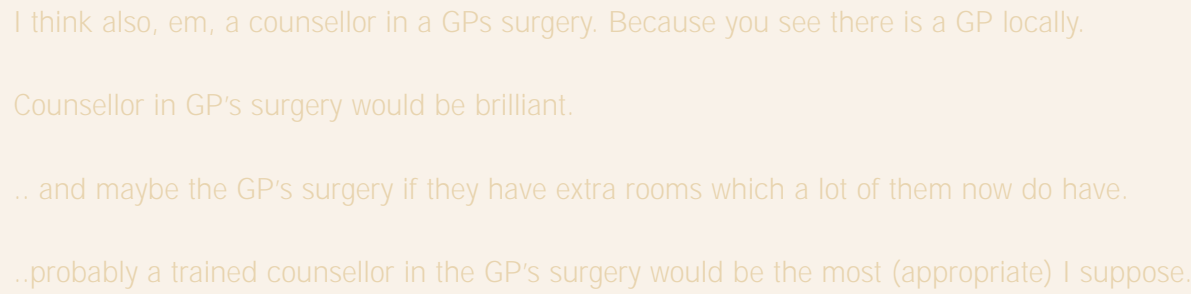


Women's health centres:

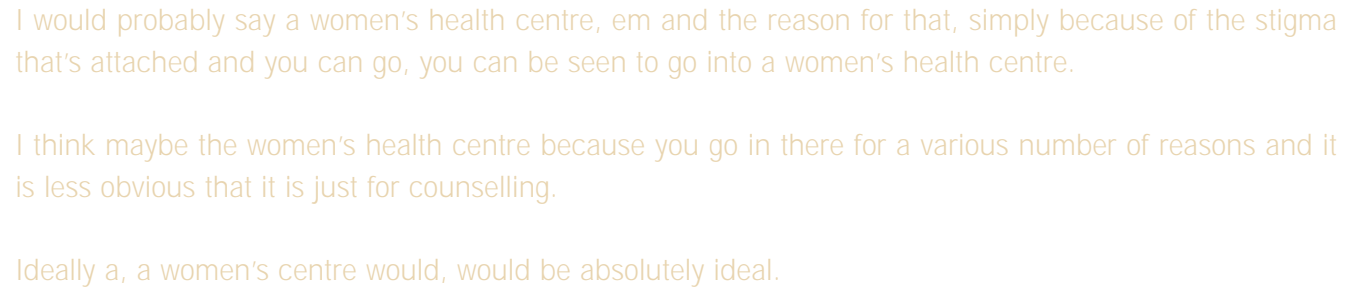

The next most commonly cited locations were, in order, family resource centres, health clinics, workplaces, and at the clients' home:

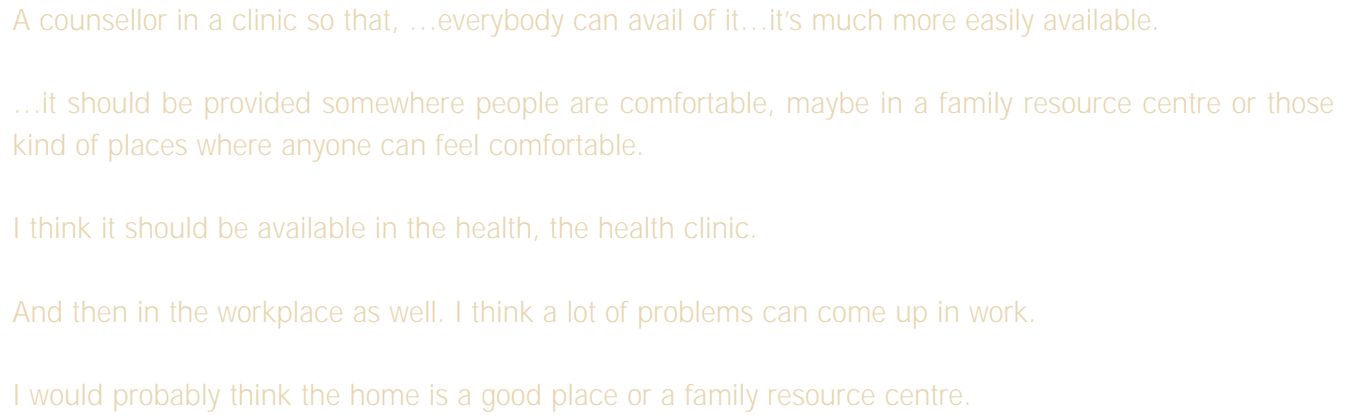

Fewer women mentioned hospitals, private practice, schools, and mobile units. In addition, a small minority of women reported some concerns in relation to the GP surgeries, this was specifically in relation to their anonymity and the public nature of visiting their GP:

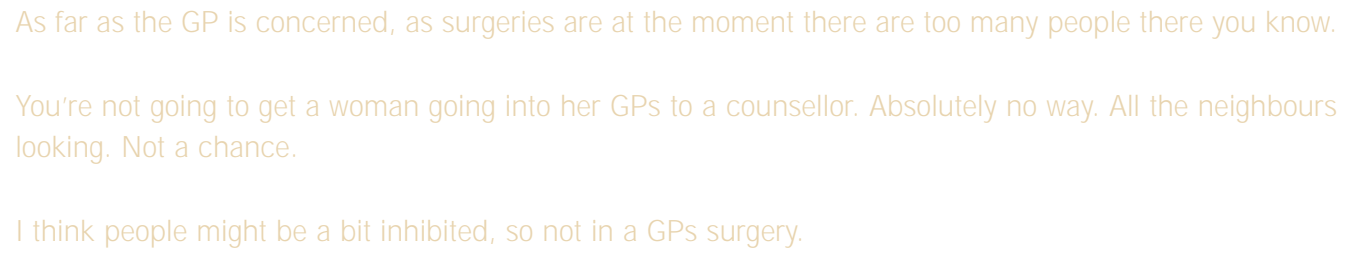

A minority mentioned the workplace and the clients' home as unsuitable venues.

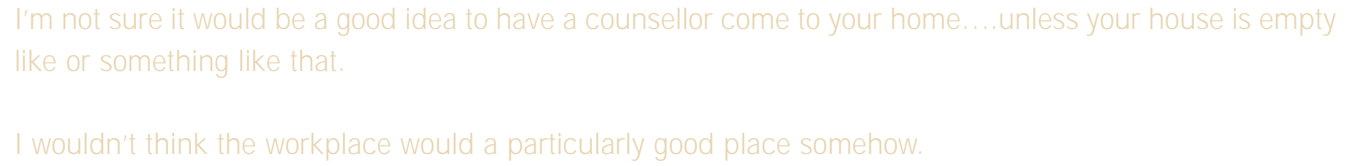

A small number of women raised issues of privacy and were emphatically against any specific 'counselling centre' as the primary location:

.... rather than a specific place that would have counselling labelled on it. People won't go there 'cos they're afraid to be seen going in.

If you go in to somewhere specifically for counselling then it is very much aware when you walk in the door why you are going there and I mean for that reason might put people off. 


\section{SUMMARY}

Where counselling was experienced, it was reported that it had been in response to problems that had built up over a long time period or had been precipitated by a crisis situation. Of those who had experienced counselling, most had gained access to counselling through their GP, although a sizeable number reported that they had self-referred. Very few were offered any treatment options other than counselling.

The most common presenting problems were relationship and family difficulties, depression, anxiety, addiction and bereavement. Most chose their therapist based on the advice of family and friends or their GP. The majority did not know what kind of counsellor they had attended or what training that therapist had received. Most attended therapy weekly for an hour but the length of time they continued attending varied substantially. Most women were no longer in counselling and had terminated by their own choice. About half had paid for sessions themselves and several had received free counselling or psychotherapy.

Few women reported inter-personal influences on their decision to attend for therapy while about half reported that there had been no barriers to their receipt of counselling or psychotherapy. Where barriers were mentioned, the most frequently cited barrier was knowledge, both in relation to defining and to accessing counselling. Those who had not experienced counselling were more concerned about barriers than those who had. All women interviewed thought that counselling services should be provided by health boards, some thought it should be free and others that it should be means tested or on a sliding scale. The most popular options for locations were GP surgeries followed by women's health centres, family resource centres and health clinics. A small number were emphatically against specific and identifiable 'counselling centres' for reasons of anonymity. 
Chapter Four: Health

Professionals 


\section{Health Professionals}

The views of health professionals were sought in a number of ways. A postal survey of health board staff was followed by a series of interviews with individual staff members. A survey was also conducted with a sample of staff working in the voluntary and community sectors. Finally, the perspectives of professional organisations, which represent the views of counsellors or those working with counselling skills was sought by both interview and the collection of relevant documentation.

\section{Health Board Personnel}

\section{Questionnaire Survey}

It was decided at the outset of the project to survey health board staff regarding their views on the counselling services available from their board. The survey also sought to elicit on what should be incorporated into future service provision. Two strands of data collection from health board personnel were executed. First a questionnaire was sent to 600 personnel in the participating health boards. Second, a smaller sample of 15 was selected for individual interviews.

\section{Methoo}

\section{SAMPIE}

Six hundred personnel were randomly selected from three categories of health board staff; Medical, Paramedics and Allied Professional and Nursing. The sample was stratified for health board and thus 200 in each board area were initially selected. These groups primarily represent differences in training and responsibilities, although the paramedic and allied professional group is relatively heterogeneous. This includes professional groups such as Social Workers, Psychologists, Speech and Occupational Therapists. Nevertheless, based on simple random sampling from the personnel lists, the sample generated should reflect the distribution of staff in these groups, their spread throughout the board and the degree to which they provide hospital-based or community services. These three categories of staff were included to the exclusion of groups such as administrative, catering and technical staff based on their likely experience with providing help, using counselling skills or referring to other professionals for counselling.

All respondents were requested to indicate if they would be willing to be interviewed further and if they would prefer telephone or face-to-face contact. Of the 102 that responded affirmatively, 15 were selected for telephone interview. At this stage, selection was based on their health board location, the degree of contact that staff had with women and the level of their involvement with, or interest in, counselling.

\section{MEASUREMFNT}

The questionnaire (see Appendix 5) included factual questions such as job title, whether the participants worked predominantly in a rural or urban setting, and the number of years working within the health services. Questions were designed to elicit participants' knowledge of counselling and/or psychotherapy, and the degree to which they offered counselling and/or counselling skills to their clients. They were asked for the type of problem for which their female clients had received counselling, and the type of organisation to which they were referred (e.g. health board practitioners, private practitioners or voluntary organisations). Levels of training received in counselling or psychotherapy were also ascertained. More qualitative aspects included asking whether the participant felt that counselling is a useful method for helping people and whether they felt that their health board offers a satisfactory counselling service. Participants were also asked who should provide counselling and where it should be provided, and how the health boards' counselling service could be improved.

Topics covered during the semi-structured interviews with personnel examine their awareness of the counselling services currently provided by their organisations and whether they felt these to be adequate and accessible. Barriers and ways of overcoming barriers to counselling were explored. Participants were also asked questions about planning and service provision.

\section{PROCEDURE}

The questionnaire was posted to all randomly selected personnel accompanied with a cover letter of explanation, which assured anonymity and confidentiality and a FREEPOST envelope. This was accomplished through the three health boards, as it was not 
possible to gain direct access to the names and contact addresses of those selected. Reminder letters and replacement questionnaires were sent to staff in one health board only. For logistical and practical reasons it was not possible for the other health boards to assist with reminders. Questionnaires received were coded and inputted into SPSS.

In order to elucidate further the data collected, an interview schedule was devised (see Appendix 6) and a total of 15 health board personnel were contacted and arrangements made for telephone interviews. These took place at the convenience of the participants and were audio-recorded. Following transcription, these data were analysed using QSR NUDIST.

\section{RESULTS}

One hundred and ninety two questionnaires were returned from health board staff, reflecting a response rate of $32 \%$. Of these, 30\% were from the ERHA, 31\% from the SHB and 38\% from the NWHB. These were experienced health board employees, reporting an average of 14 (sd 10) years experience within the health service. They were broadly classified into Doctors / Dentists (22\%), Nurses and Nurse Managers (39\%) and Paramedics and other Allied Professionals (39\%). Sixty six per cent reported that they were members of professional organisations. Forty four per cent reported that they worked predominantly in a rural area and $56 \%$ that they worked in an urban area.

The specific concerns of the health board personnel departments influenced the data collection procedures for the sample of professionals employed by the boards. Given that they would not, for reasons of confidentiality, provide full lists of personnel, it was necessary to request that they randomly select staff from their own lists. Given that each board was to select 200 staff through simple random sampling, it could be assumed that a representative number of each category would be selected. However, as it was not possible to conduct follow-ups with staff in two of the three board areas, the response rates are disappointing at $32 \%$. It is therefore impossible to determine how representative these health board employees are of their wider colleagues. Nevertheless, the staff who did return questionnaires provided some data of immense value and appeared to be interested and involved in the issues of concern.

The questions asked of these employees fall into a number of specific areas and are dealt with sequentially below. All data are presented by urban and rural locations and all statistically significant differences between the two groups are presented. In addition, any significant differences between those who had been trained in counselling or psychotherapy and those who had not and between the three classifications of employees are mentioned below.

\section{Experience of counselling}

Forty three per cent of rural and $35 \%$ of urban based practitioners reported that they had been trained in counselling or psychotherapy methods or skills $(p=n s)$. The nature of this training varied substantially from fully accredited post-graduate training to short courses in listening skills.

\section{Figure 6: Percentages of personnel reporting that they have offered the following services to clients by location}

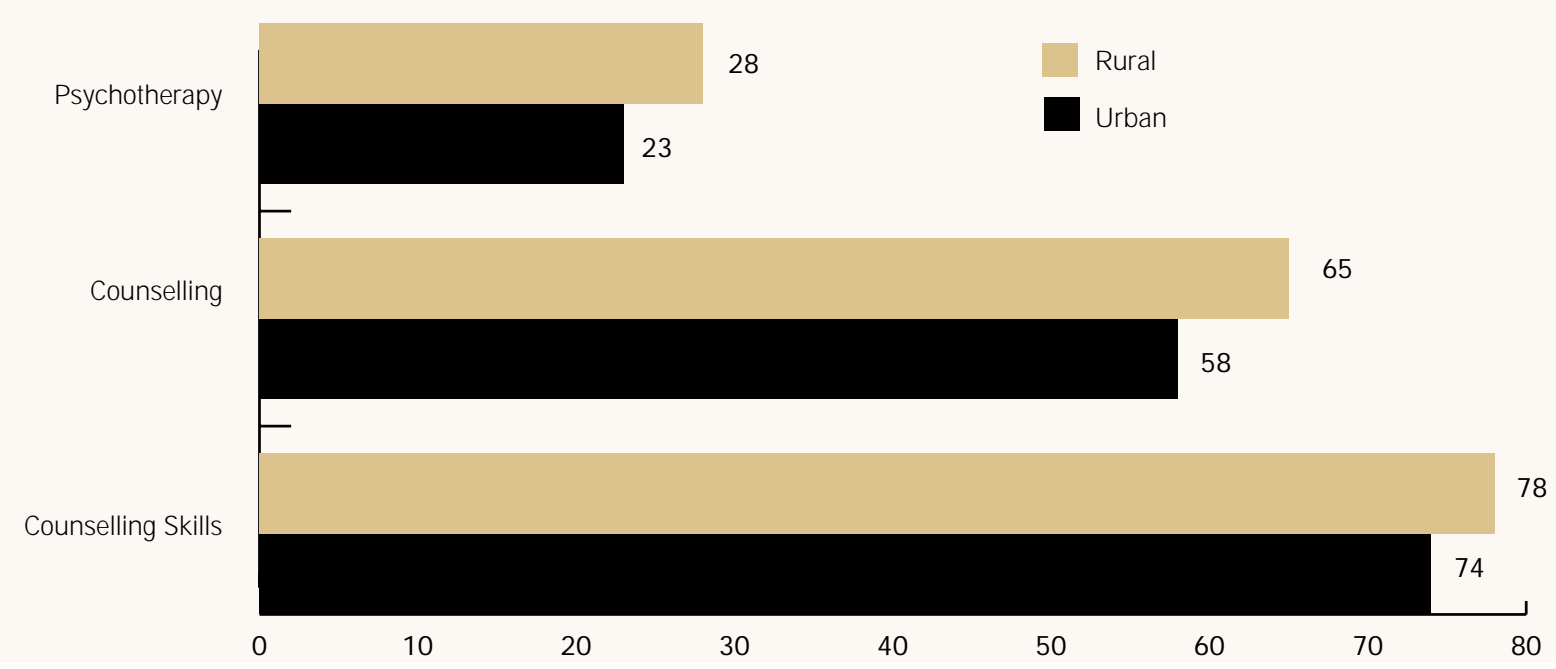

There was no statistically significant difference between those working in urban and rural locations.

While most respondents reported using counselling skills, fewer reported that they engaged in counselling or psychotherapy with clients. 
Figure 7: Percentages of personnel reporting that they have referred a female client to counselling for the following problems by location

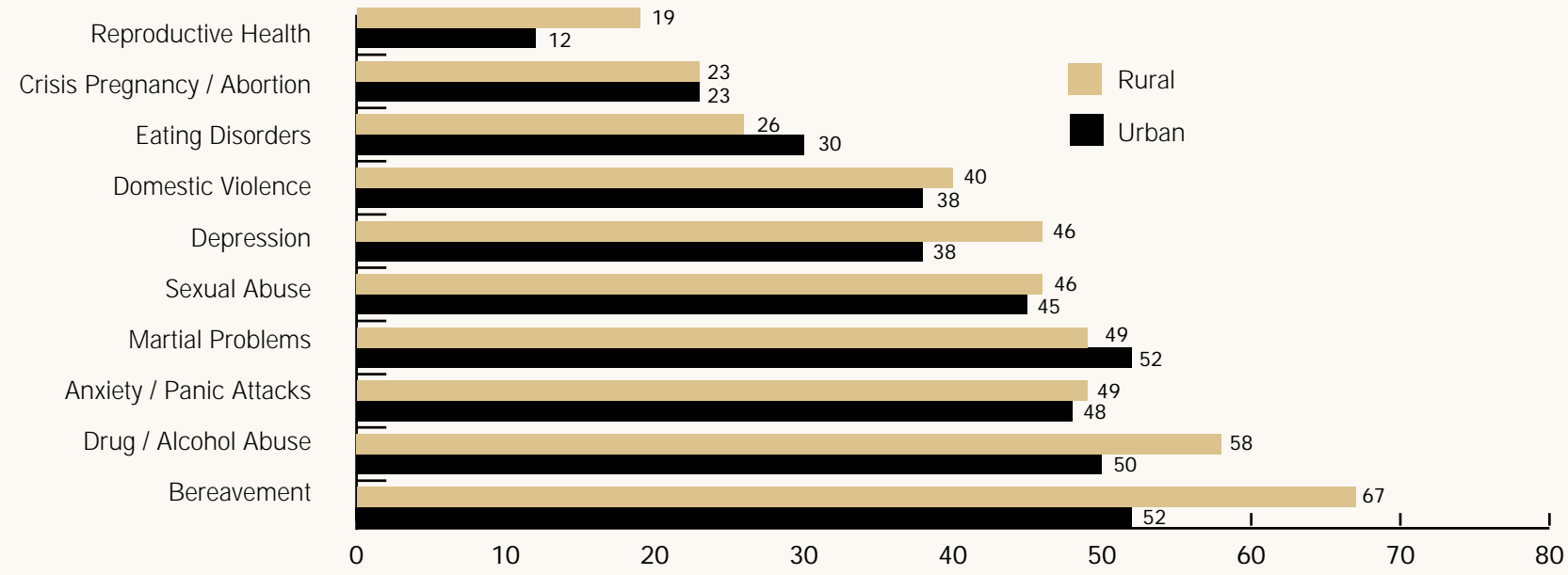

There was no statistically significant difference between those working in urban and rural locations. The most common problems which respondents reporting referring female clients were bereavement, substance abuse, anxiety or panic attacks, relationship and marital problems and sexual abuse.

\section{Figure 8: Percentages of personnel reporting that they referred clients to the following sources by location}

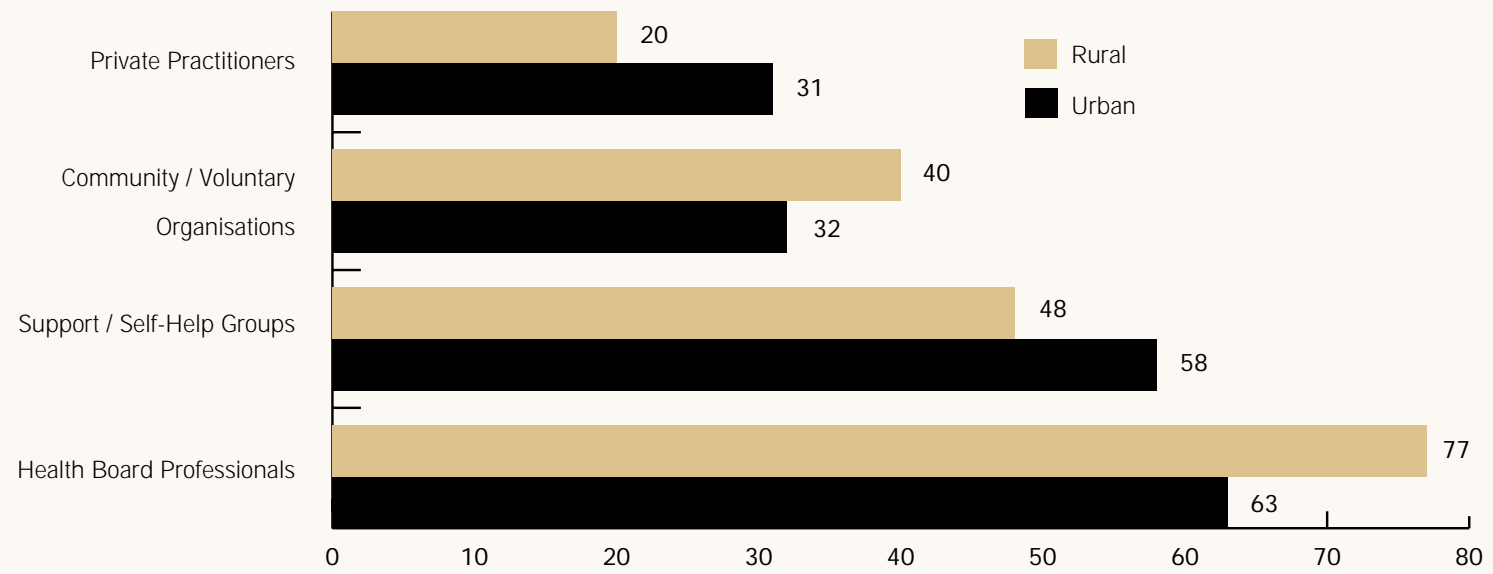

There was no statistically significant difference between those working in urban and rural locations. Most respondents had referred clients to other health board professionals and about half had referred to support or self-help groups.

Differences between those who have received training and those who have not

Those who had been trained in counselling or psychotherapy were more likely $(p<0.001)$ to report that they had offered a counselling service $(79 \%)$ than those who had not been trained $(51 \%)$, they were also more likely $(p<0.001)$ to report that they had offered a psychotherapy service (52\%) compared to those who reported they had no training ( $11 \%)$. Similarly, those with training were more likely $(p<0.001)$ to report that they used counselling skills with their clients $(96 \%)$ as compared to those without training $(63 \%)$.

Those who had been trained were more likely $(p<0.05)$ to report that they referred clients to counselling for marital problems $(59 \%)$ as compared to those who had no training $(40 \%)$, but there was no other statistically significant difference between these two groups. Nor was there any difference between those who had been trained and those who had not in relation to whom they referred clients. 
Differences across employee groups

There was a significant difference $(p<0.05)$ across employee groups in relation to the reported use of counselling skills. Sixty per cent of Doctors and Dentists, $81 \%$ of Nurses and Nurse Managers and $82 \%$ of Paramedics and Allied Professionals reported using counselling skills with their clients. In addition, there were a number of significant differences across problems that they had referred for as indicated in table 22 below.

\begin{tabular}{|c|c|c|c|}
\hline Problem & $\begin{array}{c}\text { Doctors \& } \\
\text { Dentists (\%) }\end{array}$ & $\begin{array}{l}\text { Nurses \& Nurse } \\
\text { Managers (\%) }\end{array}$ & $\begin{array}{c}\text { Paramedics \& } \\
\text { Allied Professionals (\%) }\end{array}$ \\
\hline Drug / Alcohol Abuse** & 79 & 39 & 53 \\
\hline Anxiety / Panic Attacks**k & 71 & 39 & 53 \\
\hline Sexual Abuse* & 8 & 30 & 55 \\
\hline Eating Disorders*k & 54 & 15 & 31 \\
\hline
\end{tabular}

$* p<0.05 ; * * p<0.01 ; * * * p<.001$. Doctors and dentists were more likely to report that they have referred clients for substance abuse, anxiety and panic attacks, sexual abuse and eating disorders than were nurses and nurse managers or paramedics and allied professionals.

Paramedics and Allied Professionals were more likely $(p<0.05)$ to have referred clients to private practitioners $(37 \%)$ when compared to either Doctors and Dentists (17\%) or Nurses and Nurse Managers (17\%).

\section{SUMMARY}

- About three quarters of the health professionals surveyed have employed counselling skills in their jobs and over half reported that they have provided counselling while fewer reported that they had provided psychotherapy.

- Most have referred clients to therapists, and the most common problems for which they have referred were bereavement, substance abuse, anxiety or panic attacks, relationship and marital problems and sexual abuse. Most have referred to other professionals within the health board and a minority have referred to private practitioners.

- Those who have received training in counselling or psychotherapy are more likely to have both provided services and to have referred clients on to other practitioners.

- Doctors and dentists are less likely to have used counselling skills or provided counselling or psychotherapy but are more likely to have referred on for a variety of problems.

\section{PERCEPTION AND KNOWLEDGE OF COUNSELLING}

Seventy eight per cent of rural practitioners and $90 \%$ of urban practitioners $(p<0.05)$ reported that counselling and psychotherapy differed from each other. Among those working in rural areas, $92 \%$ reported that they think that counselling is a useful method of helping people, while the figure for those working in urban areas was $88 \%$ ( $p=n s)$. Seven per cent of those working in rural areas and $14 \%$ of those in urban areas reported that they thought that their health board offers a satisfactory counselling / psychotherapy service ( $p=n s$ ). 
Figure 9: Percentages of personnel reporting their preferred provider of counselling / psychotherapy services by location

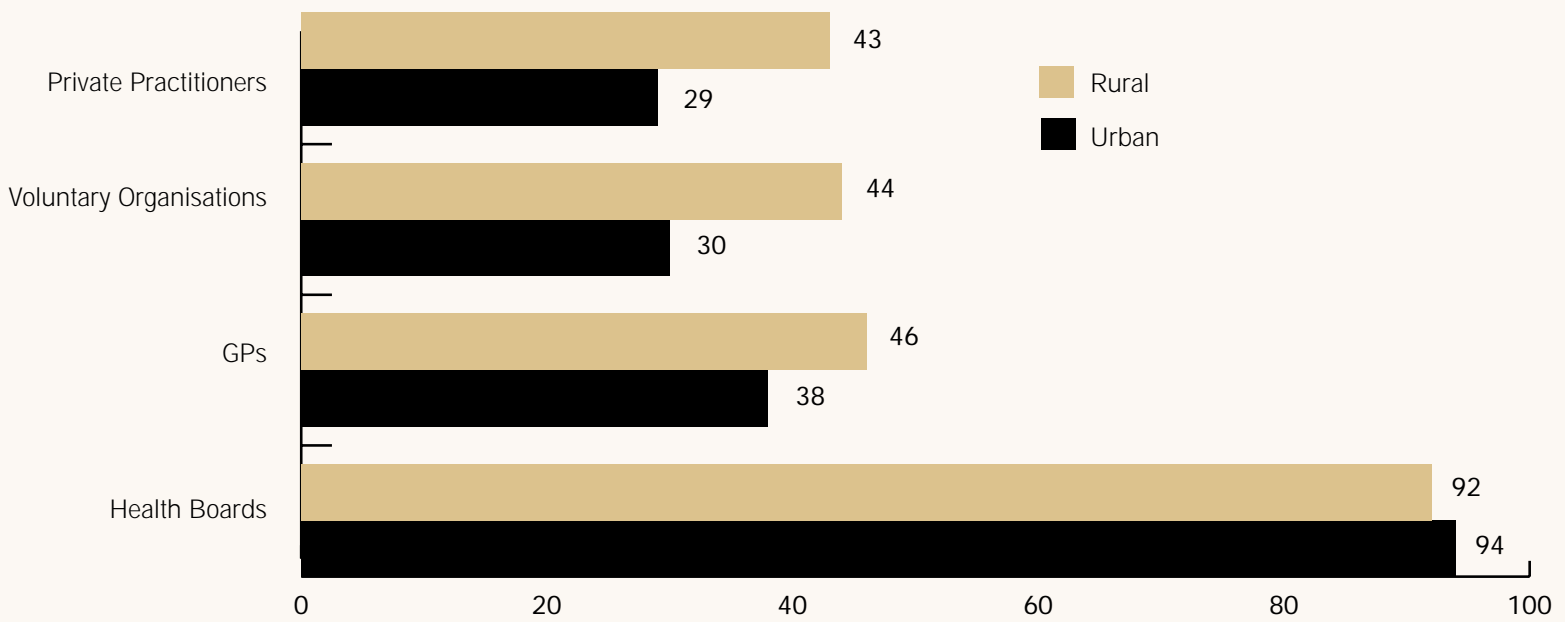

There was no statistically significant difference between those working in urban and rural locations. Respondents were most likely to report that their preferred provider of counselling services was their health board, followed by GPs in order of preference. Figure 10: Percentages of personnel reporting their preferred location for counselling / psychotherapy services
by location

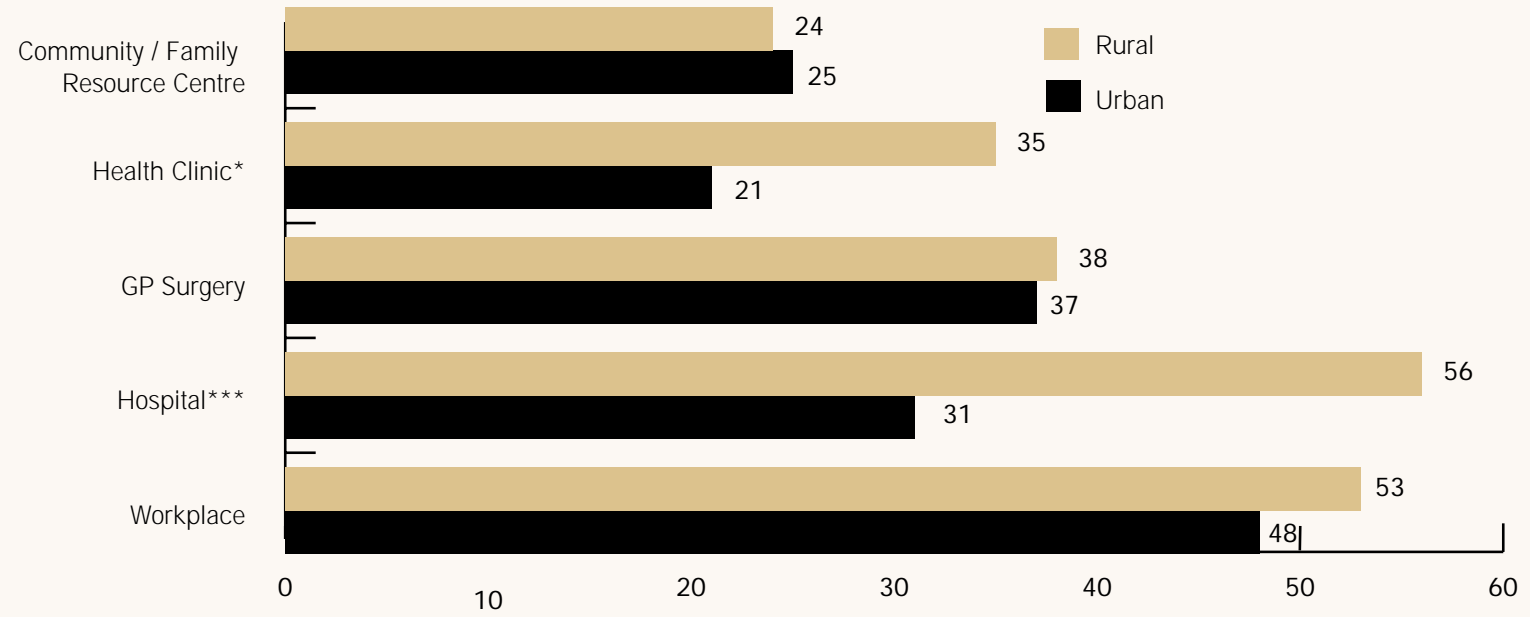

${ }^{*} p<0.05 ;{ }^{* *} p<0.01 ; * * * p<001$. The most popular preferred location for services was the workplace, followed by the hospital for rural respondents and GP surgeries for urban respondents. Those working in rural areas were more likely than those working in urban areas to report preferring the hospital and the health clinic as locations for the provision of counselling services. Workplace is taken to mean place of work, with services offered on-site through personnel departments, employee assistance programmes or trade unions (or indeed any combination of these). 
Figure 11: Percentages of personnel reporting that their health boards counselling / psychotherapy service could be improved through the following means by location

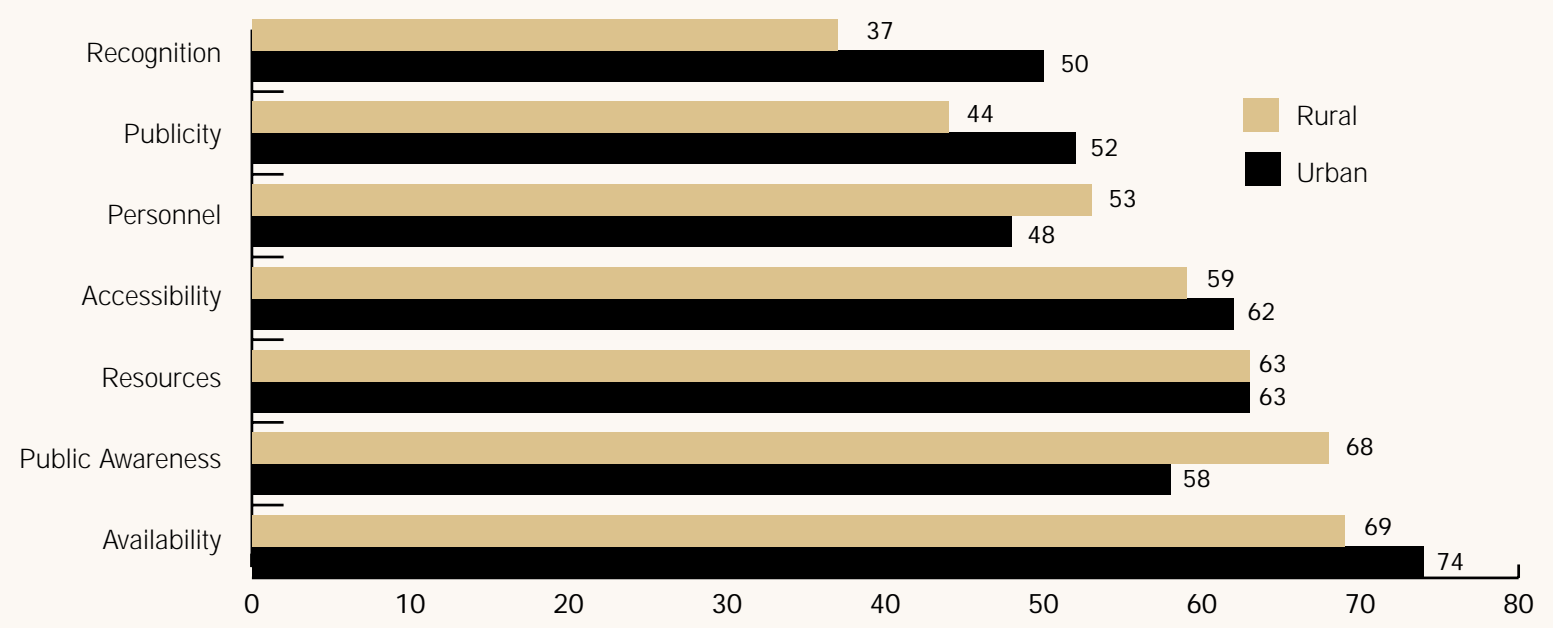

There was no statistically significant difference between those working in urban and rural locations. The most frequently reported means for improving services provided by the health boards were increased availability, more public awareness, increased resources and increased accessibility.

Differences between those who have received training and those who have not

Those who had been trained in counselling or psychotherapy were more likely $(p<0.001)$ to report that their health board did not provide a satisfactory service $(66 \%)$, than those who had not been trained $(41 \%)$. Note that $50 \%$ of those who had not been trained and $19 \%$ of those who had been trained reported that they did not know whether the service provided was satisfactory.

Those who had been trained in counselling / psychotherapy were more likely $(p<0.05)$ to report that they thought that counselling should be provided by voluntary organisations $(70 \%)$ than were those who had not been trained (55\%), they were also more likely $(p<0.05)$ to report that they thought that private practitioners should provide services $(74 \%)$ than those who had no training $(57 \%)$. There were no significant differences between those who had been trained and those who had not in relation to their preferred location for services.

Those who had received training were more likely $(p<0.01)$ to report that resources would improve the service $(75 \%)$ when compared to those who had not been trained $(54 \%)$ and they were also more likely $(p<0.01)$ to highlight personnel issues $(62 \%)$ than were those with no training $(41 \%)$.

\section{Differences across employee groups}

Paramedics and Allied Professionals were more likely $(p<0.05)$ to report that their health board did not provide a satisfactory service (Doctors and Dentists 50\%, Nurses and Nurse Managers 41\%, Paramedics and Allied Professionals 63\%) and less likely to report that they did not know if the service provided was satisfactory (Doctors and Dentists 45\%, Nurses and Nurse Managers $41 \%$, Paramedics and Allied Professionals 29\%).

Doctors and Dentists were less likely $(p<0.05)$ than other groups to report that counselling or psychotherapy should be provided within the workplace (33\%) when compared to Nurses and Nurse managers (58\%) and Paramedics and Allied Professionals (50\%). In addition, Nurses and Nurse Managers were less likely $(p<0.05)$ to report that services should be located within family resource centres (64\%) as compared to both Doctors and Dentists (79\%) or Paramedics and Allied Professionals (83\%). There were no other statistically significant differences across employee groups. 


\section{SUMMARY}

- Perceptions of counselling are very positive, but very few think that their health board service was satisfactory.

- The most popular service provider is the health board followed by GPs, while the most popular location for services is the workplace, followed by the hospital and the GP surgery.

- Most respondents report that availability, public awareness, increased resources and accessibility could improve the service provided by the health board.

- Allied professionals and paramedical staff and those who had received training are more critical of the services provided by their health board. Those with training are more positive about the involvement of voluntary groups and private practitioners in service provision, while allied professionals and paramedics are most positive about locating services within family/community resource centres.

\section{Interviews with Health Board Personne}

Of the 15 personnel selected, 14 were willing and available to be interviewed. They included representatives of 5 separate professions from the nursing and allied professional and paramedic categories. The five professions comprised Nursing, Psychology, Occupational Therapy, Social Work and Counselling. The staff that were interviewed were not intended to be representative of the whole staff of the board, but were those interested in the topic who felt they had something more to offer the debate. The same criteria were applied in their selection as was applied to the selection of the women interviewed. They were distributed throughout the regions, had already indicated that they were willing and interested in being further involved. They also appeared to have more in-depth experience of counselling services. The data collected are presented below by theme.

\section{PERSPECTIVES ON CURRENT PROVISION}

While most were aware of counselling or psychotherapy provision for specific issues within the health board, none appeared to be informed or knowledgeable about the overall provision of services.

\section{Very little really. I work in Adult Mental Health and what is on offer is very limited. None specifically for women. \\ There are a number of family centres that would offer counselling to families and women that we work with. One for each local health board area. Also counselling services for drug users. Adult survivors of Child Sexual Abuse.}

A minority could only comment on their service and were vague about the availability of counselling elsewhere.

\section{They have a counselling service for adult survivors of sexual abuse. Other than that I'd say it's very much on an ad hoc basis, depending on the individuals in the health board.}

Participants also varied in relation to their views of the counselling services available. A number reported that while the service itself was of good quality, access to it and resources allocated were poor. Others were unclear as to the exact nature of what was available.

\section{I'm not au fait with a lot of services at all. I didn't get a pack saying this is where you go if you need this help. I think it's one of those places where you're left and you find out by asking your colleagues.}

Totally inadequate. Totally, abysmally inadequate. When somebody presents there might be a crisis, which might be a window of opportunity for something to be done and if nothing is done it can take years to pull them back out of that. 


\section{BARRIERS}

Respondents identified a variety of other barriers to counselling for women. These included cost, transport, childcare and waiting lists. The most frequently mentioned barrier was lack of information regarding services.

Lack of information. They don't know about the service. Also transport would be a big one in rural areas.

Cost was also referred to as a barrier to women accessing counselling services.

Geographical accessibility - only in the city, poor financial circumstances, it could cost $£ 5$ to get to Cork -

finance is a huge thing. Having children minded, could cost $£ 10$.

Views on the accessibility of counselling services highlighted issues in relation to transport and childcare for women. There was considerable disagreement on how services could be located; for example respondents did not concur on whether or how selfreferrals could be followed through.

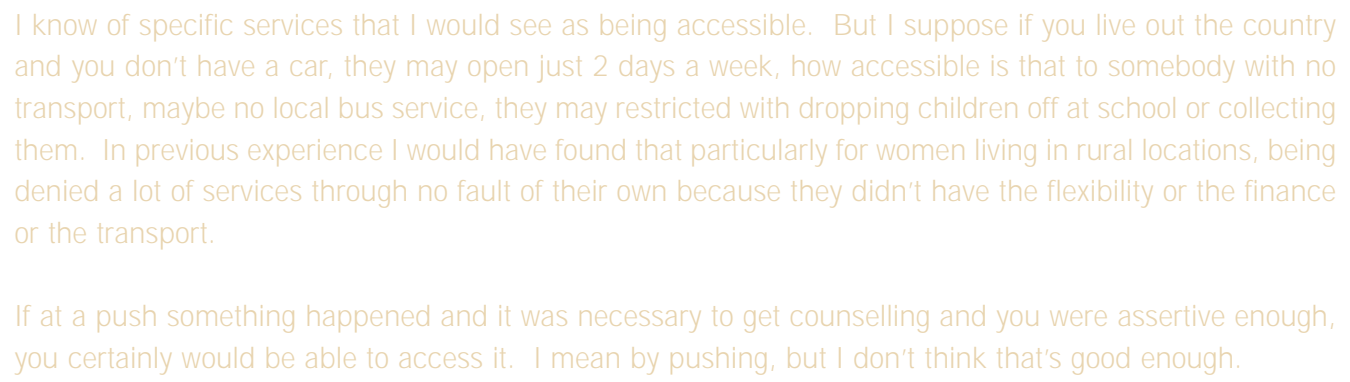

Waiting lists were also referred to as a potential barrier, with views appearing to vary according to the specific service in which the counselling is situated.

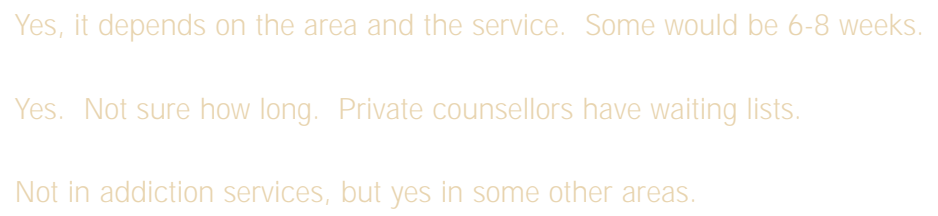

Finally, stigma and fear were cited as barriers to women accessing services.

People must think I'm mad if I go for counselling.

While another interviewee mentioned the perception that some women were not strong enough to start to tackle the issues in their lives.

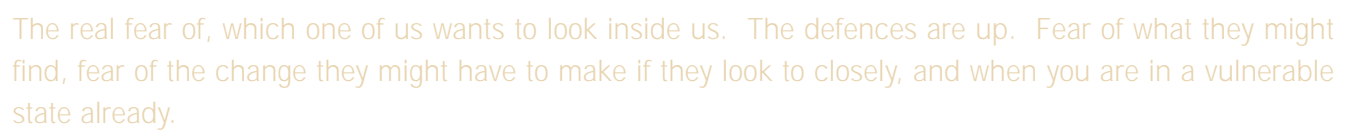

\section{PLANNING}

Interviewees either did not know or were negative about the degree of planning that had gone into the development of services by the respective health boards. Most reported that staff were not consulted during the planning process, but there was some recognition of changes in practice in relation to consultation. 


\section{Staff feedback to managers, which percolates to a higher level and a decision is made. But staff are not directly consulted, it is not round table talks.}

\section{PERSPECTIVES ON FUTURE PROVISION}

In response to the barriers identified respondents suggested a number of alterations to current practice, which could improve matters. These focused on cost, physical location and service promotion or education.

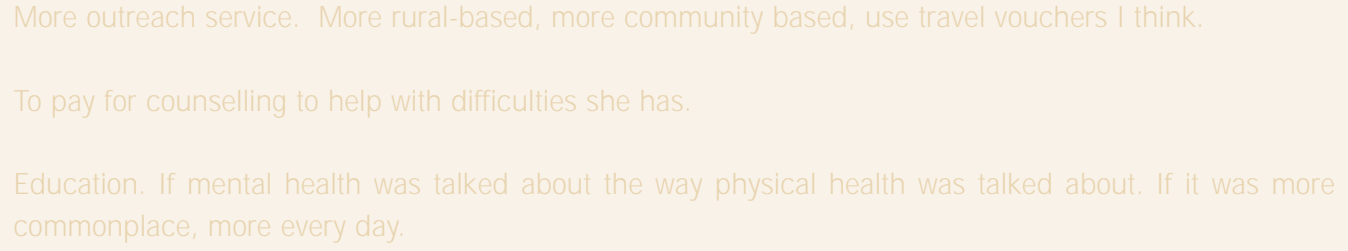

A variety of suggestions were made for the improvement of services. Some were general, relating to accessibility or costs, other were specific, suggesting that the health board employ specific types of counsellors.

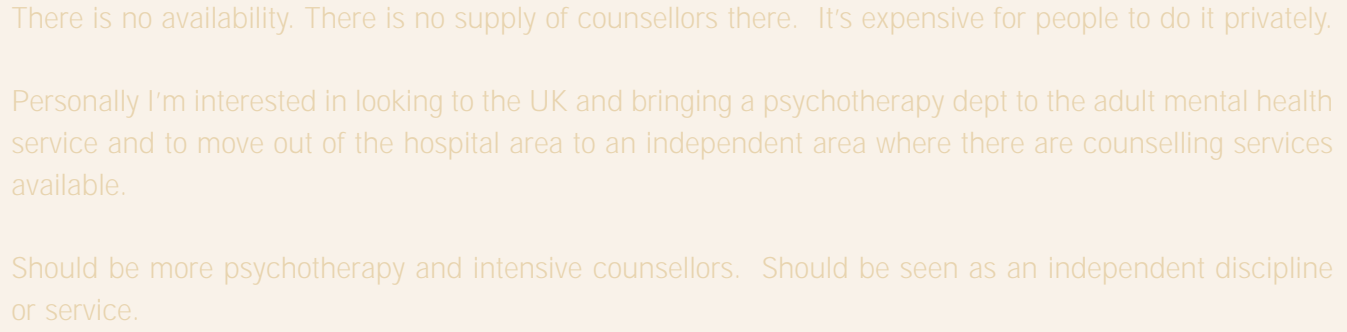

Most respondents reported that they thought that counselling should be provided at no cost to the client, although some qualified that by suggesting that the service be means tested. A couple were concerned at this suggestion and implied that paying for such a service should be part of the therapeutic process.

\section{People should pay if possible what they can pay... some people because they're not paying, they're not putting anything into it ... someone is more willing to engage as well if they're paying \\ Where we are offering a service to women I think it should be provided free, but means tested. I don't think money should be a barrier, and my gut reaction is that should be for all types of counselling \\ When there's a nominal fee like $f 5$ it is good. I am of the belief that when people get something for nothing they really don't value it, you know.}

\section{SUMMARY}

In general, interviewees do not report full knowledge of the counselling or psychotherapy services provided by the health boards within which they worked. Most frequently, they praise the quality of the service provided, but criticise structural and bureaucratic issues, such as access, resources, waiting lists and the service planning process. They identify barriers to counselling for women, most frequently lack of information or a lack of readiness to deal with issues on the part of the women. The suggestions for service improvement include increased availability and easier access, which include the employment of specific types of therapists, creating low-threshold services and reducing cost to the client. 


\section{SAMPLE}

Self-completion questionnaires were sent out to 39 voluntary organisations that receive part of their funding from the various health boards involved in this study. Thirteen organisations that dealt with women and/or counselling were purposively selected from each of the lists provided by the 3 health boards (ERHA, SHB, NWHB). Thus this sample is not designed to be representative of all voluntary organisations, rather it is weighted to reflect those who have an expressed interest in this area.

\section{MEASUREMENT}

The questionnaire (see Appendix 7) mirrored that which was distributed to health board employees and included factual questions such as job title, whether the participants worked predominantly in a rural or urban setting, and the number of years working in their health related settings. Questions eliciting participants' knowledge of counselling and/or psychotherapy and the degree to which they offered counselling and/or counselling skills to their clients were also included. This section also included questions on their own training and accreditation in relation to counselling. They were asked about the types of problems for which they referred their clients to counselling, and about the kinds of organisations or individuals to whom they were referred. Qualitative questions explored whether the participant felt that counselling is a useful method for helping people and whether they felt that their health board offers a satisfactory counselling service. Finally, participants were asked by whom and where counselling should be provided, and how the health boards' counselling service could be improved.

\section{PROCEDURE}

Self-completion questionnaires were sent blind to each organisation along with an accompanying letter and a FREEPOST envelope to facilitate return. The accompanying letter explained the background to the study and requested co-operation from the voluntary organisations in order to include their opinions and ideas in the project. Each organisation was asked to identify one employee or staff member to complete the questionnaire. A reminder phone call was subsequently made to those organisations which had not returned their questionnaires and where necessary further copies of the questionnaire and explanatory letter were sent out. All data received were coded and inputted into SPSS.

The organisations were selected from the lists of community and voluntary groups were purposively selected. Each organisation that received grant aid or other funding from any of the three boards was considered for inclusion. Those who had an expressed interest in counselling or psychotherapy and/or women were included. In total, 20 questionnaires were returned, one was not completed and three indicated that the survey was not relevant to their organisation or their work (response rate $51.3 \%$ ). Of the remainder, most were based in urban areas, although some of these reported that they also worked in rural areas on an outreach basis. This is not surprising given the weight of voluntary activity towards urban centres. Thus this data is considered to represent the views of community and voluntary groups who receive funding from the health board, who have an interest in women and/or therapy and are situated in urban areas. Of those who responded, most were experienced counsellors, more than half with over 5 years experience in their current setting. Almost all had received lengthy training in counselling and were members of professional counselling organisations. While all but three had personally offered counselling to clients, about half had offered psychotherapy and about half used counselling skills and reported that they had referred their clients onto to other counselling or psychotherapy services, usually for specific issues.

Respondents reported that they had referred their clients on, primarily to other community or voluntary groups or to support groups, rather than to private practitioners or health board services. They had referred them for a variety of problems, most frequently marital and relationship difficulties. Almost all reported that they thought that counselling was a useful method of helping people, but only one person reported that the services available from their health board were satisfactory. However, it should be noted that a number reported that they did not know very much about the health board services available.

In relation to the future of counselling service provision, the most widely endorsed service providers were, jointly, private practice and health boards, followed closely by the voluntary and community sector. The most popular service location were family / 
community centres, followed by health clinics and GP surgeries. Respondents were also asked how they thought the service provided by the health board could be improved. The most popular response to this was by increasing resources followed by improving accessibility and availability.

\section{SUMMARY}

Most respondents are experienced staff that have been trained in counselling skills or methods. They work primarily in urban areas and frequently either use counselling or counselling skills with clients. They most frequently refer clients to other community or voluntary groups for relationship problems. Only one respondent thought that the service provided by their health board was satisfactory. The most popular service providers are private practice and health boards while the most widely endorsed location for services is family/community centres.

\section{Professional Organisations}

\section{Method}

\section{SAMPLE}

Eleven organisations were selected for inclusion in this phase of data collection. These were all selected because of their relevance to the subject matter and included the eight most frequently named professional organisations of which health board and voluntary and community sector personnel reported that they were members and the three national accrediting organisations (IACT, ICP and CDoP, PSI). In addition, a response was sought from the Department of Health and Children.

\section{MEASUREMENT}

All organisations were asked to provide any public documentation available. Failing that, informal comment in relation to the following issues was requested; Accreditation, Statutory Registration, European Mobility and the future provision of services. The Department of Health and Children was also asked to provide material in relation to the statutory registration of health and social care professionals.

\section{PROCEDURE}

Initial letters were sent to all of the organisations, outlining the rationale and purpose of the contact and requesting information and comment as outlined above. These letters were subsequently followed up by telephone calls. The format of responses received, and therefore subsequent procedures, varied according to the specific organisation. The format of received responses varied. A number designated a representative to discuss the issues by telephone; others compiled a group response on paper while a smaller number sent existing documentation. No organisation opted for a face-to-face interview.

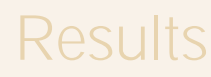

The professional associations were purposively sampled and were selected on the basis that the professionals in the previous section had mentioned them most frequently as organisations of which they were members. In total, responses were received from 8 of the organisations (72.3\%) These included: the Irish Association of Counselling and Therapy (IACT), the Irish Council of Psychotherapy (ICP) and the Counselling Division of Psychology, Psychological Society of Ireland (CdoP, PSI), the Medical Council, An Bord Altranais, the Irish Association of Social Workers, the Irish Association of Alcohol and Addiction Counsellors (IAAAC), the Irish Council of GPs (ICGP) and the National Department of Health and Children. Their responses summarised by theme below.

\section{ACCREDITATION OF COURSES}

The three main counselling/psychotherapy organisations in Ireland are the Irish Association of Counselling and Therapy (IACT), the Irish Council of Psychotherapy (ICP) and the Counselling Division of Psychology, Psychological Society of Ireland (CdoP, PSI): All three organisations have established accreditation criteria for professional training in counselling, counselling psychology and psychotherapy. The various training courses in counselling and psychotherapy throughout Ireland have their programmes 
accredited to at least one of these organisations. The view of the PSI is that accreditation criteria should be sufficiently flexible to allow a new area of professional training to grow and find its own shape, while at the same time the criteria should demand a standard comparable to existing provision.

None of the GP, Nursing or Social Workers associations had specific policies on training, supervision, registration or accreditation of counsellors. They mentioned that the use of counselling skills, rather than counselling per se, is an integral element of their professional work, used in almost all settings and this is reflected in their training syllabi. The ICGP did note and support the call for access to counselling services described in the Plan for Women's Health. However they argued that "counselling" requires definition and the counselling process needs to be clearly regulated.

\section{STATUTORY REGISTRATION}

Statutory registration is a system whereby each individual member of a profession is recognised by a specified body as competent to practice within that profession under a formal mechanism that is provided for by law. At present, statutory registration only covers Dentists, Nurses, Opticians, Doctors and Pharmacists. Social Workers are also accredited by a central agency established by statutory instrument. The Department of Health and Children is currently working with health professionals concerning their statutory registration, an area which was highlighted by all sectors consulted in this research. Statutory registration of counselling and psychotherapy would define exactly what each profession is, prevent people describing themselves as 'counsellors' or 'psychotherapists' without the recognised qualifications and would include mechanisms for regulating training standards, accountability procedures and other relevant areas.

If there were one national body for counselling or psychotherapy it would be relatively straightforward for the Department of Health and Children to work with them on statutory registration. Difficulties arise as there are currently three main bodies with backgrounds in counselling, psychotherapy and psychology, all of which wish to represent their fields at national level. The ICGP state that they welcome the establishment of a national competence authority for counselling and psychotherapy in Ireland and would suggest that this authority should be multi-disciplinary to reflect the multi-disciplinary nature of those practicing in the field of counselling. The IACT would like to join with the other two bodies (ICP and CDoP, PSI) and discuss commonalities between them, in terms of setting, maintaining and monitoring standards. The PSI is involved in current discussions around statutory registration of mental health professionals and is happy with this and report that all indications are positive, although they did mention that progress has been slower than was initially hoped. The ICP state that they are ready to set up statutory registration for psychotherapists. Overall, discussions are still in the embryonic stages, but with all organisations working together it is hopeful that appropriate and acceptable legislation will soon emerge.

\section{EUROPEAN RECOGNITION}

One of the main purposes of establishing a national authority in counselling/psychotherapy is as a result of recent EU directives on the mobility of professionals. The PSI stated that there is disappointment with Directive 89-48, which has not produced the mobility envisaged. They are currently establishing a better framework for a professional qualification in psychology. The framework document is out for consultation, and if approved, there will ultimately be a European Diploma of Psychology, which will be a qualification and will ensure the mobility of accredited Psychologists within and between member states.

This vision of European accreditation is also supported by the ICP, which has strong connections with the European Association of Psychotherapy (EAP) and was involved in the creation of requirements for a European standard. The ICP is the national awarding organisation in Ireland for the European Certificate in Psychotherapy, which sets the standard across Europe, and states that psychotherapy is an independent and scientific profession with a multiplicity of methods.

\section{LOCATION}

The national accrediting organisations did not comment on the location of services. They felt that they were responsible for issues such as accreditation, training, supervision and registration but were not in a position to comment on appropriate location of services. The ICGP recommends that counselling services be located in a variety of different locations in response to established needs. They suggest that as services are likely to be primarily community-based this should include placement of counsellors within the General Practice setting. 


\section{SUMMARY}

Respondents indicate that a flexible system of accreditation of counsellors/therapists is needed to set standards and to facilitate regulation of the profession(s). The need for a national competence authority for statutory regulation of counsellors/therapists is recognised and supported by these professional organisations. Several of the national organisations also work at a European level in the accreditation of counsellors/therapists, which will further facilitate the mobility of their members. 
Chapter Five: Service Providers 


\section{Service Providers}

The views of service providers were investigated with two distinct groups of participants. Both represent management and organisational perspectives on the issues of interest. Senior health services managers and the representatives from community / voluntary groups were selected for inclusion. Their responses are dealt with separately below.

\section{Health Board Managers}

\section{Method}

\section{SAMPIE}

Personnel, who were felt to be central to the operation of counselling services, and women's counselling in particular, were selected for inclusion. These included General Managers of Community Care, Directors of Mental Health \& Addiction Services, Directors of Psychological Services and Principal Psychologists in the participating Health Boards. A total of 15 people were selected throughout the three health board regions.

\section{MEASUREMENT}

A flexible interview schedule was constructed for use with these key personnel. It was designed to obtain their opinions of current services and what they perceived as important issues for counselling in Ireland. Each participant was asked how important counselling is to the health board, and whom they felt should provide counselling within it. Their policies on training, supervision, registration and accreditation of counsellors were investigated. Participants were asked if funding for counselling was a major issue for their health board. Their opinions were also sought on the development of counselling services nationally and the appropriate location of services.

\section{PROCEDURE}

Following selection, letters were sent to each manager outlining the purpose and rationale of the research project. These letters were followed up with telephone calls, a month later, during which respondents were offered the choice of telephone or face-to-face interviews. These interviews were not audio-recorded. The interviewer took notes, with the agreement of the interviewee and finished writing up these notes immediately other the interview itself.

\section{Results}

The health board managers were purposively selected based on their job titles and responsibilities. There were no refusals to participate; however it was not possible to arrange interviews with 4 of the originally selected managers. Seven telephone and four face-to-face interviews $(n=11)$ were completed, representing a response rate of $73.3 \%$.

\section{COUNSELLING PROVISION}

Nine of the eleven respondents detailed their current counselling provision and these were found to fall into three main categories: addiction, sexual abuse and mental health. Counselling is a core treatment modality within both the Mental Health and Addiction/AIDS services. Outreach treatment programmes appear to be very popular and growing in number, particularly in relation to addiction services.

\section{Counselling (is) an equal alongside Psychiatry, Nursing, general Medicine and Pharmacology.}

The Department of Health and Children has established a 'National Counselling Service: For Adults who Experienced Childhood Abuse'. This is a national, free, confidential service located in a community setting within each health board region. As it is a recent initiative, services are only becoming established. 
The health boards offer a variety of mental health services to the general public. Recent developments largely in response to the Report of the National Task Force on Suicide has seen suicide initiatives expand rapidly within the areas of Mental Health, Health Promotion and Public Health. Several health boards have taken a holistic approach to the problem and have put programmes in place to support communities and families where suicide has occurred.

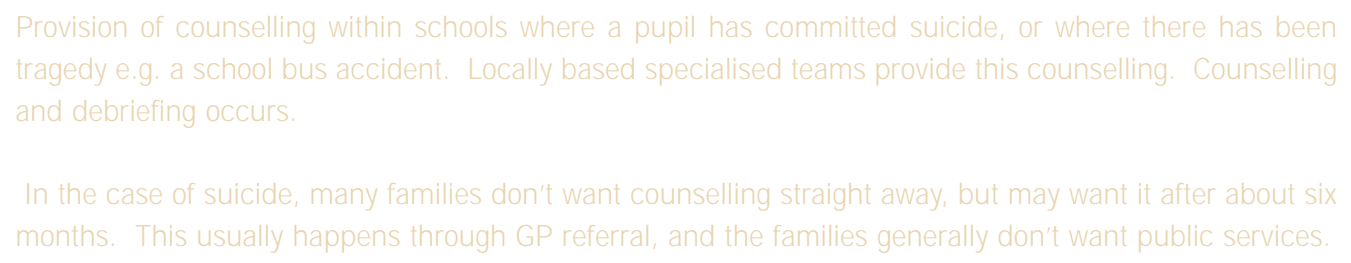

Service providers were very clear about what was provided in their own section, particularly in the three areas mentioned above. Other service providers, for example in the areas of public health nursing and women's health, were more uncertain about what services were available.

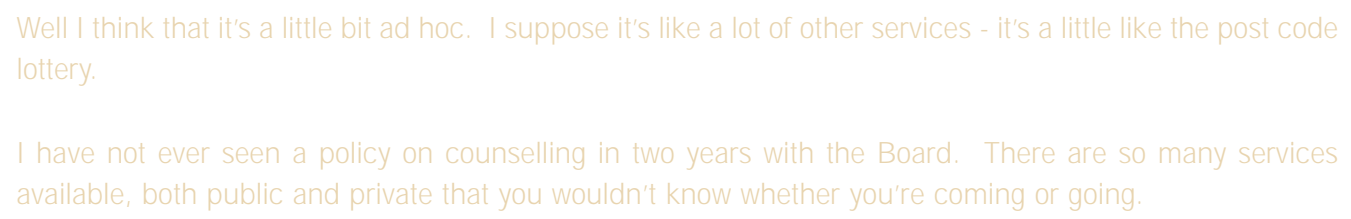

\section{IMPORTANCE OF COUNSELLING TO THE HEALTH BOARDS}

Personnel were asked whether they thought the health board valued counselling as a health strategy and whether it was perceived as important. Although respondents were generally positive they tended to repeat their descriptions of current counselling provision within their section of the health board. Responses were, in general, vague referring to increased provision and commitment in certain areas, but not stating in which areas these were.

\section{POLICIES ON TRAINING, ACCREDITATION AND SUPERVISION}

All of the eight respondents to this question were knowledgeable about the existence of the professional accrediting organisations and in agreement that the accreditation of counsellors was essential. Several also mentioned that community organisations that applied for grants to support counselling would only be supported if they were offering a counselling service that was accredited by the IACT or IAAAC.

\section{There is a number of accrediting bodies in this area, and all of them have greatly increased qualifications and standards and monitoring of practice over the past number of years.}

Within (adult sexual abuse) service (there is) a clear picture of who should provide counselling - they need counsellors with accredited counselling qualification.

Concerns were expressed regarding the accreditation of counsellors working within the voluntary and private sectors and it was stated that this is taken into account when referring patients to these sectors.

The Health Board has always had a concern regarding the accreditation issue. It has been reluctant, in the past, to refer clients to private counsellors because of worries over accreditation.

There was also general agreement that the health board should standardise their requirements on the matter of accreditation, training and supervision and that, ideally, standards should be equal across all health boards.

They need clarity around having a standard regarding professional qualification(s).

The difficulty of recruiting and securing accredited staff also frequently emerged as an issue in this area. 
Respondents were aware that accreditation requires regular supervision and stated that policies needed to be clarified by the health boards or Department of Health and Children on this issue.

There is no overall policy (on registration) - things change when there is money available and a good proposal made - very much ad hoc

\section{DEVELOP MENT AND LOCATION OF SERVICES}

Recommendations for the development of counselling services within each of the respondent's health board regions were discussed. Several respondents mentioned the desire for off-site counselling services away from health board premises, as they are perceived as being generally more accessible and associated with fewer stigmas.

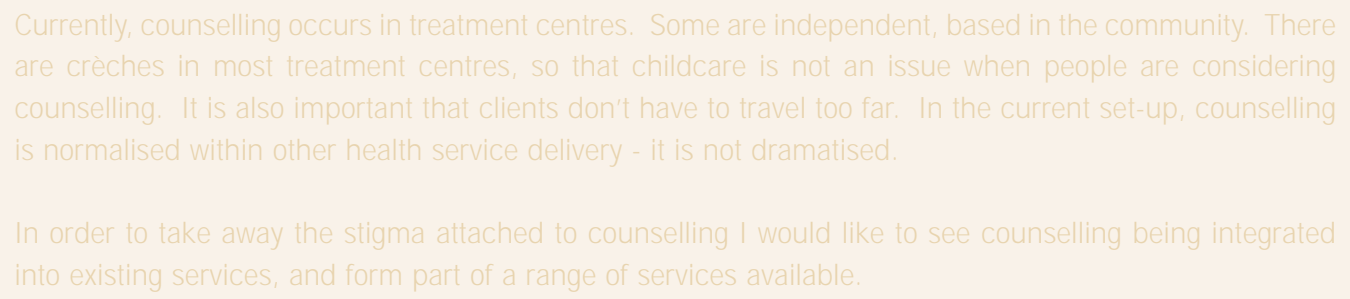

The development of outreach services was also frequently mentioned. GP based counsellors were mentioned in relation to both generic and specialised services. One health board detailed a pilot scheme, which has been established in which a counselling nurse works with 5 GP practices. An evaluation of this scheme has not yet been completed.

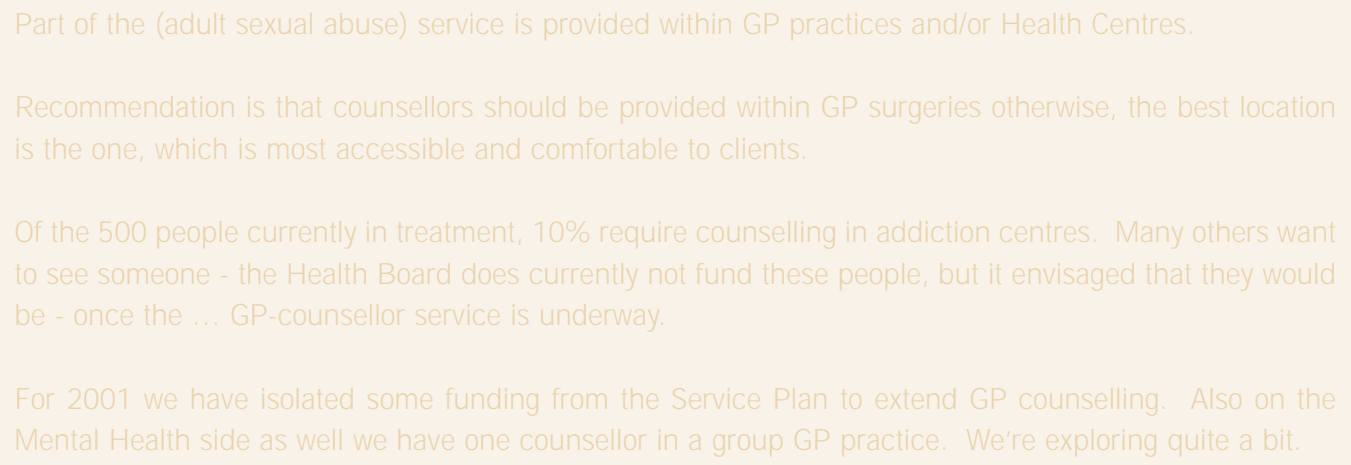

Apart from the recognition of the need for more community located services there was little vision regarding future service provision. Some suggested taking a more holistic approach, amalgamating services and tackling the underlying issues of the problem in question with generic counselling.

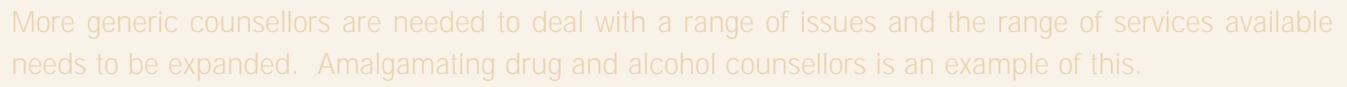

Others reported the interest being shown by nurses in being trained in counselling. 
Several respondents also mentioned the demand for and advantages of brief therapy.

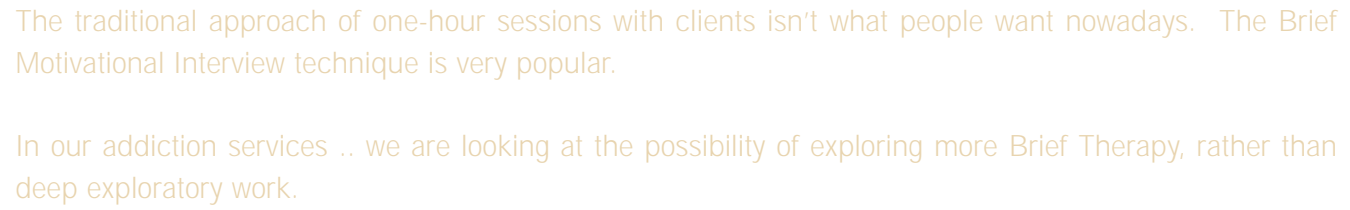

\section{WHO SHOULD PROVIDE COUNSELLING SERVICES?}

Few respondents noted the involvement of the community/voluntary sector in the provision of counselling services. Those who were supportive, welcomed the contribution of the voluntary sector and felt that the two sectors work well alongside one another. They noted that counselling should be on offer from more than just the health board and that funding should be made available for counselling provision within the community sector.

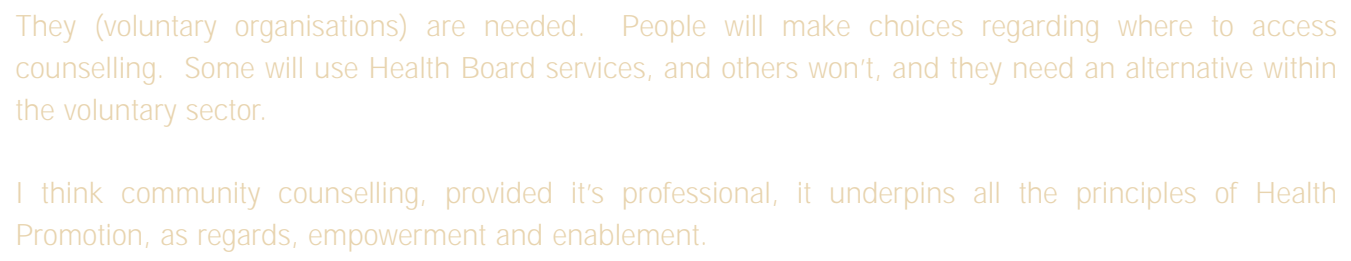

However, the general consensus was that the community sector is not a substitute for the public sector.

Only one respondent mentioned private practitioner's role in the development of services. The issue of accreditation was also raised here.

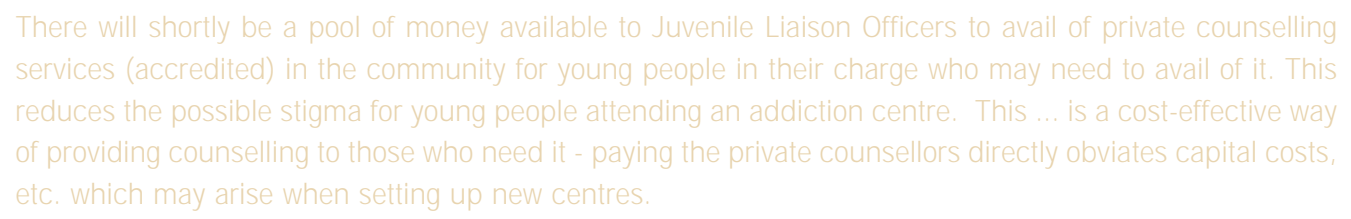

\section{PHYSICAL LOCATION}

Several respondents mentioned the appropriateness of premises for the delivery of counselling services. Disabled access and soundproofing were mentioned in addition to issues of physical distance from clients, in terms of bus routes, etc. The location of this building within other services was noted as important for the reduction in stigma and again, for accessibility.

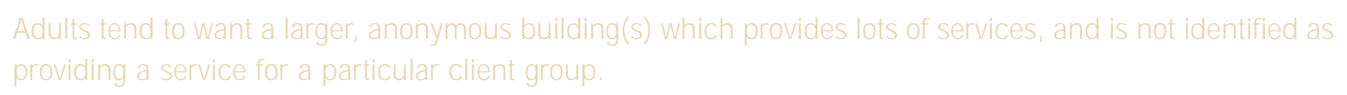

\section{FUNDING}

Responses were generally positive regarding the funding of counselling services. There has been a welcome increase in funding over the past number of years. More negative views were expressed on the issue of poor salary scales and the difficulties that this causes when trying to recruit staff.

Staff retention area is a major issue. We're losing skilled individuals who can have higher standards somewhere else. In the past for staff who wanted to develop their skills, there was a 40\% refund scheme on successful completion of programme. That has now been revised to $100 \%$ refund. For counsellors the motivators aren't necessarily financial.

One of the problems we have is actually filling all the posts we have approved. Certainly we could buy more counsellors if they met the criteria. We now have our own in-house training programmes, so we can grow our own counsellors to an extent. 
Currently there are a number of permanent posts vacant and there is also a need to create more positions as the demand (customers) is there. People don't work in the public service for money - it is vocational.

\title{
BARRIERS TO PROVISION
}

Throughout the interviews, barriers to provision were expressed in response to development, funding, location and so on. The need for childcare facilities were frequently mentioned along with the stigma associated with accessing mental health services, availability and comprehension of information and transport issues.

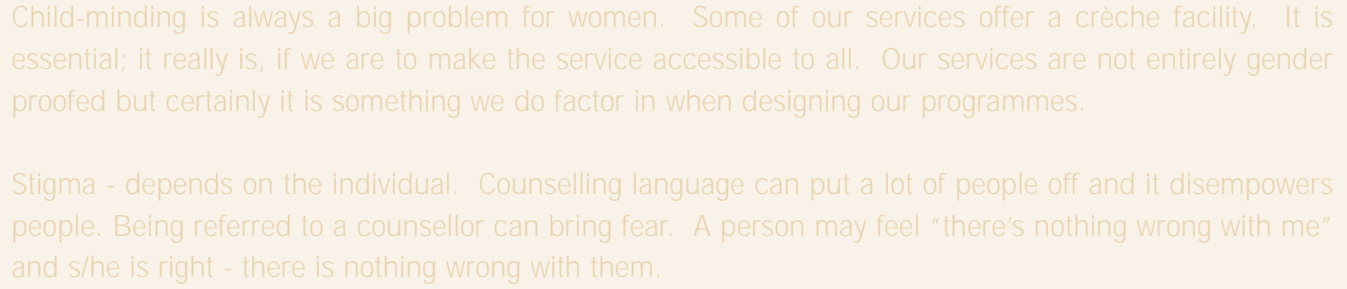

Transport is more of an issue, for both men and women, mainly due to financial constraints.

\section{OTHER PERTINENT ISSUES}

Respondents were also given the opportunity to elaborate on any pertinent matters in relation to women and counselling within the health board. The main problems that were mentioned in regard to women and counselling were drug abuse, sexual abuse, violence, bereavement and post-natal depression.

\begin{abstract}
The one thing as regards counselling is that it can be the first point towards prevention of what would otherwise have to become a mental health illness before it would to be treated by psychiatric services. I think that's key.

Also, women are therapeutised to death. Counselling needs to be seen more as personal development rather than treatment of a pathology. It should be incorporated as an integral part of other things that are ongoing. Often counselling for women is hyped when it is for issues such as rape or CSA. The range of therapies which are on offer are far broader than that. A large number of women who use services often get huge benefit on the personal development side of things and opens up avenues.
\end{abstract}

Needs of men and women are different. Men find it more difficult to articulate their needs and find it less comfortable.

\section{NEED VERSUS PROVISION?}

Many of the respondents expressed fears concerning ongoing demands for counselling, with several afraid that it would become an issue of insatiable need.

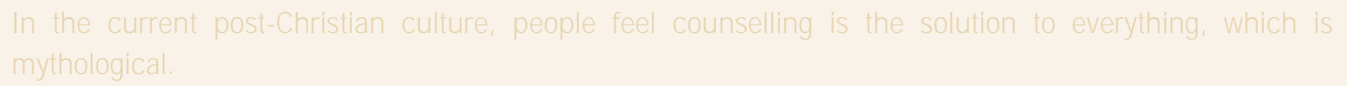

However, others were more optimistic that only those people that needed the service would request it.

\section{SUMMARY}

Interviewees stress that health boards need to standardise their regulations concerning the professional accreditation, training and supervision of counsellors/therapists. They recognise that there is a need to increase the physical accessibility of services and reduce the stigma associated with availing of counselling. This could be addressed through the provision of off-site and outreach services. Recent increases in funding of this area are welcome but low salary scales within public service remain an issue. 


\section{SAMPLE}

Lists of organisations that received some funding from each of the three health boards were obtained. Ten organisations were randomly selected from each board list. An additional 60 organisations which were obviously relevant to women's counselling (e.g. Rape Crisis Centres, Counselling Centres), were also purposively selected for inclusion. In total 90 projects or organisations were initially sampled.

\section{MEASUREMENT}

The organisations were invited to make written or oral reports on a variety of issues related to counselling. They were asked their policy on training, supervision, registration and accreditation of counsellors, their opinions on the development of counselling, the mobility of counsellors within and between EU member states, and their views of the appropriate location of counselling services within Ireland.

\section{PROCEDURE}

Introductory letters were sent to individual organisations. A second letter, that was sent one month later, included a reply slip on which organisations had the option of indicating whether or not they felt the study was relevant to them. Where necessary, these were followed-up by telephone calls. Responses were received in the form of written submissions and telephone contact during which their opinion on the topic was noted and later transcribed for qualitative analysis. A small number of organisations sent relevant literature that was also analysed.

Managers from the community and voluntary sector were randomly selected from lists of funded groups. This sample was supplemented by purposeful selection of organisations based on the activities of the organisation for which they worked. Five organisations had moved and were not traceable, while 34 organisations responded (response rate of $40 \%$ ).

\section{PROVISION OF SERVICES}

The provision of services within these representatives of the community/voluntary sector varied enormously. Fourteen of the organisations offered a counselling service, and/or provided listening services, helplines and/or facilitated the organisation of selfhelp groups. Many also mentioned that staff frequently used counselling skills in their everyday contact with clients. The majority of organisations that responded specialised in one specific area, e.g., sexual abuse, mental health, schizophrenia, Multiple Sclerosis, deafness. There were also several generic counselling services and women's centres included in the sample.

\section{TRAIN ING AND ACCREDITATION}

$\mathrm{N}$ ine of the organisations stated that their counsellors were accredited with an external professional organisation, four mentioned their own national accrediting network and one mentioned that the counselling was provided by qualified Social Workers who are supervised by a Psychotherapist.

They all felt that appropriate training and supervision were essential for quality counselling provision and provided detailed information about the supervisory protocol of their organisations. 
Several organisations mentioned their commitment to the provision of ongoing and additional training for their staff.

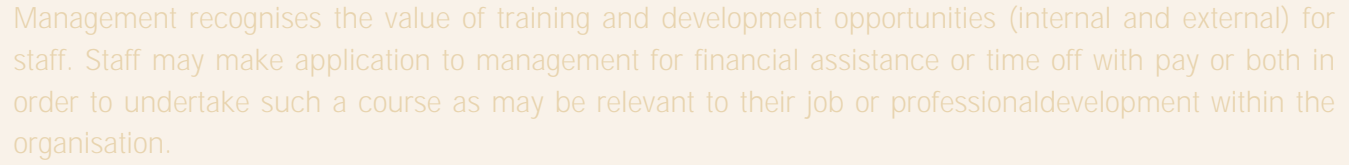

\section{RECOMMEN DATIONS}

\section{Government Action}

Several organisations felt quite strongly that the Department of Health and Children should be taking a more pro-active, positive response towards the recognition of counselling as a profession. The general opinion was that there is a need for legislation to deal with counselling services and private counsellors. The lack of restrictions or accountability on setting up a practice was detailed as a matter of concern.

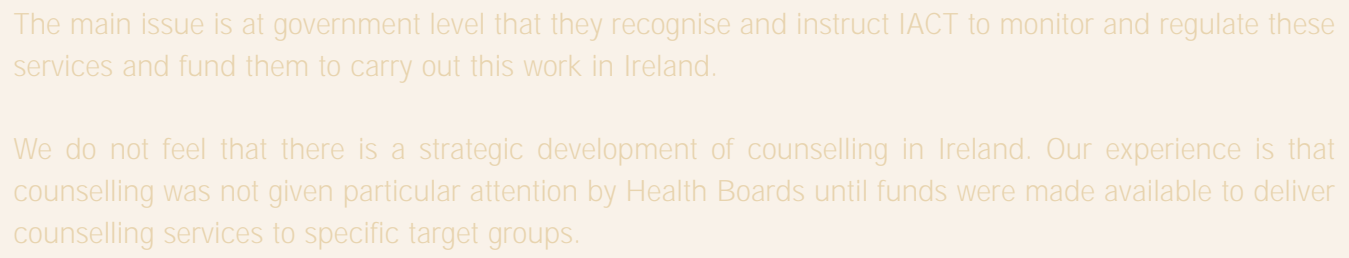

Several suggestions were proposed under the theme of funding. These included counselling costs being covered by private health insurance companies, employee assistance schemes, health board funding to community organisations, possibly with the secondment of counsellors out to organisations, and free provision to medical card holders.

\section{Remuneration (to community organisations) from the Health board is important}

That it should be available to clients like all other health services, be recognised by the government that fee paying clients should be able to claim for it either through BUPA, VHI or Employee Assistance Schemes at work.

\section{Difficulties regarding accreditation}

As a large proportion of the organisations had counsellors accredited to professional organisations, very few expressed any concern that enforced accreditation could impact on their organisation. One organisation felt quite strongly that potential difficulties could arise particularly in rural areas where accredited training and supervision was very difficult to locate (restricting the services that could be offered as counsellors themselves have to be regularly supervised as part of their registration agreements).

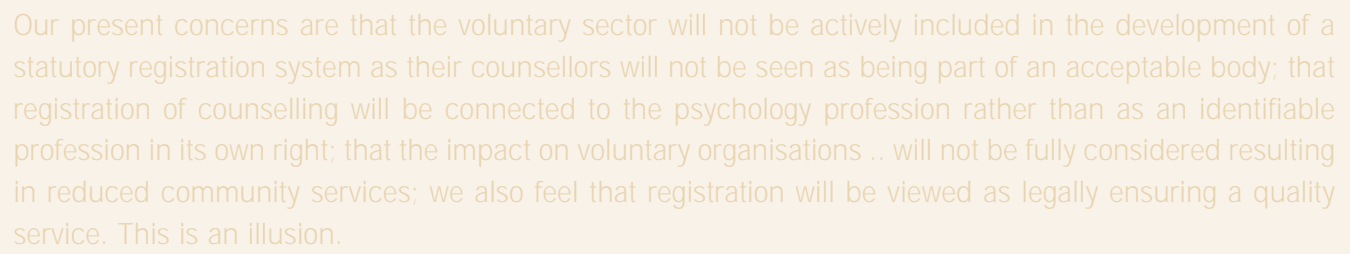

\section{LOCATION}

There was overwhelming consensus that there should be a mixture of public and private provision of services. The need for the public to have a choice was emphasised. The requirement of an appropriate physical space for service provision was also mentioned.

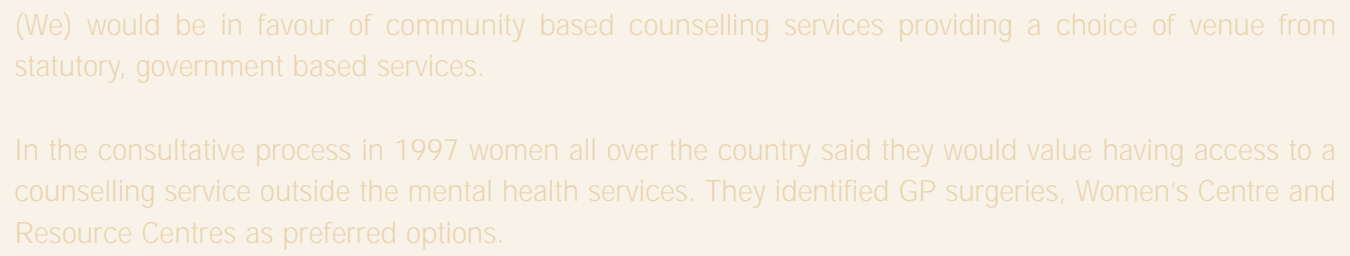


The feed back that we have received from our clients is that they found it easier to avail of our services when

there were other service providers operating out of the building.

\section{EUROPEAN PERSPECTIVE}

Participants were asked if they were concerned that the changes in EU legislation regarding the mobility of counsellors within and between member states would impact on their organisation.

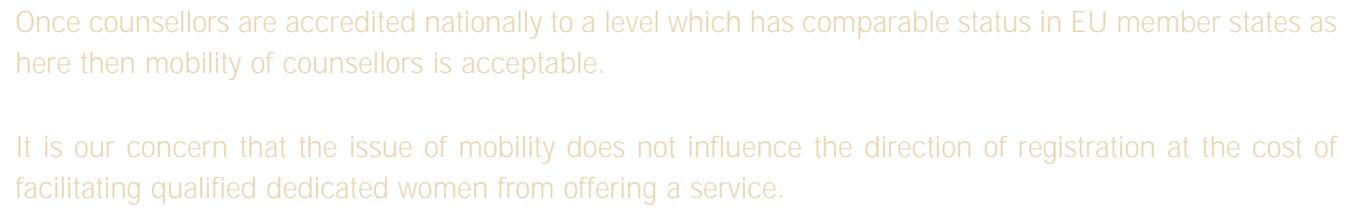

The majority of the organisations did not consider that EU legislation regarding the mobility of counsellors within Europe was an issue for them, it seemed rather remote from their basic needs.

\section{SUMMARY}

Respondents agree that good quality; continuous training and supervisory protocols should be available within all organisations. These organisations are not particularly concerned over possible enforced accreditation of counselling; more concern was expressed over the availability and provision of appropriate training and supervision, particularly in rural areas. There is a general consensus that counselling should be as available as other health services within the public health sector and should be available to those eligible for GMS and those with private health insurance. There should be a mixture of both public and private counselling services. The public should have a choice. 
76 
Chapter Six: Discussion 


\section{Overview of the Study}

This study investigated the views of key stakeholders regarding the provision of counselling and psychotherapy services in Ireland. Specifically, it was designed to assess experiences of counselling services, perceptions of accessibility and views on how effective services could be provided in the future. In order to address these aims data was collected from women in the general public, women who had personal experience of counselling or psychotherapy. It also came from health service and community based professionals who directly provide and refer women to services as well as the organisations, which represent these professionals. Finally, data were collected from management representatives of health boards and the voluntary and community sector. The data collection included both self-completion questionnaires, interviews and secondary data, which comprised of written materials collected from service providers and professional organisations. The key themes that emerged from the data analyses are discussed below.

\section{Data quality}

Sampling techniques and response rates vary across samples and the quality and generalisability of the collected data should be considered within that light. Table 15 summarises the main features of these procedures.

\section{Table 15: Sampling and response rates for each phase of data collection}

\section{Sample}

Women in the

Electoral Register

\author{
Women with \\ Knowledge of \\ Counselling \\ Health Board \\ Employees \\ Health Board \\ Employees
}

\section{Staff in Community / \\ Voluntary Groups \\ Professional \\ Organisations}

Health Service Managers

Voluntary / Community Sector Managers

\section{Sampling Frame}

Electoral Register

(a)

Respondents to the

questionnaire study, who

indicated that they would

be willing to participate

Personnel held lists in the

three board areas

Respondents to the

questionnaire study who

were willing

Lists of organisations

funded by the health boards

Organisations of which the

employees above were

members

The IPPA yearbook

Lists of organisations

funded by the health

boards

\section{Sampling Technique}

Two stages a) urban / rural DEDs then b)

simple random selection

of women in each area.

Purposeful

$100 \%$

Simple random

Purposeful

$93 \%$

Purposeful

Most frequently

mentioned organisations

Purposeful

Simple random selection board area, supplemented by those with known involvement. 
The following sections describe the responses from across the various sub-studies in relation to key areas of interest, these comprise; context, information and help-seeking behaviour, knowledge and experience of counselling, counselling service provision and the future provision of counselling and psychotherapy services. Where relevant these findings are compared to those in the literature. However, it should be noted that for many of the issues being examined here, no prior comparable work is available for this purpose, and most of what still exists may not be relevant to the Irish situation.

\section{Context}

The data from the questionnaire survey of women illustrate that they generally perceive themselves as healthy and possessing a good quality of life. Other important contextual information collected confirm that the vast majority of women report that they have a GP and that there are similarly high levels of depressive symptoms among both urban and rural women. Nevertheless, there are important differences between urban and rural women. Of particular interest are the issues of isolation, transport and access that divide the women. Rural women are further away from key services, have less access to transport, are less likely to be in employment outside of the home and are more likely to be GMS eligible. These findings confirm the specific issues that need to be addressed for service provision to rural populations. Where relevant differences have emerged between these groups they are discussed below.

Information is often the first port of call for women who feel they need help. The importance of accurate, reliable and appropriate information should not be overlooked (Marcella \& Baxter, 1999). However, in order to improve the quality of information available to potential service users, it is important to know where women go to source help and information. These data could be particularly useful in the dissemination of relevant educational materials and the relative needs of the various groups must be considered.

\section{Women}

The women who responded to the questionnaire were most likely to report that they received their health information from their GP, followed by family and friends and the media / internet. This concurs with the SLÁN survey (Friel et al., 1999a) in which GP, media and family/friends were the most common source of health information. However, it contrasts with Barry (1994) who explored the perceptions and implicit beliefs of mental disorder held by members of a rural community in the West of Ireland. In her study, apart from personal life experience, the prime source of information concerning mental health matters was television or radio, with few of the respondents having read anything on the topic. The reason for this contrast in findings could be that Barry's study focused specifically on mental health whilst the current and the SLÁN surveys asked about general health information (including mental health).

There were a number of interesting differences between urban and rural women in relation to sources of health information. Urban women reported being more likely to source such information from a variety of sources, including family and friends, workplace, health boards and Well Woman clinics. These may be explained by their being more likely to be in paid employment outside the home and their closer proximity to the other services and resources than the rural women. Women with medical cards were more likely to obtain their health information from their GP and health board than those without medical cards and were less likely to report the workplace as a source of information. This fits well with the characterisation of the medical card as an indicator of social status and health service utilisation. Medical cardholders are likely to be more frequent service users and less likely to be in employment outside the home. They were also more likely to report sourcing information through family and friends and the media/internet. This is more difficult to explain but may reflect their relative higher access to the media during the day or their increased reliance on social networks as compared to those in employment or in higher social class groups. The finding that women who have experienced counselling and those who were found to be depressed were more and less likely respectively to access health information from family and friends again illustrates the pivotal role that such social networks play in the distribution of appropriate and relevant information.

Women were asked to whom they had sought help from for specific problems, e.g., depression, and relationship difficulties. A high proportion of women had turned to anyone for help, with family/friends and GP being popular sources of help for a wide range of problems. When asked where they would go to obtain information on counselling services the survey respondents were most likely to report that they would go to their GP, followed by to family and friends. This data concurs with the findings of Corney (1990), O'Hare \& O'Connor (1987) and Barry (1994) in relation to the central role of the GP as a source of help for women with emotional 
difficulties. However, Barry (1994) also reported that the Psychiatrist was cited as the second most likely source of help, whilst respondents in this current study did not report considering other professionals such as Psychologists, Counsellors or Social Workers. In their study of four rural communities in Ireland, Barry et al. (2000) reported the percentages of respondents who would advise a person with depression to take various courses of action. These comprised, in order, talking to someone close followed by contact with the GP and seeing the Psychiatrist. A similar pattern is found in the current study.

Where significant differences emerged between the women from urban and rural areas, rural women were less likely to report seeking help for relationship difficulties from family or friends or counsellor / therapist and more likely to have sought help from noone. In addition they were less likely to have asked for professional help for depression or anxiety. This mirrors the findings in relation to the information above, and may be a reflection of the lack of accessibility of these services and resources to rural women (Byrne et al., 1991; Byrne \& Owens, 1996). Those with medical cards were also less likely to have sought help from family and friends in relation to bereavement, relationships or anxiety as well as less likely to have sought help from their GP in relation to reproductive health, but more likely to have accessed their GP for relationship difficulties. This presents a more complex pattern and contrasts with the findings above in relation to sources of health information. Those who had experienced counselling were more likely to report having sought help from most sources for most problems, which may indicate that the experience of counselling facilitated these respondents in their help-seeking strategies. Alternatively this could reflect a more generalised effect, where these respondents could be characterised as multiple help-seekers, irrespective of previous counselling experiences. Those who were depressed or psychologically distressed based on the CES-D or the GHQ-12 were more likely to report having sought help from Psychiatrists or Psychologists for anxiety or depression. This provides some validity for these measures of psychological distress and depression in this context as the symptoms of depression; feelings of worthlessness, excessive guilt and lack of motivation could deter these individuals from seeking help.

The self-help literature suggests that self-help groups are seen as especially useful in the treatment and management of addictive behaviours and mood disorders (Nic Gabhainn, 1999) and respondents were asked if they were members of such groups. There was a marked difference between those urban and rural respondents who were members of a self help group (28\% \& 15\% respectively). However, as weight-watchers was included in this category, and meetings are less likely to be held in rural locations (due to low membership numbers) this could be an explanation for this difference. Although a substantial minority reported being members, participants in the survey of women rarely reported self-help groups as sources of help.

\section{Conclusion}

The importance of the GP and social networks in sourcing health information and help seeking behaviour has been clearly demonstrated (O'Hare \& Connor, 1987; Friel et al., 1999). What is of particular concern is that those participants who were most likely to require help (those who were depressed) were less likely to use social networks to sourcing information. This may reflect that they do not perceive this as an available source of help; possibly as a consequence of depression or indeed that this source does not exist for them. It should be noted that a considerable proportion of women reported that they did not seek help from anyone - 'no-one' was the third most common response given by women in the sample. The findings of this survey were confirmed in the interviews with women, most of who also said that they had accessed counselling services through the advice of the GP or their family and friends.

\section{Knowledge and Experience of Counselling}

\section{Perceptions of Counselling}

Counselling within Ireland has grown along with the development of therapies and training that are now available in Ireland (O'Leary, 1990 b). This in itself can cause confusion in determining the services that are available and in identifying the most suitable for one's personal needs. For example, many members of the general public have difficulty distinguishing between the terms counselling and psychotherapy and even within the academic literature, the boundaries between the two terms are blurred. 


\section{Women}

J ust under half of those who responded to the questionnaire reported that there was a difference between psychotherapy and counselling. However, while a fifth of the respondents from the questionnaire survey of women had sought and received counselling, and the vast majority of those reported that they found it helpful, only a small proportion knew what type of counselling/therapy service they had accessed. This pattern was also displayed in the face-to-face interviews with women, the majority of whom did not know or could not remember what kind of therapy they had received. Of the questionnaire sample, most knew somebody who had attended for counselling or psychotherapy. In relation to perceptions of counselling, most thought it could be useful, would recommend it to others, and indicated that they would attend for counselling or psychotherapy. Responses show that respondents were generally positive on the usefulness of counselling for others and themselves.

Rural women were less likely to have experienced counselling themselves or to report knowing anyone who had attended counselling. In addition, rural women were less likely to report that they thought that counselling could be useful. This could be due to access issues (Byrne et al., 1991) and those with less experience or knowledge being less likely to attribute usefulness to counselling. Medical card holders were less likely to be positive about counselling, they were less likely to report that they perceived counselling as useful, would suggest it to others, knew someone who had experienced counselling or would consider counselling for themselves. This pattern cannot be explained by lack of direct experience with counselling, but may be influenced by knowing few people who had received counselling. Those who had direct experience of counselling were more likely to be positive on every parameter, which again would support the hypothesis that experience is associated with more positive perceptions.

Those who were psychologically distressed were more likely to have received counselling or psychotherapy themselves, a pattern which fits with the data above on help-seeking behaviour. However, the majority of those receiving counselling are neither psychologically distressed nor depressed, and that only a minority of those with such symptoms have received counselling. This lack of help-seeking behaviour in the psychologically distressed and depressed women in this sample may be a consequence of the symptoms of depression; feelings of worthlessness, helplessness, lack of motivation, etc. It is vital that information on counselling provision is widely disseminated so that information for identifying these disorders and possible sources of help are readily available for the families, friends and health professionals who are likely to be in contact with these women. It should also be recognised that the reason that many of those that have received counselling are not psychologically distressed or depressed may be because the counselling worked as a preventive measure for these women, helping them to develop coping skills and self-assertiveness and thus preventing the development of more serious problems.

\section{Health Professionals}

The vast majority of health board and community or voluntary service personnel knew that there was a difference between psychotherapy and counselling and they perceived counselling as a useful method for helping people. However, while perceptions of counselling and psychotherapy were generally positive, both in the abstract and in relation to potential service utilisation, a lack of clarity in relation to specific types of therapy was identified. This finding has implications for clients if staff are unable or not trained to give appropriate advice on matching problems to the therapy type or provider, or to evaluate information on the counselling qualifications of service providers.

\section{Information about Counselling}

Having a high regard for counselling as a useful technique for helping people with their problems, is not sufficient if you do not know where to go to access these services. Nor is it particularly useful if you wish to locate the most appropriate service for yourself or indeed, in the case of a health professional or voluntary group, for a client or patient.

\section{Women}

Over three-quarters of the women surveyed did not know whether counselling or psychotherapy is available from their health board. Those potential service users who were depressed were less likely to report that counselling was available from their health board. This may reflect a pattern specific to the psychological distress and depression that these scales are designed to assess.

\section{Health Professionals}

While most of the health board personnel were aware of counselling or psychotherapy provision for specific issues within their health board, none appeared to have an overall perspective. A minority could only comment on their own services and were vague about 
the availability of counselling elsewhere. Most of the community/voluntary personnel responded that they did not know much about what the statutory services provided.

\section{Service Providers}

Health board service providers were very clear about what was provided in their own section, particularly those working in the areas of sexual abuse, addiction and suicide awareness. However other service providers were more uncertain about what counselling services were available for the general public.

\section{Conclusion}

Knowing others that have received counselling appears to increase respondents perceptions of the usefulness of counselling, the likelihood of recommending it to others and possibly attending themselves. The lack of information or knowledge in relation to available services is most notable among the women surveyed, but is also an issue for the health professionals. It is to be predicted that the service providers would be more informed, being involved as they are in service planning and delivery. Even so, it should be noted that many were unclear about services available outside of their own direct areas of work. This may be a result of a simple lack of information about these services or it may reflect the way services have developed in an ad hoc manner in Ireland.

\section{Counselling Service Provision}

\section{Typical Problems}

Women have a higher incidence of certain psychiatric disorders, particularly depression and anxiety (Breslau et al., 1995). The few studies that have analysed the reaction of specific subgroups to counselling suggest that particular groups may benefit from counselling more than others. The characteristics of people who have been found to particularly benefit include women with relationship difficulties, with low levels of social support and with a diagnosis of depression (Corney, 1984), as well as those who have been emotionally distressed in the past (Catalan et al., 1991). It has been illustrated (Cummings et al., 1993) that specific focused counselling interventions can improve patient care and health gain as well as improving patient satisfaction and cost reductions.

\section{Women}

Of the survey respondents who had attended counselling, the most commonly cited problems were marital or family difficulties, followed by depression, self-esteem or personal issues and then anxiety/panic attacks. Other problems mentioned included bereavement, and physical disability/illness. This mirrors the pattern within the interview data from women where the three most common problems reported were relationship difficulties, personal issues and addiction problems. While these are the specific issues volunteered by the women surveyed and interviewed, it is clear that these problems are not easily divisible, e.g. example, addiction, depression or anxiety can often be associated with relationship and personal difficulties.

\section{Health Professionals}

The majority of referrals made by health board personnel were made to health board professionals followed by support/self-help groups. The most common problem for which referrals were made was bereavement, followed by drug/alcohol abuse, marital problems, and anxiety/panic attacks. This pattern differs slightly to the problems that women cited, but this may be explained by the fact that only a minority of women in the questionnaire survey or the series of interviews that had attended counselling had been referred by an employee of the health board.

Those health board personnel who had been trained in counselling or psychotherapy were more likely to report that they referred clients to therapy for marital problems that those personnel who had not received training. This may reflect that training has improved either their knowledge of facilities available or else their ability to identify signs of marital distress with their clients.

The employee groupings of paramedics/allied professionals and nurses/nurse managers reported that they were more likely to use counselling skills with their clients than doctors/dentists. However, this is clarified when you examine referral patterns as doctors / 
dentists are more likely to have referred clients onto professional services, typically for drug/alcohol abuse, anxiety/panic attacks, sexual abuse and eating disorders than the other employee groupings.

The community sector respondents reported that they had referred their clients on, primarily to other community or voluntary groups, rather than to private practitioners or health board services. The community personnel respondents had referred their clients for a variety of problems, most frequently marital or relationship difficulties.

\section{Service Providers}

The main problems as cited by the health service providers for which women sought help were drug abuse, sexual abuse, violence, bereavement and post-natal depression. Counselling was reported to be a large component of both the mental health and addiction/AIDS health board services. Outreach treatment programmes are growing in popularity and number, particularly in relation to addiction services.

The different patterns of reported referrals are likely to be explained by the combination of different service providers operating in this arena. Nevertheless, the key issues that clients are presenting with are similar to those reported elsewhere. There is however no guarantee that this will be maintained and as services targeted at specific client groups continue to be developed by statutory services, the presenting patterns may indeed change.

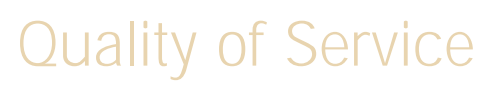

The services currently provided have often developed in an ad-hoc manner. As has been reported earlier, that it can be difficult to source information about services and many respondents were unsure as to availability and other access issues. Nevertheless, this does not necessarily preclude quality of service. It is important that the views of all stakeholders, not just service users, are taken into account when reviewing such service parameters.

\section{Women}

The women in the questionnaire survey who had received counselling or psychotherapy were satisfied with the service that they had received, in that over three-quarters said that they had been helped. There were no differences between any of the sub-groups of women on this issue. Most of the women who were interviewed concurred and reported that they were satisfied with their experience of therapy. This is a promising pattern of response, which should be taken into account during the planning of any future service provision. However, as Conlon (1999) argues, interpreting quality merely in terms of consumer satisfaction is excessively limited, since consumers, by virtue of their lack of technical knowledge, may be satisfied with a service that is of inferior technical quality.

\section{Health Professionals}

A very small proportion of health board personnel felt that their organisation offered a satisfactory counselling/therapy service. Those who had been trained in counselling or psychotherapy and those who were from the allied health professions were more likely to report that the service provided was unsatisfactory. Of the community personnel respondents, only one reported that the service available from the health board was satisfactory, however many explained that they did not know very much about the services provided by them.

\section{Service providers}

The service providers were generally positive about the services that they supply and discussed the development of new services as well as issues of in-service training for relevant staff.

Women with experience of counselling or psychotherapy were, in general, satisfied with their experiences. However, health professionals were considerably less positive about the services being provided and those who were more experienced were least positive. This apparent anomaly is most likely explained by the women responding with reference to the process of counselling and the interactions with the counsellor or therapist, while the health professionals may be more likely to focus on the physical aspects of service provision, such as waiting lists, ease of access, cost and so on. 


\section{Barriers to Counselling}

While it is clear that women are generally positive about the counselling process and report willingness to access services, there remain potentially important barriers to be faced by those actually seeking help. These are key factors which should be taken into account by service providers, and the relative weight assigned to them by potential service users, need to be carefully considered.

\section{Women}

When the respondents to the questionnaire were asked to consider potential barriers that would deter someone from attending counselling, being afraid was the most frequent response, with stigma and cost coming second and third and not knowing where to go a close fourth among women who responded to the questionnaire. All these barriers were cited by more than half of the respondents. Moran (1977) reported that the stigma attached to 'mental illness' was greater for rural Irish respondent than their urban counterparts, while Barry (1994) suggested that 'mental illness' still held a certain amount of stigma for members of her rural sample. Barry et al. (2000) reported that almost two thirds of her respondents did not identify any barriers to seeking professional help for themselves. Nevertheless, a minority of those surveyed (12\%) cited social stigma surrounding mental health services, $4 \%$ cited distrust of the services, while $4 \%$ cited not recognising the need for help as possible barriers.

Rural women were more likely to report that distance would be a barrier to the receipt of counselling, which can be explained by the earlier data on location and transport (see Appendix 3). However, they were less likely to report that being afraid to face up to the problem or cost would be issues as compared to their urban counterparts. As indicated below, experience of counselling is associated with concerns over cost. Given that rural women have less experience of counselling, either directly or indirectly, this may explain this finding. It should be noted that contrary to the literature, rural respondents were not more likely than the urban respondents to cite stigma as a barrier in the current study. Medical cardholders were less likely to report stigma as a barrier, which may be related to their greater general level of health service utilisation.

Those women in the questionnaire survey that had received counselling were more likely to report that cost, not knowing where to go, shame, distrust, time and counselling not being perceived as worthwhile were potential barriers as compared to those women who had not received counselling. This suggests that the experience of seeking and paying for counselling increases your perception of how difficult it is to access, how costly it can be and how the perceived views of others can influence uptake of services. Those who were depressed were more likely to report that cost was a barrier than those who were not depressed. Those who were psychologically distressed were more likely to report that not knowing where to go was a barrier when compared to those who were not psychologically distressed. These are specific issues, which should be considered by providers targeting these groups of potential clients.

The interviewees suggested that lack of knowledge and information are the most important barriers. However, only a minority mentioned stigma and cost as possible barriers. This suggests that the experience of receiving counselling is less stigmatising in practice than originally feared (contrary to the pattern reported above). This apparent contradiction may be explained by the data collection methods employed. Respondents to the questionnaire were presented with a list of potential barriers from which to choose, while those who were interviewed would have had to recall their perceived barriers. From this perspective stigma may not be as salient for those who have experienced the process, although they may recognise it as a potential difficulty for others. Interestingly, amongst those who were interviewed, the women who had no direct personal experience of counselling or psychotherapy were more concerned with barriers, than those who had attended for therapy. This may be because those who had actually attended for counselling had managed to overcome various barriers and thus had either minimised them in retrospect, or had realised that the barriers were easier to overcome than originally perceived.

\section{Health Professionals}

When asked about the perceived accessibility of health board counselling services, their personnel interviewees responded that transport and childcare continue to cause access difficulties for women. Other barriers cited were stigma and waiting lists. The most frequently mentioned barrier was lack of information regarding services. The women consulted during the development of the Plan for Women's Health also cited lack of information.

\section{Service Providers}

Health board service providers in terms of development, funding and location expressed barriers to provision. The need for childcare facilities were frequently mentioned along with the stigma associated with accessing mental health services, availability and comprehension of information and transport issues. 
There is an interesting pattern of responses to the questions on barriers to counselling. Referrals differed depending on experience and location of services, i.e., health board personnel tended to refer clients to health boards and support/self-help groups, whilst the community/voluntary sector tended to refer to private practitioners or support/self-help groups. This finding is also reflected in the literature on self-help groups, which has found that some professionals see a role for self-help organisations in the mental health care system. However, it contrasts with the pattern of data for the women respondents who rarely reported seeking help from selfhelp groups (with the exception of weight watchers).

The majority of the health professionals were less than satisfied with the current counselling provision provided by the health boards. The typical problems referred for were consistent across the sample and included; relationship difficulties, depression, personal issues and anxiety. The majority of those that had attended counselling reported that it had helped. Women in the general public cite fear, stigma, cost and information (or lack of it) as barriers; while women with experience of services also mention cost and access issues. Health professionals and service providers were more concerned with physical or structural aspects of service such as lack of transport, waiting lists and lack of information - issues that could be more easily addressed by service providers. It is clear, therefore, that action is required on both fronts; in relation to the public understanding and acceptability of counselling and psychotherapy and the more micro factors that enable clients to avail of services. These issues are further elaborated upon in the next section.

Boyne (1993) described psychotherapy as being among the most privatised of all the caring services in Ireland. It is usually paid for directly by clients and thus is only easily accessible by those with flexible disposable income. That is, despite the fact that the poorer and more disadvantaged members of our society are more likely to exhibit symptoms of psychological distress (Hannon et al., 2000). Thus it would seem that those who are most in need are least likely to be accessing services. Key issues for future provision; concern who should provide counselling and where; how to encourage women to attend and issues of training and accreditation.

\subsubsection{Who Should Provide Counselling?}

\section{Women}

Amongst the survey respondents, the health boards were most frequently cited as preferred service providers, followed by GPs. Rural women were less likely to prefer services provided by voluntary organisations, which may be explained by their geographical location. Respondents with medical cards were less likely to report that they would prefer services provided by health boards, voluntary organisations or private individuals. This may be somewhat explained by their GMS status, where GP based services would be accessed free of charge. Those who had experience of counselling were more likely to favour private individuals or voluntary organisations. This finding is likely to be explained by their positive experiences of receiving therapy from these sources. Women who were psychologically distressed reported that they would prefer services provided by their GP. When asked directly, the overwhelming majority of women responded positively to the suggestion that health boards should provide counselling services. Half of the interviewees felt that they should pay for these services, and most of the remainder suggested a system of partial payments or sliding scales through which counselling services would be means tested, or free to those eligible for GMS.

\section{Health Professionals}

Almost all of the health board personnel felt that the health boards should be the primary providers of counselling/therapy services and this was followed by GPs, who were nominated by less than half of the respondents. Those who had been trained in counselling or psychotherapy were more positive about the involvement of voluntary groups and private practitioners in service provision. The most widely endorsed service providers suggested by community personnel were private practice and health boards, followed closely by the community and voluntary sector. The pattern of response would suggest that these preferences were influenced by respondents' experiences of current provision.

\section{Service Providers}

Health Board managers reported that counselling should be provided by both the statutory and community / voluntary sectors, but that the community sector should not be a substitute for the private sector. They also expressed concerns over pay scales in relation 
to public sector counselling / therapy staff. Community and voluntary service providers suggested that private health insurance companies, employee assistance schemes, health board funding to community organisations and free provision to GMS holders could cover counselling costs.

\section{Location of Counselling / Psychotherapy Services}

\section{Women}

Amongst the women who responded to the questionnaire, the most popular location of counselling or psychotherapy services were community/family centres, followed by GPs surgeries. Rural women were less likely than urban women to report that they would like services located in community or family centres or in workplaces. This mirrors the data reported above in relation to their lower preferences for voluntary service provision (which in turn could be associated with distance and location issues) and their lower likelihood of being employed outside the home. Those with medical cards were less likely to report that they thought counselling should be available in workplaces, which in turn probably reflects their lower employment rates. Those who had experience of counselling were more likely to prefer services provided in community or family centres which once again might be reflective of their direct experience with such services. There were no identified differences between those who were depressed or psychologically distressed and those who were not in relation to preferred location of services.

For the interviewees, the most popular source of location was GP surgeries or women's health centres. Small numbers of interviewed women were negative about locating services within GP surgeries and also questioned the appropriateness of specialist 'counselling' centres. The main concerns expressed in relation to service provision in these locations were the associated difficulties in maintaining anonymity and explaining one's attendance, for example, while in waiting rooms.

\section{Health Professionals}

Health board personnel reported that they most favoured locating services in the workplace, followed by in hospitals and then in GP surgeries. In this context it is interesting to note how out of step these responses were with those of the women surveyed and interviewed. Personnel working in a rural context were more likely to report their preferred location of services as hospital or health clinic than their urban counterparts. This may reflect the lower employment levels in rural areas (i.e., where the provision of services would not be appropriate in the workplace) and also the accessibility to services (i.e., the hospital and health clinic are possibly more accessible than the other venues suggested). Allied professionals / paramedics and doctors / dentists were most positive about the location of services in family/community centres. Doctors / dentists were less likely to suggest the workplace as a possible location for services, which may reflect their greater knowledge concerning the employment status of their clients (i.e., if they have GMS status, etc). The community personnel were most in favour of family/community centres for service provision, followed by health clinics and GP surgeries.

\section{Service Providers}

Several respondents suggested the development of off-site counselling services away from the health board premises, as they are generally more accessible and associated with fewer stigmas. GP based counsellors were mentioned in relation to both generic and specialised services. A few board service providers only mentioned the involvement of the community/voluntary sector. Those that did mention them noted that counselling should be on offer from more than just the health board and that funding should be made available for counselling provision within the community sector. However, the consensus was that the community sector was not a substitute for the public sector. The community service providers responded with overwhelming consensus that there should be a mixture of both public and private counselling services. The need for the public to have a choice was emphasised. Both the community and health board service providers mentioned appropriate physical space i.e., soundproof rooms and disability access.

\section{Improving services and encouraging women to attend}

\section{Women}

Suggestions by the survey respondents which would encourage women to attend counselling were; if the GP recommended it, 'believing it would help', low cost, easy access and reduction in stigma (in that order). Again, the importance of the GP in recommending services and the belief in 'the product' is highlighted in this pattern of results with cost, accessibility and stigma being cited as the most important issues to be considered. Rural women were less likely to cite low cost as an encouragement and this further demonstrates the pattern of women with more experience being more aware of cost issues. Those with medical cards were 
less likely to cite ease of access, reduction in stigma or publicity as encouragements. This pattern may be associated with their higher levels of access to health services via the GMS system, and it ties in with their earlier data suggesting that they less likely to perceive stigma as a barrier and were more likely to use the media as a source of information. They are perhaps were already more exposed to media based publicity in relation to these issues.

A slightly different pattern of results emerges from those women who have received counselling. They were more likely to suggest that 'believing it would help' would encourage women to attend as compared to non-attendees. In addition, the value of a low cost service is deemed as more important by the counselling attendees compared to the non-attendees. This suggests again that only by experiencing counselling does the full implication of the cost of the service become apparent. Those who have direct experience of counselling or psychotherapy also cite the importance of reduction in stigma as an encouragement to attend counselling more often. Once again, this suggests that the stigma may only be realised when you become an attendee, (but see section 6.4.3 above). This group were also more likely to cite increased publicity as a method of encouraging women to access services. Those who were depressed were less likely to report GP advice as an encouragement, while those who were psychologically distressed were more likely to report ease of access and a reduction in associated stigma as encouragements as compared to those who were not depressed or psychologically distressed.

\section{Health Professionals}

Health board personnel were most likely to cite increased availability as the key to improving services, followed by the promotion of public awareness and increased resources. Those personnel trained in counselling or psychotherapy were more likely to suggest the improvement of resources and to highlight personnel issues than those not trained. This may reflect that having been training in counselling / psychotherapy increases one's awareness of the personnel and resource requirements that are needed for an effective service. The responses from personnel in community and voluntary organisations favoured increasing resources, followed by improving accessibility and then availability. It is challenging to disentangle these suggestions as clearly increased resources could be employed to improve availability or improve accessibility. Nevertheless, it is interesting to note that increased service provision was the improvement most frequently cited by health board staff. Cost of services also emerged as an issue for health professionals. Most health board personnel said that they thought counselling should be provided at no cost to the client, or suggested that it be means tested. A minority however, expressed the belief that the negotiation of payment for a service is part of the therapeutic process. Other suggestions for improving counselling services included increasing its availability and access and the variety of counselling available.

Health board personnel interviewees either did not know or were negative about the degree of planning that had gone into the development of services by the respective health boards. Most reported that staff was not consulted during the planning process. Suggestions made to improve future provision included cost, physical location and service promotion or education.

\section{Service Providers}

The difficulty of recruiting and securing accredited staff frequently emerged as an issue for the health board service providers. Many of them expressed concerns about ongoing demand from clients, and several were concerned that the provision of counselling services would become an area of insatiable need.

Two distinct areas emerge as important for the promotion of counselling or psychotherapy services, issues that are personal to the woman or concern her perceptions of social norms in relation to help-seeking and structural factors related to the mechanics of service provision. Both would need to be dealt with in some detail for the concerns of all relevant stakeholders to be addressed.

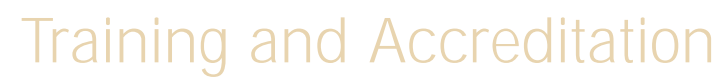

Until recently one of the problems inhibiting the expansion of therapy services has been the ambiguous position of psychotherapy and counselling as professions. There has been a great deal of debate as to whether counselling and psychotherapy should be merely an ancillary activity of certain professionals, such as Medical doctors, Psychiatrists, or Psychologists or a profession(s) in its/their own right, with separate standards of entry and qualification.

While many health practitioners would argue that they frequently use counselling skills in their daily work, few have the time or training to get involved in 'formal counselling'. For example, the majority of doctors enter general practice with little training in 
counselling and it is argued that this lack of preparation, together with the very real constraints of time has limited the capacity of many GPs to recognise patients needs adequately and to respond effectively to these needs (McLeod, 1992).

In order to move one's qualifications freely across transparent borders it will be necessary to have these qualifications recognised by one's own government. There is a requirement within the recent EU directives for equivalence in forms of training, and this in turn requires the existence of a designated authority in each country. This could more easily be established if there already exists some national body or association that sets standards and controls the work in question. In Ireland, the three main organisations that accredit counsellors and therapists are currently working with the Department of Health and Children to fulfil this role.

\section{Women}

Only two women in the survey sample stated that they would contact a professional organisation when or if seeking a counsellor. Of those women who had received counselling, a tiny minority knew what training their counsellor had received. This finding is supported by the interview data, with many of the women knowing that their counsellor had had training but being unclear about level or type of qualifications, accreditation of training, etc. None of the interviewees mentioned having contacted any professional organisations to check the credentials of their therapist. This data suggests that women are currently either unaware of the differences in training and accreditation status and what that might mean. Nor are they concerned about such issues, preferring to rely on word of mouth or professional referrals and recommendations in relation to identifying appropriate counsellors or therapists.

\section{Health Professionals}

A sizeable minority of health board personnel reported that they had been trained in counselling methods or skills, while more than three-quarters reported that they used counselling skills in their work. Although those who had been trained were more likely to report that they offered a counselling service than those that had not been trained, there remains a sizeable group who report that they provide services despite never having been trained to do so.

The professional associations involved in this research recommended that accreditation criteria should be sufficiently flexible to allow this new area of professional training to grow. At the same time criteria should be established to demand a standard comparable to existing provision in other professional disciplines.

\section{Service Providers}

Health board respondents were knowledgeable about the existence of the professional accrediting organisations and agreed that the accreditation of counsellors was essential. There was a general agreement that the health boards should standardise their requirements on the matter of accreditation, training and supervision, and that ideally, comparable standards should be set across all such organisations. Several health board respondents also mentioned that the community/voluntary organisations that seek their funding must ensure that all counsellors are professionally accredited in order to secure financial support.

The community service providers reported that they generally employed counsellors who were either accredited to one of the national accrediting organisations or to their own national accrediting network. Very few respondents expressed any concern over enforced accreditation by the government. One potential difficulty noted was that accessing accredited training and supervision can be very difficult and this may have an impact on service provision if accreditation of counsellors was centrally enforced. This issue needs to be carefully considered by the accrediting organisations as well as service providers, central enforcement of accreditation may, in the short term, result in shortages of professionally trained and accredited counsellors. This must be balanced against client needs and a sufficiently proactive and flexible transitional system should be adopted.

All of the community service providers felt that appropriate training and supervision were essential for quality counselling provision. Several respondents felt strongly that the government should be taking a more pro-active, positive response towards the recognition of counselling as a profession. The lack of restrictions or accountability in relation to setting up a practice was detailed as a matter of concern. 
The data presented in this report represent a first attempt to look at the issue of counselling and psychotherapy provision from the perspectives of key stakeholders in Ireland. The data provides a picture of services as they now stand and a critique from the perspective of service users, providers and employees. As such, they could be employed as a starting point from which to assess future service developments. They also provide a collection of specific points of information in relation to the issues of central importance to those involved in the development of services.

While the data collected differs in some ways from that in the literature, there is not sufficient prior work to be able to say whether these samples are substantially different from others. Instead and where appropriate, key issues in the literature have been employed to further elucidate some of the emerging themes from this study. The similarities across sources of data in this study are perhaps more interesting than the differences. While the specific responses of certain groups of professionals or women at risk of requiring psychotherapeutic interventions may be of interest to those involved in service planning and provision; there are broader issues that need to be addressed in the first instance. Perspectives on counselling and psychotherapy are generally positive indicating considerable goodwill towards this area amongst all groups. However, there is both a general and specific lack of knowledge in relation to available services, which needs to be addressed. GPs and family and friends have emerged as the major sources of information, advice and help and thus both groups must be specifically targeted if levels of knowledge are to improve. In this context, particular attention must be paid to information dissemination amongst rural women.

There are clear preferences emerging in relation to the clientele and location that is most appropriate to the provision of counselling services. It appears that counselling and psychotherapy are currently primarily sited in the private or voluntary sectors. Those who have experienced these services perceive this as positive. It is clear that health boards and GPs are the most popular service providers and that community and family centres together with GP surgeries are the most popular locations for services. This confirms the central role of primary care in service provision. The specific needs of rural women are also important here, as they are less likely to favour voluntary or community provision or location of services and this must be considered by those planning service provision. However, as services are further developed within the statutory services and primary care; it will be most important to determine how to maintain the positive aspects of the services already available and how to improve them in order to minimise the exacerbation of inequalities that are extant amongst the potential client groups.

There is a clear preference for counselling services to be provided by health boards and GPs in a location off-site from key services, i.e., community / family centres and GP surgeries. This issue of service location is vital. Services must be located both where women will access them and where service providers can offer appropriate levels of care. Planning in this area needs to include consideration of both the physical resources and the psychological realities for potential client groups. Perhaps the most important principle is to ensure flexibility to respond to local needs. The mismatch reported above between the perceptions of the women and those of the health professionals in relation to appropriate service location is also a key issue for service development and planning, and highlights the importance of consultation with service users during the planning process.

The majority of respondents also recommended means tested assessment or a sliding scale for the payment of fees in an attempt to improve accessibility of services. Other suggestions for improvements included doctor's recommendation and believing it will help. Stigma was not as highly prioritised as the literature had suggested. This may indicate that the general publics' acceptance of counselling has grown in recent years, or that there are strong sex differences in the perception of stigma (previous research surveyed both men and women). Effective public awareness campaigns and dissemination of information could further address these issues.

If services are to be further developed, then attention must be paid to the perceived barriers and encouragements to service use. These fall into three main groups; perceptions such as fear, believing it would work and stigma, knowledge such as knowing where to go and what counselling involves and cost. In addition, distance and transport are real issues for rural women which must be considered if equality of access is to be achieved. It must be further determined whether these are real or perceived barriers and whether they can be overcome through fundamental alterations in the process and structure of service provision or in the dissemination of educational and promotional materials. The data collected on sources of mental health information should be useful in this regard. However, these activities must not be divided from the development of best practice in relation to the promotion of positive mental health and preventive activity in relation to mental health difficulties.

The pattern of problems with which clients present may not be static and any system must remain sufficiently flexible to respond as the needs change. There are two key pillars to this development; consultation with client groups and high quality professional training and education. Neither can substitute for the other. The issue of accreditation appears increasingly important in this context. 
90 
Chapter Seven: Recommendations 


\section{Recommendations}

\section{Recommendations}

The recommendations following this study follow the main areas of investigation. They are based on the analyses conducted of the data collected as detailed in chapters 3 to 5 .

\section{Information and Help-seeking}

ADVICE SHOULD BE MADE AVAILABLE ON HOW TO CHOOSE AND LOCATE A COUNSELLOR

Information in relation to the key issues to consider before choosing a counsellor or therapist needs to become more widely available. In order to ensure that it reaches its quite specific target audiences, e.g. women who experience domestic violence, marital difficulties, depression, anxiety, crisis pregnancy and widowhood; the most appropriate methods for disseminating such information need to be considered. These should include traditional methods such as leaflets and poster alongside the use of newer technologies; web-sites, bulletin boards, etc. Channels of information provision should include GP surgeries, support networks, media, women's centres, family resource centres, health centres' and self-help groups.

INFORMATION AND TRAINING IN MAKING APPROPRIATE REFERRALS IS REQUIRED FOR HEALTH SERVICE PROVIDERS In order to help address the unmet needs of women in the population who could appropriately be helped through counselling; information and training in relation to the identification of psychological problems and the process of appropriate referral is essential for those in direct contact with potential clients. This is particularly relevant to health and community service employees and should be part of their ongoing in-service training.

MENTAL HEALTH PROMOTION INITIATIVES SHOULD ADDRESS THE STIGMA SURROUNDING SERVICE ACCESS

The perceived stigma and fear needs to be tackled surrounding accessibility to mental health services. It would be appropriate to address these issues in conjunction with groups currently working in the area, for example, AWARE, GROW. Appropriate and substantial funding for mental health promotion amongst young people, as well as other sub-groups in the population, should be provided alongside more traditional preventative approaches.

\section{Training and Accreditation}

As a result of European directives it will be necessary to establish a National Competent Authority to regulate professional activity in the area of counselling provision. Accreditation in the form of affiliation to a professional body and completion of approved training programmes is vital in order to ensure quality through the services.

\footnotetext{
STATUTORY AND VOLUNTARY AGENCIES MUST BE RESPONSIBLE FOR ENSURING STAFF ARE APPROPRIATE QUALIFIED FOR THE SERVICES THEY PROVIDE

It should be the responsibility of statutory and voluntary agencies to ensure that their staff are adequately trained for the activities they undertake, be they counsellors or support workers. The term 'counsellor' should only be applied to persons registered with the Irish Council for Psychotherapy, the Irish Association for Counselling and Therapy, or the Counselling Division of the Psychological Society of Ireland. It is felt that there is a role for support workers who are not qualified but who have undertaken the appropriate training by their organisation.
}

\section{ACCESS TO IN-SERVICE TRAINING, SUPERVISION AND ACCREDITATION MUST BE AVAILABLE}

Training, supervision and accreditation are appropriate in-service as well as pre-service activities. Statutory and voluntary agencies must work in conjunction with staff and their representatives to develop policy on in-service training with concomitant financial support and suitable leave and substitution arrangements.

COUNSELLING TRAINING PROGRAMMES SHOULD BE FLEXIBLE AND ENSURE EQUALITY OF ACCESS

Training courses in counselling should be provided by accrediting organisations and educational establishments, in a flexible manner 
in order to ensure equality of access. This includes deploying the full potential of information technology, as well as the use of nonhealth board sites, to deliver education, training and supervision.

\section{Access and Service Provision}

THE PRINCIPLE OF EQUALITY OF ACCESS SHOULD GUIDE SERVICE DEVELOPMENTS

Those responsible for the planning of service provision must ensure that all women in their catchment area have an equal opportunity to gain access to services. This will require attention to physical location, cost structure, transport and child care and other services on the premises.

\section{THE REPORTED DIFFICULTIES ASSOCIATED WITH CURRENT SERVICES REQUIRES ATTENTION}

It must be determined whether the negative perceptions associated with Health Board counselling services are legitimate. All service developments should include consultation with staff and client groups, as well as with those external organisations that frequently refer clients to statutory services. It would be beneficial if the voluntary and statutory sectors could collaborate on the core issues of service development to ensure that the most relevant range of services are available to clients.

\section{THE APPROPRIATE USE OF SELF-HELP GROUPS SHOULD BE ENCOURAGED}

The potential of self-help groups as sources of help does not appear to be effectively utilised at present. Information in relation to their appropriate use, either as an adjunct to or independently of professionals' services, needs to be more widely disseminated. Service providers should support these groups and adequate resources should be provided for such activities.

\section{PRIMARY CARE SERVICE PROVISION REQUIRES CONSIDERABLE SUPPORT AND DEVELOPMENT}

The role of the provision of counselling within the primary care setting should be explored and developed further. Collaboration with the relevant representative professional groups, for example, GPs, public health nurses, counsellors, psychotherapists and support workers will be essential for future provision.

ATTENTION MUST BE PAID TO APPROPRIATENESS OF VENUES WHERE SERVICES ARE PROVIDED

In all locations where counselling or psychotherapy is to be provided, attention must be paid to the physical resources; secure filing, sound-proofing, confidential waiting rooms and physical access for all.

\section{INCLUDING COUNSELLING AND THERAPY IN THE GMS MUST BE SERIOUSLY CONSIDERED}

The issue of cost to clients has been identified as a barrier to accessing services. At present there are a wide variety of levels of service provision, from different sources and sectors with differing objectives and associated cost differentials. It is recommended that the Department of Health and Children consider the provision of counselling services as part of the GMS system.

\section{Implementation}

\section{LEADERSHIP AND COLLABORATION ARE VITAL}

Two principles should guide the implementation of these recommendations; support and leadership from statutory and voluntary organisations as well as collaboration and consensus between all stakeholders (e.g., funders, managers, health professionals and clients).

\section{MODELS OF BEST PRACTICE SHOULD BE ADOPTED}

The process of implementation must include consultation with specific client groups. Models of best practice in relation to consultation should be adopted, e.g. the process adopted during the drawing up of the Plan for Women's Health or the Youth at Risk Policy Document (Department of Health \& Children, 1998).

\section{PREVENTATIVE AND CURATIVE APPROACHES MUST BE MATCHED}

Actions taken must combine prevention as well as curative approaches. In order to ensure a balanced and measured approach, services should be reviewed and planned in conjunction with those experienced in service provision; mental health promotion, mental ill-health prevention and the provision of services to enable early intervention. 
94 
Bibliography 


\section{Bibliography}

A bu-Rasain, M .H .M . \& W illiams, D.I. ( 1999) Peer counselling in Saudi A rabia. Journal of A dolescence, 22 (4), 493-502.

A herne, D. \& G riffin, M . (1991) I rish general practice and clinical psychology. Irish Journal of Psychological M edicine, 8, 75-78.

A lloy, L.B., Kelly, K.A., M ineka, S. \& Clements, C.M. (1990) Comorbidity of anxiety and depressive disorders: a helplessnesshopelessness perspective. In J.D. M aser \& C.R. Cloninger (Eds.) Comorbidity of M ood and A nxiety Disorders. Washington, DC: A merican Psychiatric Press.

A nderson, S. \& Hasler, J. (1979) C ounselling in general practice. Journal of the R oyal College of General Practitioners, 29, 3526.

A ngst, J., Vollrath, M., M erikangas, K.R., \& Ernst, C. (1990) Comorbidity of anxiety and depression in the Zurich cohort study of young adults. In J.D. M aser \& C.R. C loninger (Eds.) C omorbidity of M ood and A nxiety Disorders. W ashington, DC: A merican Psychiatric Press.

Balestrieri, M ., Williams, P. \& Wilkinson, G . (1988) Specialist mental health treatment in general practice: A meta-analysis. Psychological M edicine, 18, 711-717.

Barker, D.C., Robinson, L.A . \& Rosenthal, A.C. (2000) A survey of managed care strategies for pregnant smokers. Tobacco Control, 9, 46-50.

Baron, J. (1997) Recognition and Professional status. In Horton, I. et al. (Eds.) T he N eeds of C ounsellors and Psychotherapists. London: Sage.

Barry, M ., Doherty, A ., H ope, A ., Sixsmith, J., \& Kelleher, C. (2000) A community needs assessment for rural mental health promotion. Health Education Research, Theory and Practice, 15 (3), 293-304.

Barry, M .M . (1994) Community perceptions of mental disorder: A n I rish perspective. Irish Journal of Psychology, 15 (2\& 3), 418 441.

Bartlam, B. \& M CLeod, J. (2000) Infertility counselling: the ISSU E experience of setting up a telephone counselling service. Patient E ducation and Counselling, 41 (3), 313-321.

Bayne, R. \& N icolson, P. (1993) C ounselling and Psychology for H ealth Professionals, Therapy in Practice 35. London: Chapman and Hall.

Belenky, M .F., Clinchy, B.M ., Goldberger, N.R., \& Tarule, J.M . (1986) Women's ways of knowing: the development of self, voice and mind. N ew York: Basic Books.

Bergin, A .E. (1971) The evaluation of therapeutic outcomes. In S.L. G arfield \& A .E. Bergin (Eds.) H andbook of psychotherapy and behavior change. $\mathrm{N}$ ew York: W iley.

Blackburn, I., Bishop, S. \& G lenn, A . (1981) The efficacy of cognitive therapy in depression: a treatment using cognitive therapy and pharmacotherapy, each alone and in combination. B ritish Journal of Psychiatry, 193, 181-189.

Blakey, R., Sinclair, J., \& Taylor, R. (1994) Patient satisfaction with short clinical psychology contact. C linical Psychology Forum, July, 13-15.

Bland, R.C., O rn, H . \& N ewman, S.C. (1988) Lifetime prevalence of psychiatric disorders in Edmonton. A cta Psychiatrica Scandinavia, 77 (suppl.), 24-32. 
Booth, H., C ushway, D., \& N ewnes, C. (1997) Evaluation of counselling in primary care: how can research be made more useful for practitioners? C ounselling Psychology Q uarterly, 10 (1), 51-68.

B oot, D., G illies, P., Fenelon, J., Reubin, R., W ilkins, M ., \& G ray, P. (1994) Evaluation of the short-term impact of counseling in general practice. Patient Education \& C ounseling, $24,79-89$.

Borkham, T.A . (1997) A selective look at self-help groups in the U nited States. H ealth and Social C are in the C ommunity, 5(6), 357-64.

Borkowski, M ., M urch, M . \& W alker, V. (1983) M arital violence: T he community response. London: Tavistock.

Boyne, E. (1993) Psychotherapy in Ireland. Dublin: The Columbia Press.

Breslau, N ., Schultz, L. \& Peterson, E. (1995) Sex differences in depression: a role for preexisting anxiety. Psychiatry Research, 58, 1-12.

Brodaty, H.\& A ndrews, G . (1983) Brief psychotherapy in family practice. A controlled prospective intervention trial. British Journal of Psychiatry, 143, 11-19.

Brook, A . \& Temperley, J. (1976) The contributions of a psychotherapist to general practice. Journal of the Royal C ollege of $G$ eneral Practitioners, 26, 86-94.

Brown, L. (1992) W hile waiting for the revolution: the case for a lesbian feminist psychotherapy. Feminism and Psychology, 2 (2), 239-53.

Byrne, A ., Laver, M ., Forde, C., C assidy, L., Keane, M . \& O 'C inneide, M . (1991) N orth-W est C onnemara; A Baseline Study of Poverty. Galway: FORU M.

Byrne, A .\& O wens, M . (1996) Family, work and community - rural women's lives, rural women's research project: summary account. U CG Women's Studies C entre Review, IV, 77-94.

C atalan, J., G ath, D., A nastasiades, P., Bond, S.A .K., Day, A . \& H all, L. (1991) Evaluation of a brief psychological treatment for emotional disorders in primary care. Psychological M edicine, 21, 1013-1018.

C atalan, J., G ath, D., Edmonds, G. \& Enis, J. (1984) The effects of non-prescribing of anxiolytics in general practice. 1. Controlled evaluation of psychiatric and social outcome. B ritish Journal of Psychiatry, 144, 603-610.

CDC (1993) Behavioural Risk Factor Q uestionnaire. Center for Disease C ontrol and Prevention: A tlanta, G A .

C entral Statistics 0 ffice (1997a) C ensus 1996: Planning for the Ireland of tomorrow. A ges and M arital Status (Volume 2).

Dublin: Government Publications.

C entral Statistics O ffice (1997b) C ensus 1996: Planning for the I reland of tomorrow. H ousehold composition and family units (Volume 3). Dublin: Government Publications.

C entral Statistics O ffice (1998) C ensus 1996: Planning for the Ireland of tomorrow. Principal socio-economic results Dublin: Government Publications.

Chesler, P. (1972) W omen and M adness. N ew York: Doubleday.

Churchill, R., Dewey, M \& \& G retton, V. (1999) Should general practitioners refer patients with major depression to counsellors? A review of current published evidence. B ritish Journal of $G$ eneral Practice, 49 (446), 738-743. 
Clarke, G.N . (1995) Improving the transition from basic efficacy research to effectiveness studies: methodological issues and procedures. Journal of $\mathrm{C}$ onsulting and $\mathrm{C}$ linical Psychology, 63, 718-725.

Coleman, A . (1997) W here do I stand? Legal implications of telephone triage. Journal of C linical N ursing, 6, 227-231.

Conlon, C. (1999) Women - The Picture of H ealth: A review of research on women's health in Ireland. Dublin: Women's H ealth Council.

Cook, T.D. \& C ampbell, D.T. (1979) Q uasi-experimentation: measurement \& analysis issues for field settings. Boston, M A : Houghton M ifflin.

Cooper, J. \& Lewis, J. (1995) W ho can I talk to?: the user's guide to therapy and counselling. London: H odder and Staughton.

Cooper, B., H arwin, B.J., Delpa, C. \& Shepherd, M . (1975) M ental health care in the community: an evaluative study. Psychological M edicine, 5, 372-380.

Copeland, J.R.M ., D ewey, M.E., W ood, N ., Searle, R., Davidson, I.A . \& M cWilliam, C. (1987) Range of mental illness among the elderly in the community. British Journal of Psychiatry, 150, 815-23.

Corney, R. (1984) The effectiveness of attached Social W orkers in the management of depressed female patients in general practice. Psychological M edicine, 14 (monograph suppl. 6), 47.

Corney, R. (1990) Counselling in general practice-does it work? Discussion paper. Journal of the Royal Society of M edicine, 83, 253-257.

Corney, R. (1984) The effectiveness of attached social workers in the management of depressed female patients in general practice. Psychological M edicine, 14 (monograph suppl. 6), 47.

Crose, R. (1991) W hat's special about counselling older women? C anadian Journal of C ounselling, 25(4), 617-23.

Cryan, E., Keogh, F., Connolly, E., Cody, S., Q uinlan, A \& \& Daly, I. (2001) Depression among postnatal women in an urban Irish community. Irish Journal of Psychological M edicine, 18(1), 5-10.

Cummings, N ., Dorken, H ., Pallak, M.S. et al. (1993) M edical managed behavioural health and implications for public policy. $\mathrm{H}$ ealth care: utilisation and cost series. U tilisation and $\mathrm{C}$ ost Series for the F oundation of B ehavioural $\mathrm{H}$ ealth, 2, 3-23.

Department of H ealth and C hildren (1998) Youth at Risk. Dublin: Department of $\mathrm{H}$ ealth and Children.

Dryden, W. (1996) A Rose by any other name: a personal view on the differences among professional titles. In I. James and S. Palmer (Eds.), Professional Therapeutic Titles: M yths and Realities. O ccasional Papers 2. Leicester: British Psychological Society.

Dunne, E.A . \& Fitzpatrick, A .C. (1997) Whose patient is it anyway? Forum 1997, 13 (11), 14-6.

Dunne, E.A . \& Fitzpatrick, A .C. (1999) The views of professionals on the role of self-help groups in the mental health area. Irish Journal of Psychological Medicine, 16(3), 84-89.

Dryden, W. (1996) A Rose by any other name: a personal view on the differences among professional titles, in I. James and S. Palmer (Eds.), Professional Therapeutic Titles: M yths and Realities. O ccasional Papers 2. Leicester: British Psychological Society.

Earll, L. \& Kincey, J. (1982) C linical psychology in general practice. Journal of the Royal C ollege of $G$ eneral Practitioners, 32, 32-37.

Eatock, J. (2000) Counselling in primary care: past, present and future. British Journal of G uidance \& C ounselling, 28 (2), 161-174. 
Epstein, W.M. (1999) The ineffectiveness of psychotherapy. In: C. Feltham (Ed.) C ontroversies in therapy \& counselling. London: Sage.

Eysenck, H.J. (1952) The effects of psychotherapy: A n evaluation. Journal of C onsulting Psychology, 16, 319-324.

Feltham, C. (1999) Controversies in psychotherapy and counselling. London: Sage.Friedli, K.\& King, M . (1996) Counselling in general practice - a review. Primary C are Psychiatry, 2, 205-216.

Friedli, K., King, M., Lloyd, M . \& Horder, J. (1997) Randomised controlled assessment of non-directive psychotherapy verses routine general-practitioner care. Lancet, 350, 1662-1665.

Friel, S., Barry, M . \& Kelleher, C.C. (forthcoming) M easuring Q uality of L ife and M ental H ealth Status: U se of the W H OQ O LBREF in the G eneral Population. Centre for H ealth Promotion Studies, N ational U niversity of Ireland, Galway.

Friel, S., N ic Gabhainn, S. \& Kelleher, C. (1999) The N ational H ealth and Lifestyle Surveys. Dublin: C entre for H ealth Promotion Studies, NUI G alway \& Department of $\mathrm{H}$ ealth $\&$ C hildren.

G illigan, C . (1982) In a different voice: Psychological theory and women's development. C ambridge M A : H arvard U niversity Press.

Godber, E. (1996) Is counselling in primary care growing too fast? A clinical, economical and strategic assessment. Southampton: Institute for Health Policy Studies.

G oldberg, D.P. (1978) M anual of the G eneral H ealth Q uestionnaire. W indsor: N FER-N elson.

Goldberg, D. (1991) Filters to care - A model. In: R. Jenkins, S. G riffiths, (Eds.). Indicators for M ental H ealth in the Population. London: HMSO.

Goldberg, D.P. \& H uxley, P. (1980) M ental Illness in the C ommunity, the pathway to psychiatric care. London: Tavistock.

G overnment of I reland (1998) Report of the N ational Task F orce on Suicide. Dublin: Stationary O ffice.

G overnment of I reland (2000) A Plan for Women's H ealth 1997-1999. Dublin: Stationary O ffice.

Gray, D.J.P. (1988) Counsellors in general practice. Journal of the Royal C ollege of $G$ eneral Practitioners, 38, 50-51.

G reene, S.M ., N ugent, J.K., W ieczovek-Deering, D., O'M ahony, P. \& G raham, R. (1991) The patterning of depressive symptoms in a sample of first-time mother. Irish J ournal of Psychology, 12, 263-275.

H annon, F., Kelleher, C. \& Friel, S. (2000) G eneral Healthcare Study of the Irish Prisoner Population. Dublin: Department of $\mathrm{H}$ ealth and $\mathrm{C}$ hildren.

H arrington, J. (1997) Validation of a F ood Frequency Q uestionnaire as a Tool for A ssessing N utrient Intake. M A thesis: Department of H ealth Promotion, N UI Galway.

H arris, R., Stickney, J., G rasley, C., H utchinson, G ., G reaves, L. \& Boyd, T. ( 2001) Searching for help and information: A bused women speak out. Library \& Information Science Research, 23(2), 123-141.

H emmings, A . (1997) C ounselling in primary care: A randomized controlled trial. Patient Education and C ounselling, 32, 219230.

H emmings, A . (2000) C ounselling in primary care: a review of the practice evidence. B ritish Journal of $G$ uidance $\&$ C ounselling, 28 (2), 233-252. 
H olmes, J. \& Lindley, R. (1998) The Values of Psychotherapy. London: Karnac.

H ooper, D. (1997) Then, now, and tomorrow. In S. Palmer et al. (Eds.) T he Future of C ounselling and Psychotherapy. London: Sage.

H oulihan, B., Fitzgerald, M \& \& O'Regan, M . (1994). Self esteem, depression and hostility in Irish A dolescents. Journal of A dolescence, 17, 565-77.

H oward, K.I., Kopta, S.M ., Krause, M .S. \& Orlinsky, D.E. (1986) The dose-effect relationship in psychotherapy. A merican Psychologist, 41, 159-164.

Jacobs, M. (1988) Psychodynamic C ounselling in A ction. London: Sage.

Jacobs, M. (1996) Suitable clients for counselling and psychotherapy. Self and Society, 24 (5), 3-7.

Kelleher, M ., O'Sullivan, M \& \& M CM ahon, N . (1998) M ental illness in an elderly rural population in Ireland: a prevalence study. Irish Journal Psychological M edicine, 15(4), 139-141.

Kelly, M. (1997) Pilot Phase of the N ational Lifestyle Survey. M A thesis: Department of H ealth Promotion, N U I G alway.

Kennedy, P., Q uinn, S., M urphy-Lawless, R.J. \& Hickey, E. (2000) Survey of views and perceptions of women who attended symptomatic breast clinics. Dublin: The W omen's H ealth Council.

Kennedy, P. (1999) A personal reflection on counselling. Éistach, Winter 1999.

Kessler, R.C., M cG onagle, K.A ., Swartz, M., Blazer, D.G \& \& elson, C.B. (1993) Sex and depression in the National Comorbidity Survey 1: Lifetime prevalence, chronicity and recurrence. Journal of A ffective Disorders, 29, 85-96.

Kirby, M ., Bruce, I., Radic, A ., Coakley, D. \& Lawlor, B.A . (1997) M ental disorders among the community-dwelling elderly in Dublin. B ritish J ournal of Psychiatry, 171, 369-72.

Lawlor, M . \& James, D. (2000) Prevalence of psychological problems in Irish school going adolescents. Irish J ournal of Psychological M edicine, 17(4), 117-122.

Lefébure, M . (1996) W ho will count as a counsellor? G leanings and tea-leaves. In, R Bayne, I. Horton \& J. Bimrose (Eds.) N ew Directions in C ounselling. London: Routledge.

Lester, D. \& Brockopp, G. (1973) C risis intervention and counseling by telephone. Springfield, IL: Charles C Thomas.

Lester, D. (1995) Counselling by telephone: advantages and problems. C risis Intervention, 2, 57-69.

Marcella, R. \& Baxter, G. (1999) The information needs and the information seeking behaviour of a national sample of the population in the U nited Kingdom, with special reference to needs related to citizenship. Journal of D ocumentation, 55, 159-183.

Marks, I. (1985) Controlled trial of psychiatric nurse therapists in primary care. British M edical Journal, 290, 1181-1184.

Maser, J.D. \& Cloninger, C.R. (1990) C omorbidity of M ood and A nxiety Disorders. Washington, DC: A merican Psychiatric Press.

M att, G .E. \& N avarro, A .M . (1997) W hat meta-analysis have and have not taught us about psychotherapy effects: a review and future directions. C linical Psychology Review, 1 (1), 1-32.

M cInnes, R.J., Love, J.G . \& Stone, D.H. (2000) Evaluation of a community-based intervention to increase breastfeeding prevalence. Journal of Public H ealth M edicine. 22(2), 138-145. 
M cKeon, P. \& Carrick, S. (1991) Public attitudes to depression: a national survey. Irish Journal of Psychological M edicine, 8, 116121.

M cLeod, J. (1992) The general practitioner's role. C ounselling in general practice. London: Royal C ollege of G eneral Practitioners.

M cLeod, J.M. (1987) T he W ork of C ounselors in G eneral Practice. Occasional Paper 37. London: Royal College of G eneral Practitioners.

M ellor-Clarke, J. (2000) Developing practice and evidence for counselling in primary care: the agenda. British Journal of G uidance \& C ounselling, 28 (2), 253-266.

M ental Health A ssociation of Ireland (1973) Public A ttitudes to M ental IIIness. Dublin: M HA I.

Mercy, J. (1990) O ut of the closet .... and onto the couch. A Q ueer Tribe 5.

M onach, J. \& M onro, S. (1995) Counselling in general practice: issues and opportunities. British J ournal of G uidance and Counselling, 23, 313-325.

M oran, R.A . (1977) C onceptualisation of mental illness and attitudes to the mentally ill and ex-mental patients: Structure, determinants and correlates in an I rish sample. U npublished master's thesis, U niversity College Cork.

M orrows, A .L., Guerrero, M.L., Shults, J., Calva, J.J., Lutter, C., Bravo, J., Ruiz-Palacios, G ., M orrow, R.C. \& Butterfoss, F.D. (1999) Efficacy of home-based peer counselling to promote breastfeeding: a randomised controlled trial. Lancet, 353 (9160), 1226-1231.

N aylor-Smith, A . (1994) C ounselling and psychotherapy: is there a difference? C ounselling, 7 (4), 307-11.

N CH S (1979) Highlights from wave one of the N ational Survey of Personal H ealth Practices and C onsequences: U nited States. Data from the $\mathrm{N}$ ational Health Survey, Series 15, N o. 1.

N iaz, U . (2000) W omen's M ental H ealth; A M illennium Publication. Pakistan Psychiatric Society, M onograph Series II.

N ic Gabhainn, S. \& Kelleher, C. (2000) N ational Survey of G eneral Practice: Final Report. Dublin: Irish College of G eneral Practitioners.

N ic Gabhainn, S. (1999) Social N etworks, Social Support and A Icoholics A nonymous. U npublished Doctoral Dissertation, U niversity of N ottingham.

N olen-H oeksema, S. \& G urgus, J.S. (1994) The emergence of gender differences in depression during adolescence. Psychological Bulletin, 115, 424-443.

O 'C arroll, A . \& O'Riordan, M . (1996) C ounselling in Practice: A G uide for G eneral Practitioners. Dublin: Irish C ollege of G eneral Practitioners.

O 'H are, A . \& O 'C onnor, A . (1987) G ender differences in treated mental illness in the Republic of Ireland. In C. C urtin et al. (Eds.) G ender in Irish Society, G alway: G alway U niversity Press.

0 'M ahony, M. (1997) Perceptual and attitudinal factors in the relationship between a self-help group and mental health professionals. U npublished B.A. Thesis in A pplied Psychology, U niversity College Cork.

O 'N eill, T., M urphy, P. \& G reene, V.T. (1990) Postnatal depression - aetiological factors. Irish M edical Journal, 83, 17-18. 
O 'Leary, E. (1990a) C ommunity C ounselling in the Republic of I reland: A n O verview. Journal of M ental H ealth C ounselling, $12(4), 470-479$.

O 'Leary, E. (1990b) Research on School Counselling: A n Irish perspective. T he School C ounselor, 37, 261-269.

O rlinsky, D., Grawe, K. \& Parks, B. (1994) Process and outcome in psychotherapy. In A .E. Bergin \& S.L. Garfield (Eds.) $\mathrm{H}$ andbook of Psychotherapy and Behavior $\mathrm{C}$ hange. C hichester: John W iley.

Ormond, K.E., H aum, J., Cook. L., Duquette, D., Ludowese, C., \& M atthews, A.L. (2000) Recommendations for Telephone Counseling. Journal of $\mathrm{G}$ enetic C ounseling, 9 (1), 63-71.

Paykel, E.S., H art, D. \& Priest, R.G. (1998) C hanges in public attitudes to depression during the Defeat the Depression Campaign. British Journal of Psychiatry, 173, 519-522.

Paykel, E.S., M angen, S.P., G riffith, J.H., \& Burns, T.P. (1982) Community psychiatric nursing for neurotic patients: a controlled study. British J ournal of Psychiatry, 140, 573-581.

Perkins, R. (1992) W aiting for the revolution - or working for it? A reply to Laura Brown and Katherine Sender. Feminism and Psychology, 2 (2), 258-61.

Perry, J. (1993) C ounselling for Women. Buckingham: O pen U niversity Press.

Prioleau, L., M urdock, M . \& Brady, N . (1983) A n analysis of psychotherapy verses placebo studies. Behavioural \& Brain Science, 6, 275-310.

Radloff, L.S. (1977) The CES-D Scale: a self-report depression scale for research in the general population. A pplied Psychological M easurement, 1, 385-401.

Riboli, E. \& Kaaks, R. (1997) The EPIC project: rationale and study design. International Journal of E pidemiology, 26, Suppl. 1, S6-S14.

Robbins, L.N ., H elzer, J.E., W eissman, M.M . et al. (1984) Lifetime prevalence of specific psychiatric disorders in three sites. A rchives of $G$ eneral Psychiatriy, 41, 949-958.

Roberts, H., Dengler, R. \& M agowan, R. (1995) Trent H ealth A dult Lifestyle Survey 1992-1994: results. N HS Executive Trent \& Dept of Public Health M edicine and Epidemiology, U niversity of $\mathrm{N}$ ottingham: $\mathrm{N}$ ottingham.

Robson, M .H., France, R. \& Bland, M . (1984) Clinical psychologists in primary care: controlled clinical and economic evaluation. British M edical Journal, 288, 1805-1880.

Rosenfield, M. (1997) C ounselling by telephone. London: Sage.

Roth, A . \& Fonagy, P. (1996) What W orks for W hom? A C ritical Review of Psychotherapy Research. N ew York: G uildford.

Rowland, N ., G odfrey, C., Bower, P., M ellor-Clark, J., H eywood, P. \& H ardy, R. (2000) C ounselling in primary care: a systematic review of the research evidence. Journal of $G$ uidance and C ounselling, 28 (2), 215-231.

Russell, J. (1993) 0 ut of bounds: sexual exploitation in counselling and therapy. London: Sage.

Russell, J. (1996) Feminism and counselling. In R. Bayne, I. H orton \& J. Bimrose (Eds.) N ew Directions in C ounselling. London: Routledge.

Saunders, S. (1999) It has been amply demonstrated that psychotherapy is effective. In C. Feltham (Ed.) Controversies in therapy $\&$ counselling. London: Sage. 
Scott, A .I.F. \& Freeman, C.P.L. ( 1992) Edinburgh primary care depression study, treatment outcome, patient satisfaction, and cost after 16 weeks. B ritish M edical J ournal, 304, 883-887.

Sibbald, B., A ddington-H all, J., B renneman, D. \& Freeling, P. (1993) Counsellors in English and W elsh general practices, their nature and distribution. British M edical J ournal, 306, 29-33.

Simonson, S.K. (1987) Peer counselling in health care: a collaboration of social work and voluntarism. Social W ork in $\mathrm{H}$ ealth Care, 12(4), 1-19.

Smail, D. (1987) Taking C are: An A Iternative to Therapy. London: Dent.

Smith, M .L., Glass, G.V. \& M iller, T.I. (1980) The benefits of psychotherapy. Baltimore, M D: Johns H opkins U niversity Press.

Steenbarger, B.N . (1993) On the cross-fertilization of science and practice in brief therapy. In L.J. Schneider $\&$ C.E. Watkins (Chairs), Researching and practicing brief therapy: Into the 21st $C$ entury. Paper presented to the 101st A nnual $C$ onvention of the A merican Psychological A ssociation, Toronto.

The H ealth of the $\mathrm{N}$ ation W hite Paper (1991) Point Prevalence of M ental Disorders in the A dult Population (England) section C. London: HMSO.

Thorne, B. (1999) Psychotherapy and counselling are indistinguishable In C. Feltham (Ed.) C ontroversies in therapy \& counselling. London: Sage.

Thomas, P. (1993) A n exploration of patients perceptions of counselling with particular reference to counselling within general practice. C ounselling, 4, 15-19.

Thorne, B. (1992) Psychotherapy and counselling: the quest for difference. Counselling, 3, 244-248.

Topping, K. (1996) Reaching where adults cannot: peer education and peer counseling. Educational Psychology in Practice, 11 (4), 23-29.

Tylee, A . (1997) Counselling in primary care. Lancet, 350, 1643.

W aydenfield, D., W aydenfield, S. (1980) Counselling in general practice. Journal of the Royal C ollege of G eneral Practitioners, 30, 671-7.

W eissman, M .M., Leckman, J.F., M erikangas, K.R., Gammon, G.D. \& Prusoff, B.A . (1984) Depression and anxiety disorders in parents and children. A rchives of $G$ eneral Psychiatry, 41, 845-852.

W eissman, M .M ., W arner, V., W ickramaratne, P., M oreadu, D., O Ifson, M . (1997) 0 ffspring of depressed parents - 10 years later. A rchives of $\mathrm{G}$ eneral Psychiatry, 54 (10), 932-940.

W eisz, J.R., D onenberg, G.R., H an, S.S. \& W eiss, B. (1995) Bridging the gap between laboratory and clinic in child and adolescent psychotherapy. Journal of $C$ onsulting and $C$ linical Psychology, 63, 688-701.

W ells, K.B., \& Sturn, R. (1995) Care for depression in a changing environment. H ealth A ffairs, 14, 78-89.

W heeler, S.H . \& Siebelt, B. (1997) Calling all nurses: how to perform telephone triage. N ursing, 27, 37-41.

W HO M onica Project (1997) M onica M anual Part III: Population Survey 1997. W H O : G eneva.

W illiams, S., Crouch, R. \& Dale, J. (1995) Providing health-care advice by telephone. Professional N urse, 10, 750-752.

W orld H ealth O rganisation (2001) M ental H ealth A nd Brain Disorders Background Topics Publications Events \& M edia Links Sitemap, http://www.who.int/mental_health/Topic_Depression/depression1.htm. 
104 
Appendices 


\section{List of Appendices}

Appendix 1: $\quad$ Questionnaire for the survey of women

Appendix 2: $\quad$ Reminder postcard for the survey of women

Appendix 3: $\quad$ The percentages of women reporting using the various modes of transport and the distances to key services

Appendix 4: $\quad$ Two structured interview schedules - one for women who had received counselling and one for women who had not received counselling.

Appendix 5: Health Board Personnel Questionnaire

Appendix 6: $\quad$ Interview schedule for Health Board Personnel

Appendix 7: $\quad$ Community / Voluntary Sector Personnel Questionnaire

Appendix 8: $\quad$ Health Board Managers Interview Schedule

1 The term counselling is used throughout this document to include both counselling and psychotherapy.

$\mathrm{P}<0.001$ means that the likelihood of this difference being due to chance is less that one in a thousand, $\mathrm{P}<0.01$ means that the likelihood is less than one in a hundred and $p<0.05$ means that the likelihood is less than 5 in a hundred. Any of these mean that differences are statistically significant.

The GHQ-12 Manual describes high scores as indicating that the respondent is experiencing distressing symptoms similar to those reported by cases on non-psychotic disorders seen by the specialist mental health services.

Note that this includes Weight Watchers 


\section{Questionnaire for the survey of women}

\section{Please note that all information will be treated with complete confidentiality \\ District Electoral Division No.}

\section{SECTION A: ABOUT YOU AND YOUR HOUSEHOLD}

A1. What age are you at present?

Years

A2. What is your present marital status?

\begin{tabular}{|c|c|c|}
\hline Married & Cohabiting & Widowed \\
\hline Separated & Divorced & Single/Never-married \\
\hline
\end{tabular}

A3. What type of accommodation do you live in?

Detached

Mid-terrace

Semi-detached/end of terrace

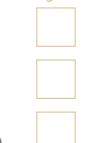

\section{Apartment block}

Multi-storey flats

Other, please specify

A6. Is

Owned with mortgage

Rented from Council

Other, please specify

A7. How many people are there in your household?

A8. Do you have children?

Yes

No

go to question $\mathrm{A} 9$

If yes, How many children do you have?

What are the ages of your children?

How many of your children live in your home?

A7 What age were you when you left school?

Years your

Rented privately

Owned outright 
No schooling

Primary school education only

Some secondary education

Complete secondary education

Some third level education at college, university or RTC

Complete third level education at college, university or RTC

A9. What is your current employment situation?

Full time employment

Homemaker

Seeking work for the first time

Part-time employment

Unemployed

At school, student

Unable to work owing to permanent sickness/disability

Other, please specify

A10. Are you a:

Manager $\square$ Supervisor $\quad \square \quad$ Other employee

A11. If self-employed, do you employ other people?

Yes $\quad$ No If yes, how many?

A12. What is your job-title?

(If you are not in a paid job at the moment, give title of your last job)

A13. If you are not the principle wage earner, please answer the following about the principal wage earner in your household: What is his/her job title?

(If he/she is not in a paid job at the moment give title of last job)

A14. If a farmer, how many acres of land do you/your partner farm?

A15. Do you have a medical card?

Yes

No 
Item

Own Car - Private

Own Car - Shared

Bus

Taxi

Mini-Bus Service

Lift - Neighbour

Bicycle

Train

Other

\section{Everyday \\ Several Days A Week}
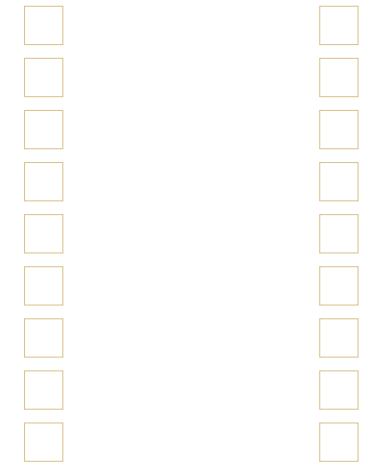

\section{Fortnight}

Monthly

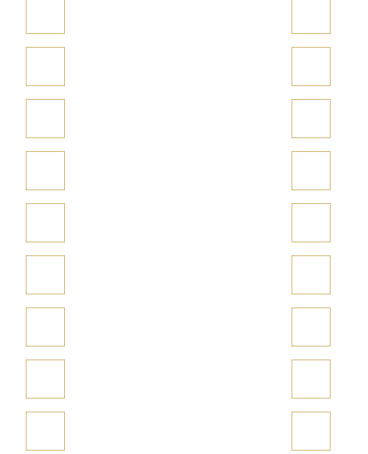

A17. Do you use the public transport system in your area?

Yes $\square \quad$ No

A18. Are you satisfied with the public transport system in your area?

Yes $\square \quad$ No

How do you think it can be improved?

A19. Please describe the distance of your accommodation (in approx. miles) from the nearest:

Primary school (which children attend)

Secondary school (which children attend)

Shop

Post Office

Public Telephone

Doctor

Public Health Nurse

General Services Hospital

Bus Route

Village

Garda Station

Bank Office (not mobile)

Library (not mobile)

Chemist

Employment Exchange

Dental Clinic

Eye Clinic 


\section{SECTION B: GENERAL HEALTH}

B1. In general, would you say your health is:

Excellent $\square \quad$ Very good Good

Fair Poor

B2. How would you rate your quality of life?

\begin{tabular}{|c|c|c|}
\hline Very poor & Poor & Neither poor nor gooc \\
\hline Good & Very good & \\
\hline
\end{tabular}

B3. How satisfied are you with your health?

Very dissatisfied

Dissatisfied

Neither satisfied nor dissatisfied

Satisfied

Very satisfied

B4. Do you have a doctor/G.P.?

Yes No

B5. Where do you get your information on health (including mental health)?

(Please tick as many as apply)

General Practitioner (GP)

Workplace

Other Health Professionals

Family/Friends

Health Organisations

Media/Internet

Health Board

Well Woman Clinic

Other, please specify 


\section{B7. Please circle the answer that applies to you. Circle only ONE item.}

\section{HAVE YOU RECENTLY (over the last few weeks):}

\begin{tabular}{|c|c|c|c|c|}
\hline $\begin{array}{l}\text { Been able to concentrate } \\
\text { on whatever you're doing? }\end{array}$ & Better than usual & Same as usual & Less than usual & Much less than usual \\
\hline Lost much sleep over worry? & Not at all & $\begin{array}{l}\text { No more than } \\
\text { usual }\end{array}$ & $\begin{array}{l}\text { Rather more } \\
\text { than usual }\end{array}$ & Much more than usual \\
\hline $\begin{array}{l}\text { Felt that you are playing } \\
\text { a useful part in things? }\end{array}$ & $\begin{array}{l}\text { Mores so than } \\
\text { usual }\end{array}$ & Same as usual & $\begin{array}{l}\text { Less useful than } \\
\text { usual }\end{array}$ & Much less useful \\
\hline $\begin{array}{l}\text { Felt capable of making } \\
\text { decisions about things? }\end{array}$ & More so than usual & Same as usual & Less so than usual & Much less capable \\
\hline Felt constantly under strain? & Not at all & $\begin{array}{l}\text { No more than } \\
\text { usual }\end{array}$ & $\begin{array}{l}\text { Rather more than } \\
\text { usual }\end{array}$ & Much more than usual \\
\hline $\begin{array}{l}\text { Felt you couldn't } \\
\text { overcome your difficulties? }\end{array}$ & Not at all & Same as usual & Less so than usual & Much more than usual \\
\hline $\begin{array}{l}\text { Been able to enjoy your } \\
\text { day-to-day activities? }\end{array}$ & More so than usual & Same as usual & Less than usual & Much less than usual \\
\hline $\begin{array}{l}\text { Been able to face up } \\
\text { to your problems? }\end{array}$ & More so than usual & Same as usual & Less able than usual & Much less able \\
\hline $\begin{array}{l}\text { Been feeling unhappy } \\
\text { and depressed? }\end{array}$ & Not at all & $\begin{array}{l}\text { No more so than } \\
\text { usual }\end{array}$ & $\begin{array}{l}\text { Rather more than } \\
\text { usual }\end{array}$ & Much more than usual \\
\hline $\begin{array}{l}\text { Been losing confidence } \\
\text { in yourself? }\end{array}$ & Not at all & $\begin{array}{l}\text { No more than } \\
\text { usual }\end{array}$ & $\begin{array}{l}\text { Rather more than } \\
\text { usual }\end{array}$ & Much more than usual \\
\hline $\begin{array}{l}\text { Been thinking of yourself } \\
\text { as a worthless person? }\end{array}$ & Not at all & $\begin{array}{l}\text { No more than } \\
\text { usual }\end{array}$ & $\begin{array}{l}\text { Rather more than } \\
\text { usual }\end{array}$ & Much more than usual \\
\hline $\begin{array}{l}\text { Been feeling reasonably } \\
\text { happy, all things considered? }\end{array}$ & More so than usual & $\begin{array}{l}\text { About same as } \\
\text { usual }\end{array}$ & Less so than usual & Much less than usual \\
\hline
\end{tabular}


Please circle the number which indicates how often you have felt this way during the past week. Circle only ONE number or item for each question.

\begin{tabular}{|c|c|c|c|}
\hline $\begin{array}{l}\text { Rarely or none } \\
\text { of the time }\end{array}$ & $\begin{array}{c}\text { Some or a little } \\
\text { of the time }\end{array}$ & $\begin{array}{l}\text { Occasionally or a } \\
\text { moderate amount of time }\end{array}$ & $\begin{array}{l}\text { Most or all } \\
\text { of the time }\end{array}$ \\
\hline (less than 1 day) & (1-2 days) & (3-4 days) & (5-7 days) \\
\hline
\end{tabular}

1. I did not feel like eating -

0

1

2

my appetite was poor

2. I felt that I could not shake off

0

1

2

4

the blues even with help from

my family or friends

3. I felt that I was just as good as other people

4. I had trouble keeping my mind 0 on what I was doing

5. I felt depressed

6. I felt that everything I did was an effort

7. I felt hopeful about the future

8. I thought my life had been a failure

0

9. I felt fearful

0

10. My sleep was restless

0

11. I was happy

0

12. I talked less than usual

0

1

13. I felt lonely

(1)

1

14. People were unfriendly

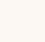

15. I enjoyed life

(1)

16. I had crying spells

0

17. I felt sad

0

18. I felt that people disliked me

0

19. I could not get going

0
0

\section{Would you consider this week a typical week?}

Yes

No 


\section{Section C: Sources of Help}

\section{Please read and answer the following questions:}

Let me tell you about Mary O'Reilly. She has not been herself recently. Her mood has been very unpredictable and she often seems very distant and preoccupied She often doesn't bother to dress in the morning and if neighbours call around she gets very agitated and is anxious that they leave quickly. She hasn't been showing up for meetings at her local group. She also doesn't answer the 'phone although her friends know she is at home. Mary feels very unsure of herself and worries about her future. She doesn't know what to do about how she is feeling, or where to turn for help.

C1. What do you think could be troubling Mary?

C2. What advice would you give Mary if she were a close friend or relative?

C3. Who could Mary turn to for help?

C4. Would you suggest that Mary consider counselling / psychotherapy?

Yes

No

C5. Do you know anyone who has received counselling / psychotherapy?

Yes $\square \quad$ No

C6. What do you think counselling is?

C7. Do you think this differs from psychotherapy?
Yes
No
Don't Know

If yes, in what way does it differ? 
C8. Have you yourself ever sought counselling / psychotherapy?

Yes

No please go to question $\mathrm{C} 11$

If yes, for what problem did you go?

If yes, do you know what kind of counsellor/psychotherapist it was?

How did you know where to go for this counselling/psychotherapy?

How long did you go for counselling/psychotherapy?

C9. What was your opinion of the help you received?
It helped
go to question $\mathrm{C} 10$
It hindered
go to question $\mathrm{C} 10$
It made no difference
go to question $\mathrm{C} 11$

C10. In what ways did it help or hinder?

C11. Do you think counselling / psychotherapy is a useful method for helping people? Yes

Maybe

No

Don't know

Why do you think it is useful or not useful?

C12. Would you suggest counselling or psychotherapy to a friend or family member?

Maybe

No

Don't know 
C13. What do you think would stop someone in your locality from seeking counselling or psychotherapy?

$\begin{array}{lll}\text { Stigma } & \square & \text { Cost } \\ \text { Distance } & \text { Time } \\ \text { Afraid to face up to problem } & \square & \text { Shame } \\ \text { Not knowing where to go } & \square & \text { Distrust }\end{array}$

Not worthwhile

Other, please specify

C14. What do think would encourage people in your locality to seek counselling or psychotherapy?

C15. Would you consider going to counselling or psychotherapy if you had a problem?

Yes

No

C16. If you needed to access counselling / psychotherapy where would you go to obtain these services?

C17. Is counselling / psychotherapy available from your Health Board?

Yes $\quad$ Sometimes $\quad$ No

No Don't know

If Yes or Sometimes, for which problems is it available?

C18. Who do you think should provide counselling / psychotherapy? (Please tick as many as apply)

Health Boards

Voluntary Organisations

Other, please specify

C19. Where do you think counselling / psychotherapy should be provided? (Please tick as many as apply)

GP Surgery

Workplace

Other, please specify
GPS

Private Individuals 
C20. Are you, or have you ever been, a member of a women's group or a community/voluntary group?

Yes No

If yes, what type of group?

C21. Are you, or have you ever been, a member of a self-help group (e.g. Alcoholics Anonymous, Al Anon, Weight Watchers)?

Yes

No

If yes, what type of group?

C22. The following is a list of common problems for which people seek help. Could you please indicate with a tick $(\div)$ whether you, personally, have personally experienced any of these problems and who, if anyone, you turned to for help.

छे

$\frac{\frac{0}{0}}{\frac{\overline{9}}{\overline{0}}}$

要

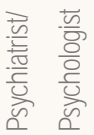

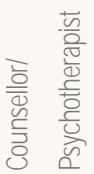

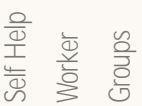

$\frac{\bar{\sigma}}{8}$

$\frac{\grave{d}}{\mathbb{E}}$

to

8े

중 웧

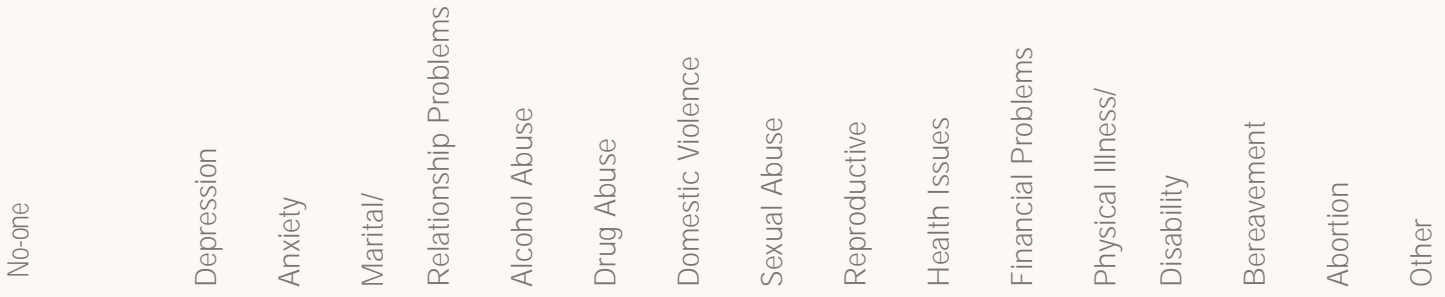

116 
C24. Would you be willing to be interviewed further?

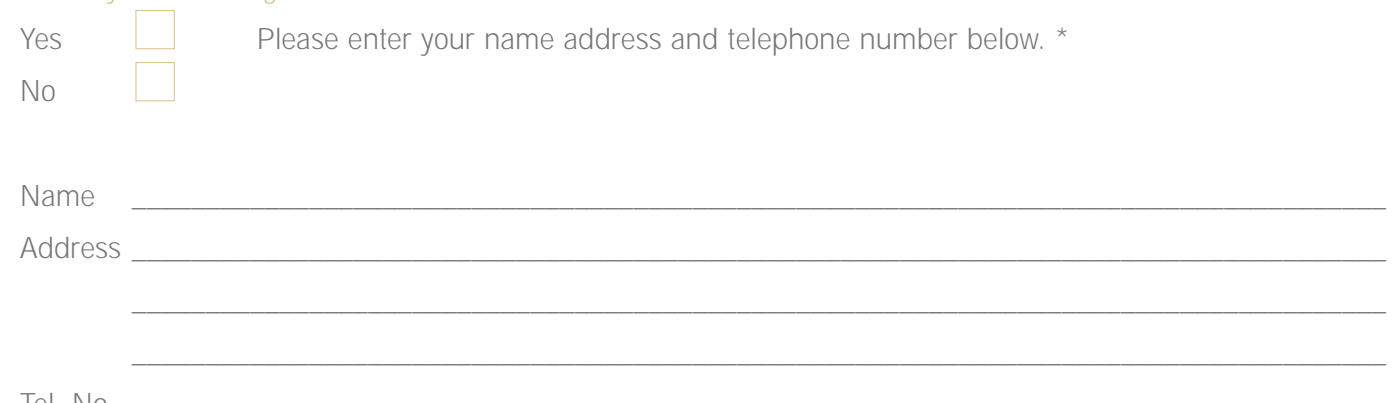

Tel. No.

* Please note that this information will be treated with complete confidentiality

Thank you very much for your help

Please put the questionnaire in the freepost envelope provided and return as soon as possible. You do not need to put a stamp on the envelope

If you have mislaid the return envelope, please post the questionnaire to:

Dr. Vivienne Batt

Women's Studies Centre

National University of Ireland, Galway

FREEPOST

Galway 


\section{Appendix 2}

\section{Reminder postcard for the survey of women}

REMINDER POSTCARD FOR THE SURVEY OF WOMEN

A5 size postcard with the Women's Studies Centre address on one side (Dr. Vivienne Batt, Women's Health Project, Women's Studies Centre, National University of Ireland, Galway FREEPOST, Galway) and the following text on the back side:

Last week, a questionnaire seeking your opinions about improving women's health services was sent to you. Your name was drawn randomly from the electoral register. If you have already completed and returned the questionnaire to us, please accept our sincere thanks. If not, please do so as soon as possible. We are especially grateful for your help because we believe that your response will be very useful in the development of such services.

If you did not receive a questionnaire, or if it was misplaced, please call us at (091) 750-455 and we will send you another one today. Sincerely, Dr. Vivienne Batt, Project Director 


\section{The percentages of women reporting using the various modes of transport and the distances to key services}

The percentages of women reporting using the various modes of transport and the distances to key services

Mode of Transport

Own Car

Shared Car

Bus***

Taxi

Mini-Bus

Lift from neighbour

Bicycle*

Train**

\section{Urban Women (\%)}

66

5

16

3

1

1

5
Rural Women (\%)

70

9

6

1

1

2

2

3

$* p<0.05 ; * * p<0.01 ; * * * p<0.001$

Distances from services reported by women in miles - mean (standard deviations) and medians by location.

Distance from (miles)

Primary School***

Secondary School***

Shop***

Public Telephone***

Post Office***

General Practitioner***

Public Health Nurse***

General Services Hospital***

Bus Route***

Village***

Gardaí***

Bank Branch***

Public Library***

Pharmacy***

Social Welfare Office ${ }^{* * *}$

Dental Clinic***

Eye Clinic***

Urban Women
$1.43(1.13) 1$
$2.13(2.10) 1$
$1.29(1.12) 1$
$1.20(0.63) 1$
$1.38(1.18) 1$
$1.68(1.56) 1$
$1.78(1.68) 1$
$6.67(8.44) 3$
$1.22(0.90) 1$
$1.67(2.37) 1$
$1.81(2.30) 1$
$2.01(2.47) 1$
$2.79(5.19) 1$
$1.59(1.63) 1$
$3.19(3.39) 2$
$2.68(3.81) 1$
$4.69(6.68) 2$

Rura Women

2.41 (1.58) 2

$7.13(4.57) 7$

2.24 (1.70) 2

2.17 (1.53) 2

$2.00(1.60) 2$

$5.98(4.16) 5$

$5.91(4.19) 5$

20.00 (15.02) 16

3.58 (3.81) 2

$2.63(1.93) 2$

$3.93(2.92) 3$

$7.74(4.55) 7$

$8.63(6.18) 8$

$6.68(4.30) 6$

$9.45(6.22) 8$

$9.17(6.65) 8$

$14.14(12.40) 10$

$* p<0.05 ; * * p<0.01 ; * * * p<0.001$ 


\section{Appendix 4}

\section{Two structured interview schedules one for women who had received counselling one for women who had not received counselling}

\section{WOMEN WHO HAVE RECEIVED COUNSELLIN G}

You mentioned when you filled out the questionnaire that you have received counselling.

1. How many counselling sessions did you attend?

2. How long were the sessions?

3. How regularly did you attend counselling?

(Prompt: Once a week

Once a month)

4. Over what period of time did you attend?

(Prompts: A year

6 months

less than 6 months)

5. How much did it cost per session?

6. What was the total cost?

7. Did you pay?

(Prompts: Did Health Board pay

Did family pay)

8. Where was the counselling located?

9. Did you have far to travel?

10. Did the counsellor explain what training she/he had?

11. If Yes, what training?

12. For what problem did you attend counselling?

13. How did you first identify the problem?

\section{(Prompts:}

Was there a build-up of the problem)

Did you talk to your GP

Did you talk to your partner

Did you talk to your mother

Did you talk to a friend)

What were the first steps in seeking counselling?

(Prompt: Who did you see first?) 
14. Why did you choose counselling?

(Prompts: GP recommended it

Family/Friend suggested it)

15. Were other options, apart from counselling, discussed with you?

(Prompts: Medication)

Support group)

16. Were you referred to the counsellor by your GP?

17. Why did you pick that counsellor?

Prompts: GP

Word of mouth recommendations

Read about it

18. How did other people's opinions affect your decision to seek counselling?

(Prompts: Family

GP

Friends)

19. If their attitude had been different, would it have been easier to seek counselling?

20. Did you encounter any problems or barriers to counselling?

Prompts: Family

Childcare
Stigma
Cost
Location
Lack of information/advice

21. How did you manage to overcome these barriers?

22. Are you still attending counselling?

If Yes, go to Page 4

If No, CONTINUE:

23. Why did you decide to finish counselling?

(Prompts: Problem resolved
Able to tackle/cope with problem
Cost/other barriers
Wasn't helping)

24. Was the decision to finish counselling your decision

(Prompts: Was it your counsellor's decision?

Was it your partner's decision?)

25. Since you have received counselling, are you experiencing problems?

26. Since you finished counselling, have you been able to cope any better?

27. In your own view, did the counselling work?

(Prompts: Did the counselling help you to address your problem? (Yes/No)

Why/Why not?)

TURN TO PAGE 5 
24. Since you have received counselling, are you experiencing problems?

25. Have you been able to cope any better?

26a. In your own view, is the counselling working?

(Prompts: Did the counselling help you to address your problem? (Yes/No) Why/Why not?)

\section{TURN TO PAGE 5}

28. If you could change anything to make it easier for yourself to access counselling in the future what would you change? (Prompts: Cost

$$
\text { Stigma }
$$

Location)

29. What would you change to make counselling more accessible for other women?

(Prompts: Cost

Stigma

Location)

31. Do you feel Health Boards should provide counselling?

Yes

No

If Yes, where do you think it should be provided? GP

Women's Health Centre

Counsellor in GP's surgery

Counsellor in (health) clinic

Workplace

Family Resource Centre

Home

Other, please specify

32. Do you feel that the Health Boards should pay for counselling?

Yes

No

33. Would you recommend counselling to other women?

34. Is there anything you'd like to add?

ASK WOMAN FOR NAME AND ADDRESS OF COUNSELLOR

GIVE LIST OF HELPLINE NUMBERS

THANK PARTICIPANT 


\section{WOMEN WHO HAVE NOT RECEIVED COU NSELLING}

1. Do you know anyone who has had counselling? If No - Go to Number 13

2. Who was it?

3. What relationship were they to you?

4. Who did they see?

5. For what problem?

6. Who referred them?

7. How long did they go for counselling?

8. How much did it cost?

9. Where was it located?

10. Did they find the counselling helpful?

11. In your view, did the counselling work?

12. Would their experiences influence you?

13. Have you ever experienced problems for which counselling would have helped? If No/Unsure, go to Number 18

14. If Yes, what were they?

15. What did you do to deal with these problems?

Prompts: GP
Self help groups
Medication
Nothing
Mother/family
Friend

16. Would you have used counselling if it had been suggested to you (Yes/No) If No, why not?

17. If Yes, what prevented you from getting counselling?

(Prompts: No-one suggested it

Cost

Time/Location

Childcare/Transport

Information/unaware

Rcommendation/advice

Family)

17.(a) Would what other people think affect your decision to get counselling?

(Prompts: Stigma
Family
GP
Friends)

18. What prevents women from getting counselling? 
19. What would encourage women to seek counselling?

Prompts: Cost/Time

Family

Reduce stigma

Location/Childcare

Transport

Information/recommendation/advice

20. If you could change anything to make it easier to access counselling in the future what would you change? (Prompts: Cost

Information

Stigma

Location)

21. Do you feel Health Boards should provide counselling?

Yes

No

If Yes:

GP

Women's Health Centre

Counsellor in GP's surgery

Counsellor in (health) clinic

Workplace

Family Resource Centre

Other

Do you feel that the Health Boards should pay for counselling?

Yes

No

22. Would you recommend counselling to other women?

23. Is there anything you'd like to add?

\section{GIVE LIST OF HELPLINE NUMBERS}

THANK PARTICIPANT 


\section{Health Board Personnel Questionnaire}

\section{PLEASE NOTE THAT ALL INFORMATION WILL BE TREATED WITH COMPLETE CONFIDENTIALITY}

1. Is the area you predominantly work in:

(Please tick one only)

Rural

Urban

2. What is your job title?

3. How many years have you worked in your organisation?

3(a) How many years have you worked within the health services?

4.

4. What do you think counselling is?

5. Do you think this differs from psychotherapy?

Yes $\square$ No $\square$ Don't know

If Yes, what do you think the difference is?

6. Have you ever offered a counselling or psychotherapy service to any clients through your job with the Health Board?

$\begin{array}{lll}\text { Counselling } & \text { Yes } & \text { No } \\ \text { Psychotherapy } & \text { Yes } & \square \\ & \text { No }\end{array}$

7. Have you ever used counselling skills with your clients?

Yes $\square \quad$ No

If Yes, in what situation did this take place?

8. Have you ever referred female clients to a counsellor / psychotherapist? 
8(a) If Yes, for what problems did you refer?

Depression

Anxiety/Panic Attacks

Marital Problems

Alcohol/Drug Abuse

Crisis Pregnancy/Abortion

Other (please specify)
Domestic Violence

Sexual Abuse

Bereavement

Eating Disorders

Reproductive Health Problems

8(b) Did you refer predominantly to:

Private Practitioners

Health Board Practitioners

Community/Voluntary Organisations (e.g. Aware, Samaritans)

Support Groups (e.g. Al Anon)

Other (please specify)

9. Are you registered or affiliated with any professional bodies?

Yes

No

If Yes, please specify

10. Have you ever been trained in counselling / psychotherapy methods or skills?

Yes

No

If Yes, please specify what training you received:

Course Name

Course Location

Duration

Accreditation (if any)

11. Do you think counselling is a useful method for helping people?
Yes
Maybe
No
Don't know

Why do you think it is useful or not useful? 
12. Who do you think should provide counselling / psychotherapy? (Please tick as many as apply)

Health Boards

Voluntary Organisations

GPS

Private Practitioners

Other, please specify

13. Where do you think counselling / psychotherapy should be provided? (Please tick as many as apply)

Attached to GP Surgery

Workplace

Hospital

Community/Family Resource Centre

Health Clinic

Other, please specify

14. Do you feel your Health Board offers a satisfactory counselling / psychotherapy service?

Yes $\quad$ No Don't know

Why or why not?

15. How do you think your Health Board's counselling / psychotherapy service could be improved?

(Please tick as many as apply)

Recognition

Resources

Availability

Public awareness

Other (please specify)
Personnel

Publicity

Accessibility

16. Have you any further comments or suggestions?

17. We would like to interview in more detail a number of health service providers on their views and perceptions of counselling provision. Would you be willing to be interviewed further?

Yes $\square \quad$ Please enter your name and telephone number below *

No

If Yes, would you prefer to be interviewed by:

Telephone interview

Face to face meeting 


\section{Name}

Address

Tel. No.

* Please note that all information will be treated with complete confidentiality

Thank you for your time and co-operation

Please put the questionnaire in the freepost envelope provided and return as soon as possible. You do not need to put a stamp on the envelope.

If you have mislaid the return envelope, please post the questionnaire to

Dr. Vivienne Batt

Women's Studies Centre

National University of Ireland, Galway

FREEPOST

Galway 


\section{Interview Schedule for Health Board Personnel}

\section{INTERVIEW SCHEDULE - HEALTH BOARD STAFF}

I would like to thank you for returning the questionnaire so promptly. You mentioned that you would be willing to be interviewed further, and I was wondering if you are available now to answer a few questions. I will record the interview with your permission. You can be assured of complete confidentiality.

What counselling services does the Health Board currently provide?

Prompts:

For what problems is counselling available?

Are there waiting lists?

(Get an approximation)

Do you feel the counselling services of the Health Board are adequate?

Yes No Don't Know

Do you feel that the counselling services of the Health Board are accessible to women?
Yes
No
Don't Know
Sometimes

How do women access counselling services provided by the Health Board?

Prompts:

Referral by GP

Self-referral

Do you feel the counselling services should be improved?
Yes
No
Don't Know

If yes, In what way do you feel they could be improved?

What do you feel are the barriers to women accessing counselling?

Prompts:

Cost

Childcare

Stigma

Lack of information

Travel

How do you feel the Health Board should overcome these barriers?

Do you feel that counselling services should be provided free of charge to women?

Yes

No

Don't Know

Sometimes

If yes/sometimes, for what problems?

Prompts:

Depression

Addiction - Alcohol/Drug Abuse

Sexual Abuse

Relationship Difficulties 
Do you feel that the Health Board works effectively with other, voluntary,agencies?

Yes No Don't Know $\square$ Sometimes

In what way?/How?

Do you feel the relationship between the Health Board and voluntary agencies could be improved?

Yes No Don't Know $\quad$ Maybe

In what way?/How?

Do you think the counselling service provided by the Health Board is effectively planned?

Do you feel the Health Board consults its staff adequately when it comes to planning its counselling services?

Yes No Non't Know Domes

If no/sometimes, in what way do you think this could be improved?

Do you feel that there are enough resources allocated to counselling, within the Health Board?

Yes

No

Don't Know 


\section{Community/Voluntary Sector Personnel Questionnaire}

\section{PLEASE NOTE THAT ALL INFORMATION WILL BE TREATED WITH COMPLETE CONFIDENTIALITY}

1. Is the area you predominantly work in: (Please tick one only)

Rural Urban

2. What is your job title?

3. How many years have you worked in your organisation?

3(a) How many years have you worked within the health services?

4. What do you think counselling is?

5. Do you think this differs from psychotherapy?
Yes
No
Don't know

If Yes, what do you think the difference is?

6. Have you ever offered a counselling or psychotherapy service to any clients through your job?

$\begin{array}{lll}\text { Counselling } & \text { Yes } & \text { No } \\ \text { Psychotherapy } & \text { Yes } & \text { No }\end{array}$

7. Have you ever used counselling skills with your clients?

Yes $\square$ No

If Yes, in what situation did this take place?

8. Have you ever referred female clients to a counsellor / psychotherapist?

Yes $\square$ No 
8(a) If Yes, for what problems did you refer?

Depression

Anxiety/Panic Attacks

Marital Problems

Alcohol/Drug Abuse

Crisis Pregnancy/Abortion

Other (please specify)
Domestic Violence

Sexual Abuse

Bereavement

Eating Disorders

Reproductive Health Problems õ

8(b) Did you refer predominantly to:

Private Practitioners

Health Board Practitioners

Community/Voluntary Organisations (e.g. Aware, Samaritans)

Support Groups (e.g. Al Anon)

Other (please specify)

9. Are you registered or affiliated with any professional bodies?

Yes No

If Yes, please specify

10. Have you ever been trained in counselling / psychotherapy methods or skills?

Yes

No

If Yes, please specify what training you received:

Course Name

Course Location

Duration

Accreditation (if any)

11. Do you think counselling is a useful method for helping people?
Yes
Maybe
No
Don't know 
12. Who do you think should provide counselling / psychotherapy? (Please tick as many as apply) Health Boards Voluntary Organisations GPS Private Practitioners

Other, please specify

13. Where do you think counselling / psychotherapy should be provided? (Please tick as many as apply) $\begin{array}{ll}\text { Attached to GP Surgery } & \square \quad \\ \text { Workplace } & \begin{array}{l}\text { Hospital } \\ \text { Health Clinic }\end{array}\end{array}$ Community/Family Resource Centre Other, please specify

14. Do you feel your Health Board offers a satisfactory counselling / psychotherapy service? Yes

15. How do you think your Health Board's counselling / psychotherapy service could be improved? (Please tick as many as apply)

\begin{tabular}{|c|c|}
\hline Recognition & Personnel \\
\hline Resources & Publicity \\
\hline Availability & Accessibility \\
\hline Public awareness & \\
\hline
\end{tabular}

16. Have you any further comments or suggestions?

17. We would like to interview in more detail a number of personnel from voluntary organisations on their views and perceptions of counselling provision. Would you be willing to be interviewed further?

Yes

Please enter your name and telephone number below *

No 
If Yes, would you prefer to be interviewed by:

Telephone interview

Face to face meeting

Name

Address

Tel. No.

Please note that all information will be treated with complete confidentiality

Thank you for your time and co-operation

Please put the questionnaire in the freepost envelope provided and return as soon as possible. You do not need to put a stamp on the envelope.

If you have mislaid the return envelope, please post the questionnaire to

Dr. Vivienne Batt

Women's Studies Centre

National University of Ireland, Galway

FREEPOST

Galway 


\section{Health Board Managers Interview Schedule}

INTERVIEW SCHEDULE HEALTH BOARD MANAGERS

1. How important counselling is to the Health Board

2. Who you feel should provide counselling within the Health Board

3. The Health Board's policy, if any, on training, supervision, registration and accreditation of counsellors

4. Funding issues for the Health Board related to counselling

5. The development of counselling services

6. The appropriate location of services

7. Pertinent issues for women and counselling within your Health Board, or generally 
136 